\title{
Optimal Anteroposterior Position of Maxillary Incisors in Caucasian Males Viewed from a Smiling Profile
}

Amer Shammaa

Follow this and additional works at: https://researchrepository.wvu.edu/etd

\section{Recommended Citation}

Shammaa, Amer, "Optimal Anteroposterior Position of Maxillary Incisors in Caucasian Males Viewed from a Smiling Profile" (2018). Graduate Theses, Dissertations, and Problem Reports. 6614.

https://researchrepository.wvu.edu/etd/6614

This Thesis is protected by copyright and/or related rights. It has been brought to you by the The Research Repository @ WVU with permission from the rights-holder(s). You are free to use this Thesis in any way that is permitted by the copyright and related rights legislation that applies to your use. For other uses you must obtain permission from the rights-holder(s) directly, unless additional rights are indicated by a Creative Commons license in the record and/ or on the work itself. This Thesis has been accepted for inclusion in WVU Graduate Theses, Dissertations, and Problem Reports collection by an authorized administrator of The Research Repository @ WVU. For more information, please contact researchrepository@mail.wvu.edu. 


\title{
OPTIMAL ANTEROPOSTERIOR POSITION OF MAXILLARY INCISORS IN CAUCASIAN MALES VIEWED FROM A SMILING PROFILE
}

\author{
Amer Shammaa, D.D.S \\ Thesis submitted \\ to the School of Dentistry \\ at West Virginia University
}

In partial fulfillment of the requirement for the degree of

Master of Science in Orthodontics

\author{
Peter Ngan D.M.D, M.S \\ Chris Martin D.D.S, M.S \\ Bryan Weaver D.D.S, M.D
}

Department of Orthodontics

Morgantown, West Virginia 2018

Keywords: AP incisors position, smiling profile, facial esthetics. Copy right 2018 [Amer Shammaa] 


\section{Abstract \\ OPTIMAL ANTEROPOSTERIOR POSITION OF MAXILLARY INCISORS IN CAUCASIAN MALES VIEWED FROM A SMILING PROFILE}

\section{AMER SHAMMAA D.D.S}

Background and Objectives: Anteroposterior (AP) position of the maxillary incisors affects the harmony of a facial profile. Different methods have been suggested to evaluate the maxillary incisor AP position, including cephalometric analysis and softtissue analysis. Andrews suggested using a lateral smiling profile to evaluate the AP position of the maxillary incisors. The objective of this study was to investigate the optimal AP position of maxillary incisors in Caucasian males using Glabella Vertical $(\mathrm{GV})$, a coronal plane tangent to soft tissue Glabella, as a reference line. In addition, an attempt was made to determine if there are differences in judged facial attractiveness between smiling versus repose profiles, and between dental professionals versus laypersons, and males versus females.

Experimental Design and Methods: Smiling and repose profile photographs of 30 randomly selected Caucasian adult males were taken in adjusted natural head position. The AP distance between the maxillary central incisors and GV was measured for each subject. A total of 36 judges ( 6 male orthodontists, 6 female orthodontists, 12 male lay judges, and 12 female lay judges) were recruited to rate the facial attractiveness of each subject's photograph using a visual analog scale. The data was examined using Tukey's test for multiple comparisons, ANOVA, and chi-square analysis.

Results: No statistically significant difference was found in judged facial attractiveness among Caucasian males with various AP positions of maxillary incisors. However, a trend was found; incisors falling on GV were preferred by the judges, followed by incisors ahead of the $\mathrm{GV}$, with incisors behind $\mathrm{GV}$ being the least preferred. A significant difference in facial attractiveness was found between smiling versus repose profiles, in particular, patients with maxillary incisors behind GV being judged less attractive. Orthodontic training and sex of the judges did not significantly affect the judgment of facial attractiveness.

Conclusions: The AP position of maxillary incisors in Caucasian males might not be a significant factor defining face attractiveness. However, there is a tendency for the preferred maxillary incisor position to fall on $\mathrm{GV}$, ahead of $\mathrm{GV}$ being less preferred, and behind $\mathrm{GV}$ being least preferred. Orthodontic training and gender does not affect perception of profile esthetics. A smiling profile view is useful for assessing facial esthetics. 


\section{DEDICATION}

To my parents Akram and Izdehar Shammaa, for their unconditional love and for being a source of encouragement and inspiration to me throughout my life.

To my brothers Imad, Ammar, and Obad, for their constant encouragement and support and making my dream comes true. I could not do it without you guys.

To my wonderful wife Aylah, for her unlimited love and support. I love you so much Ayolet 2albi. 


\section{AKNOWLEDGEMENTS}

I would like to acknowledge the support and assistance I have received during this project and throughout my orthodontic residency. My sincere appreciation to the following individuals:

Dr. Peter Ngan: Thank you for serving as my thesis advisor and chair of my committee. You have been a wonderful chairman, teacher, and mentor. I owe you a great debt of gratitude for allowing my dream to become true.

Dr. Tim Tremont: Thank you for providing an unbelievable foundation for my future orthodontic career. You have provided invaluable guidance on this project.

Dr. Chris Martin: Thank you for serving on my thesis committee and for continual and constant support during my orthodontic education.

Dr. Bryan Weaver: Thank you for serving on my research committee. Your dedication for moving the profession forward is greatly appreciated.

Jun Xiang: Thank you for your time and effort in helping to interpret the statistical analyses conducted during this project.

Dr. Tyler Crowe and Dr. MacKenzie Boyles: My friends for life who made the last three years full of fun and precious memories. Thank you.

Ghaddy, Carl, Niki, Mohamad, Joanna, and Sarah: Thank you so much for your friendship and all the good times we shared together. I wish you all the best of luck in your careers ahead. 


\section{TABLES OF CONTENTS:}

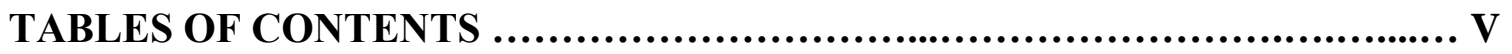

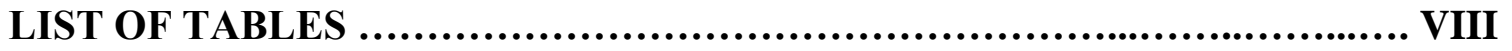

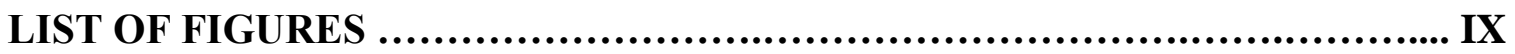

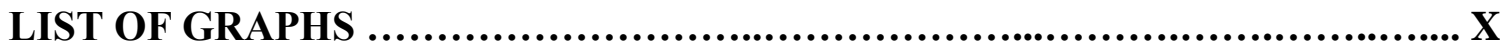

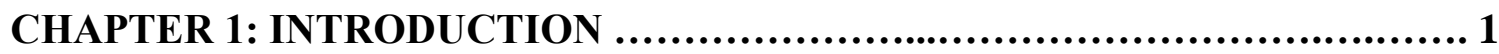

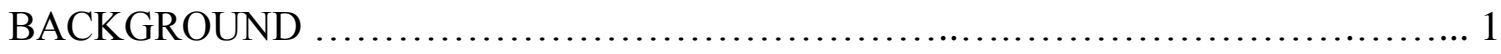

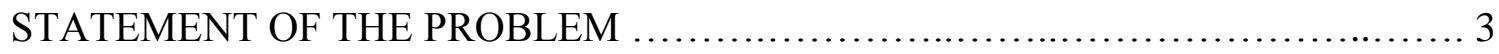

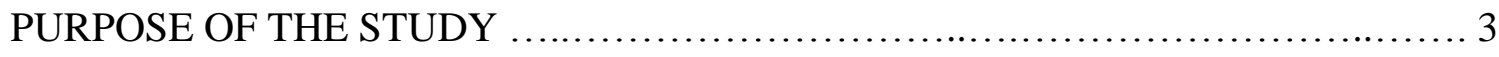

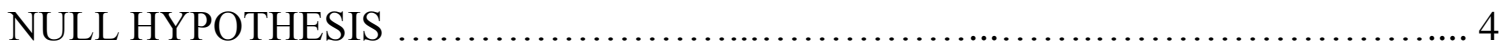

ALTERNATIVE HYPOTHESIS ................................................ 5

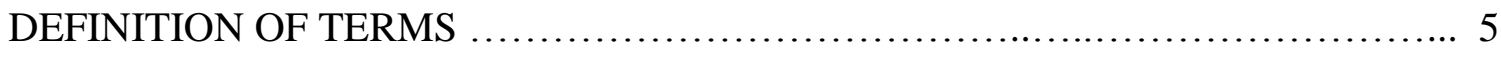

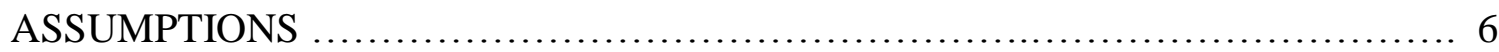

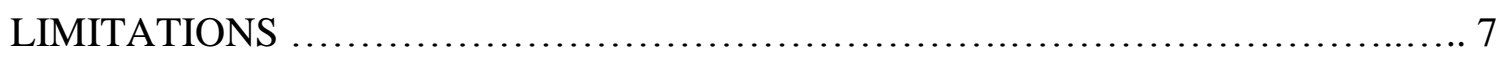

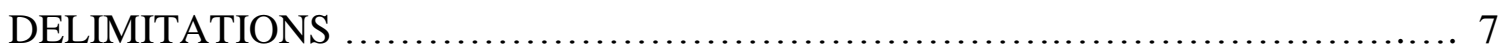

CHAPTER 2: REVIEW OF THE LITIRATURE .................................... 8

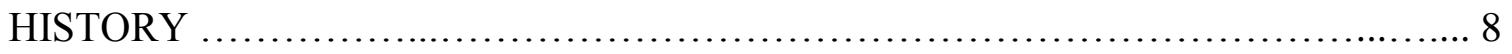

TRADITIONAL AND SOFT TISSUE ANALYSIS ................................. 9

THE SIX ELEMENTS OF OROFACIAL HARMONY .............................. 20

Glabella Vertical AS A LANDMARK ............................................ 23

MAXILLARY CENTRAL INCISORS RELATIONSHIP TO FOREHEAD ............ 23

ADJUSTED NATURAL HEAD POSITION .................................... 30

CHAPTER 3: MATERIAL AND METHODS .................................. 31 


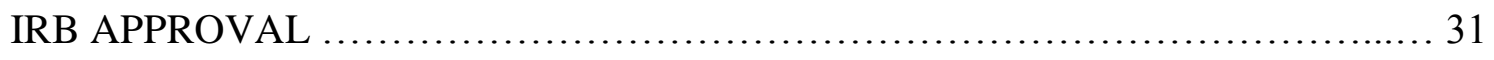

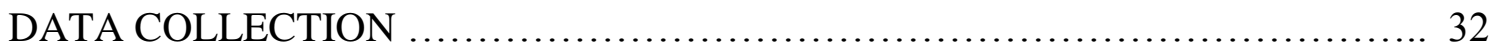

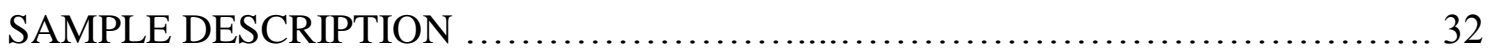

RESEARCH DESIGN .......................................................... 33

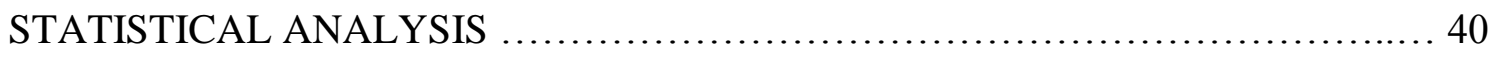

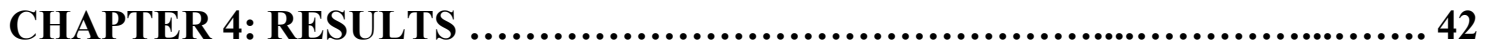

MODEL SUBJECTS SAMPLE DISTRIBUTION ................................ 42

EFFECT OF MAXILLARY INCISORS AP POSITION ........................... 44

SIGNIFICANCE OF MAIN EFFECTS _...................................... 49

REPOSE VIEW VS SMILING VIEW ........................................... 50

ORTHODONTISTS VS LAYPERSON RATERS …...........................53

MALES VS FEMALES RATERS _............................................. 55

JUDGES PREFERENCE OF MAXILLARY INCISORS AP POSITION ….......... 57

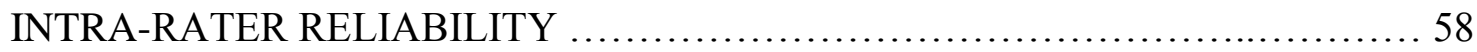

CHAPTER 5: DISCUSSION ....................................................59

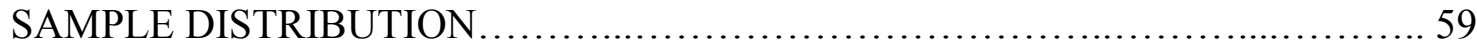

EFFECT OF MAXILLARY INCISORS AP POSITION ........................... 59

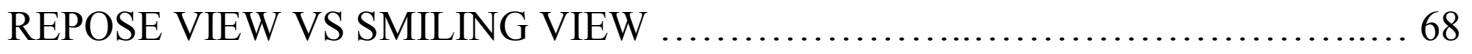

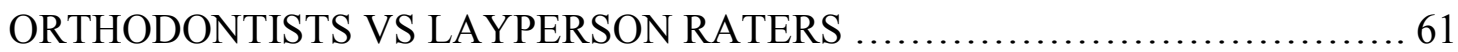

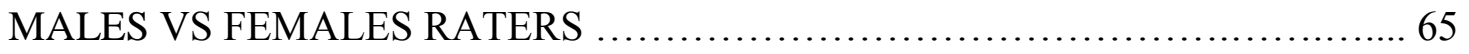

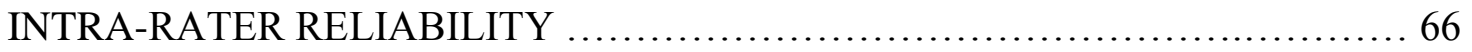

CHAPTER 6: SUMMARY AND CONCLUSIONS .............................. 66

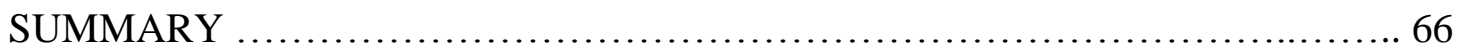


CONCLUSIONS

CHAPTER 7: SUGGESTIONS FOR FUTURE RESEARCH ................... 65

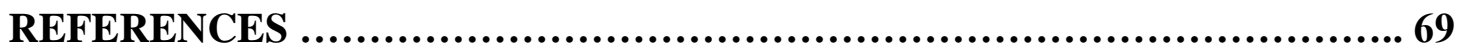




\section{LIST OF TABLES:}

Table 1: Model subjects' incisors position measurements....................... 43

Table 2: Means of rating scores for smile by patient.......................... 46

Table 3: Means of ranking scores for incisors AP position by rater ................ 47

Table 4: Mixed model analysis of ranking scores for all patients ................. 49

Table 5: Least Square means of ranking scores on view for all patients $\ldots \ldots \ldots \ldots \ldots . \ldots 0$

Table 6: Means of ranking scores of views by patient $\ldots \ldots \ldots \ldots \ldots \ldots \ldots \ldots \ldots \ldots \ldots \ldots \ldots \ldots \ldots \ldots \ldots \ldots \ldots$

Table 7: Means of rating scores (smile) of panel by patient...................... 54

Table 8: Multiple comparison for Panel*incisors position interaction $\ldots \ldots \ldots \ldots \ldots . \ldots 5$

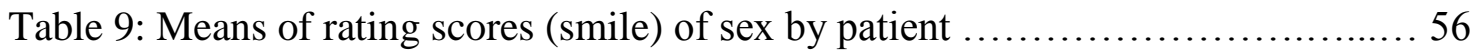

Table 10: Contingency table of GV position by Opinion $\ldots \ldots \ldots \ldots \ldots \ldots \ldots \ldots \ldots \ldots \ldots$

Table 11: Contingency table of GV position by Opinion by Panel .................. 58 


\section{LIST OF FIGURES:}

Figure 1: U1/S-N angle \& U1/FH angle ....................................... 11

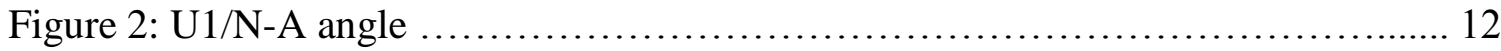

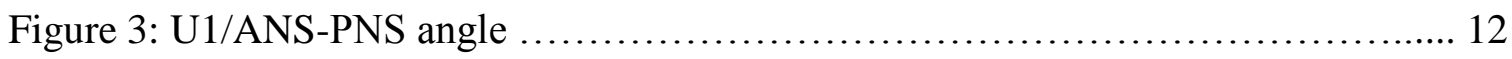

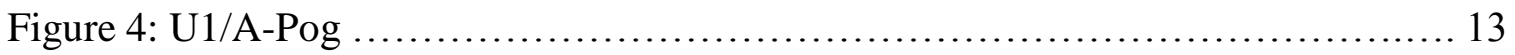

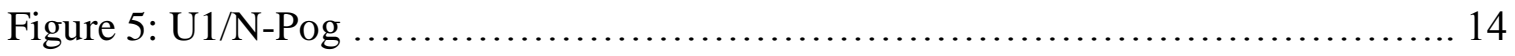

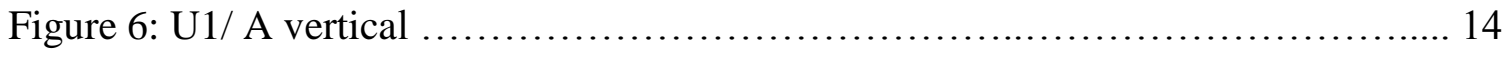

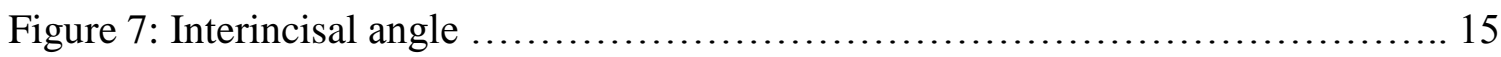

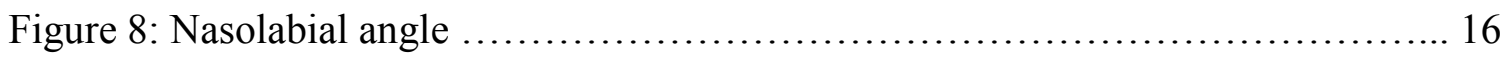

Figure 9: E line (Esthetic Plane) ............................................... 17

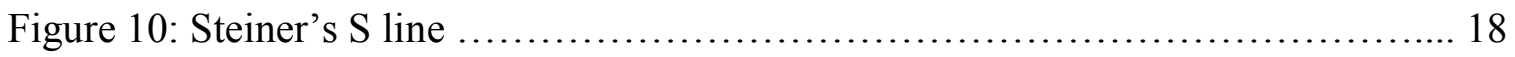

Figure 11: H-angle of Holdway ................................................. 19

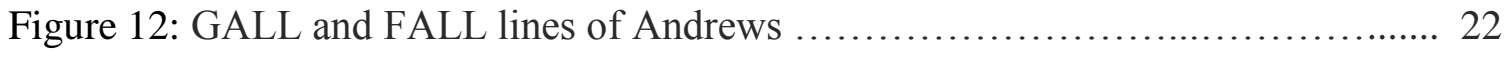

Figure 13: Schlosser,et al. study. Subject's image set ............................. 25

Figure 14: CAO,et al. study. Subject's image set ................................ 26

Figure 15: Ellis, et al. study. Subject's image set .................................. 27

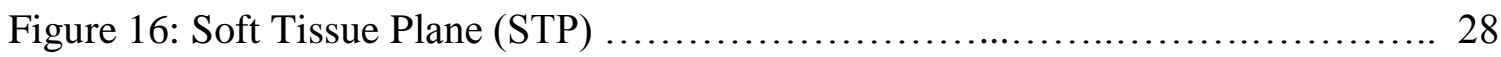

Figure 17: Najafi,et al. study. Subject's image set ................................ 30

Figure 18: Laser level used to set a white robe to simulate the TVP .................. 34

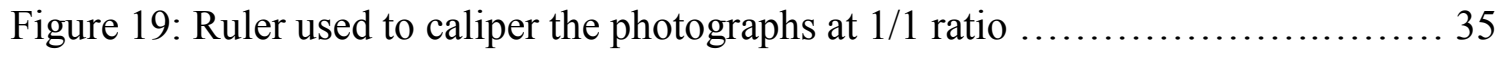

Figure 20: Photographs capturing in repose profile view ........................... 35

Figure 21: Photographs capturing in smiling profile view ......................... 36

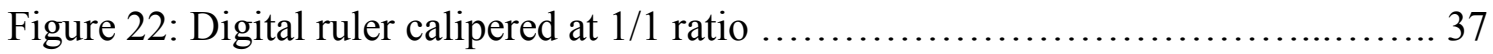


Figure 23: Measuring the distance of maxillary incisors to the GV .................. 37

Figure 24: Photograph as appeared in the rating Power Point ....................... 39

Figure 25: Visual Analog Scale (VAS) ................................... 40

\section{LIST OF GRAPHS:}

Graph 1: Distribution of the model subjects sample $\ldots \ldots \ldots \ldots \ldots \ldots \ldots \ldots \ldots \ldots \ldots . \ldots 4$

Graph 2: Mean rating of facial attractiveness for each group $\ldots \ldots \ldots \ldots \ldots \ldots \ldots \ldots . \ldots 45$

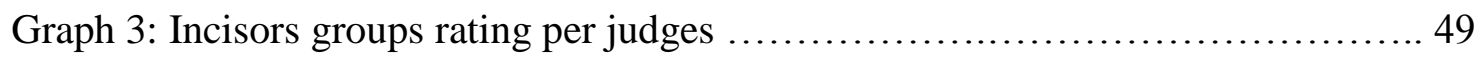

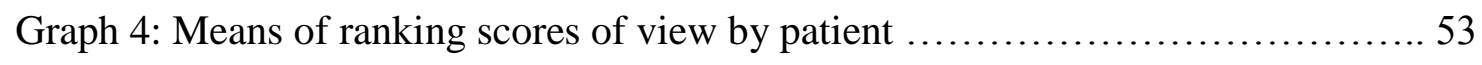




\section{CHAPTER1: INTRODUCTION}

\section{Background:}

Facial esthetics is one of the goals of orthodontic treatment, and one of the most important motivating factors for patients to seek orthodontic treatment. In fact, $80 \%$ of adults seeking orthodontic care for themselves or their children are motivated by a desire to improve appearance, regardless of structural or functional consideration [1]. A comprehensive orthodontic clinical examination includes the evaluation of the face in all three plans, and evaluation of the face in profile (sagittal plane) is an integral part. Facial profile examination includes the assessment of the soft tissue profile, jaws, lip posture, and incisors prominence in the anteroposterior and vertical planes of space. The anteroposterior (AP) position of the maxillary incisors affects the appearance of the soft tissue profile and overall facial harmony and esthetics.

In the orthodontic literature, different methods have been suggested to evaluate the maxillary incisor position, including traditional cephalometric analysis and soft-tissue analysis. These methods have some limitations and can be subjective and unreliable. In traditional cephalometric analysis, bony landmarks are used to define points and planes, which in turn are used to quantify anteroposterior (AP) incisor positions. However, using such landmarks can be unreliable because of the variability of their positions. Moreover, good facial esthetics have been shown to exist within a wide range of cephalometric values. In soft-tissue analysis, the nose, lips and chin are used to evaluate the position of 
the underlying teeth and jaws. Soft tissue structures, however, may not accurately convey the position of the underlying teeth and other hard tissue structures. Andrews rendered each of these landmarks as unpredictable because they are either internal and do not represent the external soft tissue, they are on areas that are still growing such as the nose, or they are likely to move during the course of the treatment [2]. In the Six Elements philosophy, Andrews suggested using the forehead as a landmark to evaluate the anteroposterior (AP) position of the maxillary incisors. He believed that there is a critical relationship between the maxillary incisors and the forehead and that attractive faces share a harmony between the two points regardless of ethnicity, gender, or age [2]. Andrews suggested that the ideal anteroposterior (AP) position of the maxillary central incisors is located on the GALL (Goal Anterior Limit line).

In a typical orthodontic profile examination, the maxillary incisors are not routinely evaluated in smiling profile view. Instead, the repose profile view is used. Andrews stressed the importance of using smiling profile, rather than repose profile, to evaluate the anteroposterior (AP) position of the maxillary central incisors. The rationale of this method is to assess the maxillary incisors relationship to the face directly, instead of the unpredictable method of relying on the soft tissue drape to reflect the incisors position indirectly [3].

Some researchers think that the ideal range of the maxillary incisors anteroposterior (AP) position can be affected, like most other standard references in orthodontics, by race and gender of the individual. Also, the training of the evaluator might play a role. For 
example, orthodontists are expected to be more educated and experienced in profile assessment than the lay public. This study, we tries to shed light on these issues. The purpose of this study is to evaluate the anteroposterior (AP) position of the maxillary incisors in relation to a Glabella Vertical reference in Caucasian adult males, and assess if orthodontic training and sex of the evaluator affect the judgment of the esthetically optimal anteroposterior (AP) position of the maxillary central incisors.

\section{Statement Of The Problem:}

Orthodontists might agree on treatment objectives (straight teeth, balanced facial form, good jaws relationship, mutually protected occlusion, healthy periodontium, stability), but not on treatment objectives [4]. In the era of evidence based orthodontic, there is a fundamental need for reliable landmarks to use for measurement, diagnosis, treatment, and communication. The ideal ranges can be affected by race and gender of the individual. Sex, training, and cultural background of the evaluator may also affect the judgment. There is no current research that identifies the most esthetically optimal anteroposterior (AP) position of the maxillary incisors in Caucasian males from a smiling profile view relative to the Glabella Vertical reference.

\section{Purpose Of The Study:}

The purpose of this study was:

1. To investigate the most esthetically optimal anteroposterior (AP) position of the maxillary incisors in Caucasian males as judged from a smiling profile view.

2. To investigate how this position is related to a Glabella Vertical (GV) reference.. 
3. To investigate if there is difference in judged attractiveness from smiling profile view versus repose profile view.

4. To investigate if orthodontists and laypeople judges agree upon judgment of the most esthetic anteroposterior (AP) position of the maxillary incisors in Caucasian males.

5. To investigate if male and female judges agree upon judgment of the most esthetic anteroposterior (AP) position of the maxillary incisors in Caucasian males.

6. To investigate if raters have a consistent and reproducible judgment of the most esthetically optimal anteroposterior (AP) position of the maxillary incisors in Caucasian males.

\section{Null Hypotheses:}

1. There is no difference in judged facial attractiveness of Caucasian males between smiling profiles and repose profiles.

2. There is no difference in judged facial attractiveness in smiling profile of Caucasian males with various anteroposterior (AP) positions of the maxillary incisors relative to Glabella Vertical (GV).

3. There is no difference between male versus female judgment of facial attractiveness of Caucasian males with various anteroposterior (AP) positions of the maxillary incisors relative to Glabella Vertical (GV).

4. There is no difference between orthodontist versus layperson judgment of facial attractiveness of Caucasian males with various anteroposterior (AP) positions of the maxillary incisors relative to Glabella Vertical (GV). 


\section{Alternative Hypotheses:}

1. There is a difference in judged facial attractiveness of Caucasian males between smiling profiles and repose profiles.

2. There is a difference in judged facial attractiveness in smiling profile of Caucasian males with various anteroposterior (AP) positions of the maxillary incisors relative to Glabella Vertical (GV).

3. There is a difference between male versus female judgment of facial attractiveness of Caucasian males with various anteroposterior (AP) positions of the maxillary incisors relative to Glabella Vertical (GV).

4. There is a difference between orthodontist versus layperson judgment of facial attractiveness of Caucasian males with various anteroposterior (AP) positions of the maxillary incisors relative to Glabella Vertical (GV).

\section{Definition of Terms:}

Race: is a term used to categorize humans into groups, called racial groups, based on shared physical traits, ancestry, genetics, and social or cultural traits.

Caucasian race: A term used to refer to people whose ancestry can be traced back to Europe, North Africa, West Asia, South Asia and parts of Central Asia. It was once considered a useful taxonomical categorization of human racial groups based on a presumed common geographic and/or linguistic origin [5].

Natural head position: is a standardized and reproducible position of the head when the head is in an upright posture and the eyes are focused on a point in the distance at eye level. 
Adjusted natural head position: The clinical judgment of the patient's natural head position when the head is upright and the patient is looking at a distant point at eye level, synonymous to corrected natural head position.

Anatomical forehead: The exposed skin from the hairline (or where the hair line once was) to the glabella.

FA point (tooth): The point on the facial axis of the clinical crown that midway between the gingival and occlusal borders.

FFA point (forehead): The midpoint of the clinical forehead that is between superion and glabella for round and angular foreheads, and is between trichion and glabella for straight foreheads.

Fall (Face Anterior Limit Line): A frontal plane of the face passing through the FFA point of the forehead.

Gall (Goal Anterior Limit Line): A frontal plane of the face representing the anterior limit of an element I maxillary incisors. Synonymous to Glabella Vertical Plane.

\section{Assumptions:}

1. Investigators can reliably position subjects in the corrected natural head position.

2. Investigators are orthodontically trained and have experience in identification of Glabella Vertical.

3. Investigators can reliably position the millimeter ruler on the level of the patient's midsagittal plane.

4. Glabella Vertical (GV) is a valid landmark that can be used to measure the anteroposterior (AP) position of maxillary incisors, 
5. The measurement of anteroposterior (AP) incisors position in relation to Glabella Vertical was accurately recorded with the patient in corrected natural head position.

6. Raters can judge facial attractiveness of the subjects.

7. Randomly selected subjects are an adequate representation of the Caucasian male population.

8. Randomly selected judges are an adequate representation of the society.

\section{Limitations:}

1. Glabella Vertical is relative to the corrected natural head position. If adjusted natural head position is incorrect, then Glabella Vertical judgment may be incorrect.

2. Investigator error in identification of Glabella Vertical line.

3. The judgment of esthetic and face attractiveness in this study depend on a two dimensional photograph of a three dimensional objects.

4. Other facial features (nose, chin, complexion, hair color ... etc.) may influence raters' judgment of subjects' attractiveness.

5. Age of model subjects may influence raters' judgment of subjects' attractiveness.

6. Racial, cultural background and personal preference of the raters can affect the personal judgment on facial attractiveness.

7. Rater gender might affect the judgment of the subject's facial attractiveness.

\section{Delimitations:}

1. Investigators are orthodontically trained and may have acquired biases. 
2. Photographs of the subjects were changed to black and white and all backgrounds were cropped out to decrease the effect of other facial features on the rater's judgement,

3. Only model subjects of ages between eighteen and thirty were used to decrease age effect on the rater's judgment.

\section{CHAPTER 2: REVIEW OF THE LITERATUR}

\section{History:}

Orthodontics might seem to be the most modern branch of dentistry, but actually the history of orthodontics goes back thousands of years. The perfect smile and correcting orthodontic problems such as crowded, irregular or protruding teeth has been a project at least since $1000 \mathrm{BC}$. Archaeologists found metal bands around teeth of many of the Egyptian mummies; it is believed that they tied catgut to these bands to provide pressure to move the teeth [6]. Also, primitive and surprisingly well-designed appliance have been found in both Greek and Etruscan materials [6]. Hippocrates, a Greek physician and one of the most outstanding figures in the history of medicine, wrote the earliest known texts about teeth irregularities around 400 B.C. [7]

According to Wahl, significant contributions to the field of orthodontics in the United States started in the 19th century [7]. In 1822, J.S. Gunnell invented the occipital anchorage headgear that applies gentle pressure on the protruding teeth from the outside 
of the mouth. After 1850, Norman Kingsley published the first paper on modern orthodontics, Oral Deformities [8]. Kingsley was a dentist, artist, and a pioneer in the treatment of Angle Class II malocclusions and cleft palate. The father of modern orthodontics and one of the most outstanding figures in the orthodontics field is Edward Hartley Angle (1855 -1930). He was trained as a dentist, but he was interested in orthodontics and he was the first to declare orthodontics as dental specialty. He also established the first orthodontic school, The Angle School of Orthodontia, in 1900. His classification of malocclusion is probably one of the most notable contributions in his life, because it subdivided the major types of malocclusion and included the first clear definition of normal (Class I) occlusion.

As time passed, orthodontists learned that even a perfect occlusion was not satisfactory if it is achieved at the expense of facial esthetics and proper facial harmony. Cephalometric radiography, which became widely used in orthodontics in the second half of the twentieth century, showed clearly that many orthodontic problems are a result of a faulty jaws position and not only faulty teeth position. In the modern orthodontics, there have been changes in the goals of orthodontics to focus more on facial proportions and the effects of the teeth position and occlusion on facial harmony and appearance.

\section{The Optimal Anterior-Posterior Position Of Maxillary Incisors In}

\section{Traditional And Soft Tissue Analysis:}

As discussed earlier in this chapter, protruded teeth have always been a concern, but the problem remains of finding the optimal anteroposterior (AP) position of the maxillary 
anterior teeth. In the orthodontic literature, different approaches have been suggested to evaluate the maxillary incisor position, including traditional lateral cephalometric radiograph analysis and soft-tissue analysis.

\section{$\underline{\text { Traditional lateral cephalometric analysis: }}$}

The evaluation of maxillary incisors position is a part of most cephalometric analyses.

Downs, Steiner, Tweed, Ricketts, and Riedel introduced specific cephalometric measurements to assess the anteroposterior (AP) position of the maxillary incisors. Angular and linear measurements were described in the literature. Some measurements are sensitive to the anteroposterior (AP) position of the maxillary incisors, and other measurements are sensitive to the labiolingual inclination of the maxillary incisors. Ellis and McNamara described eight cephalometric values to evaluate the maxillary incisors position [9]:

1) U1/S-N angle (Fig1): The angle between the axis of the maxillary incisor and the S-N plane. This angular measurement determines the inclination of the central incisor relative to the anterior cranial base. A greater than average angle indicates proclination of incisors, while a smaller than average angle indicates retroclined incisors as often seen in Class II division 2 cases. This angle can be affected by the inclination of the S_N plane (position of S or N points).

2) U1/FH (Fig1): The angle between the maxillary incisor axis and the Frankfort Horizontal plane. A greater than average angle indicates proclination of incisors, 
while a small angle indicates retroclined incisors. This angle can be affected by the inclination of the Frankfort Horizontal plane, which has a questionable reliability [9].

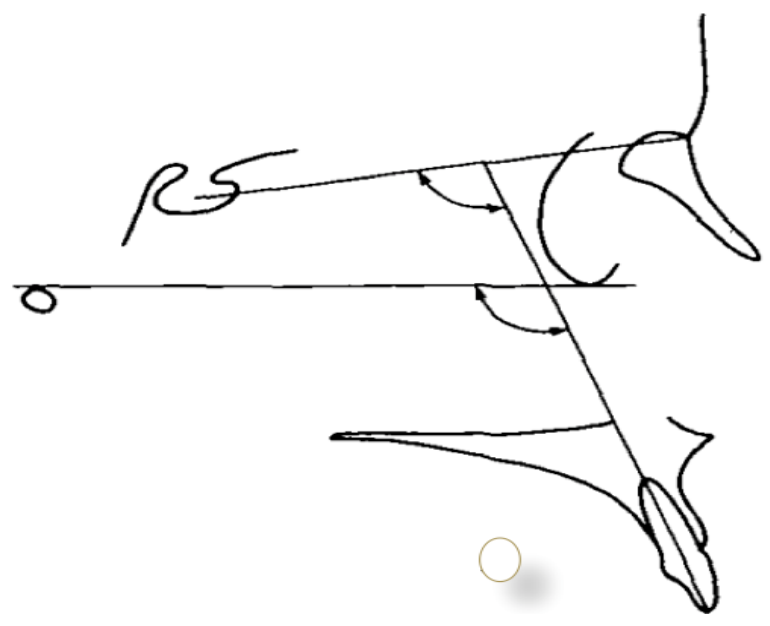

Figure 1: U1/S-N angle \& U1/FH angle [9]

3) U1/N-A (Fig 2): The relationship of the maxillary central incisor to the N-A reference line. It is used as both angular and linear reference. The angular value used to evaluate the inclination, while the linear value used to evaluate the horizontal position of maxillary incisors relative to the maxillary apical base. Proclined incisors will have a greater than average angular and linear measurement. Retroclined incisors will have a smaller than average angular and linear measurement. Positive values are recorded if the labial surface of the incisor is anterior to the NA line, negative values if it is posterior to the NA line. Although these have become two of the most accepted measures of maxillary incisor position, an examination of the N-A line shows a need for careful interpretation. When the maxillary skeleton (and therefore point A) is positioned posteriorly without changing the incisor position within the maxilla, the change in the angulation of $\mathrm{N}-\mathrm{A}$ causes the U1/N-A measures to become larger [9]. 


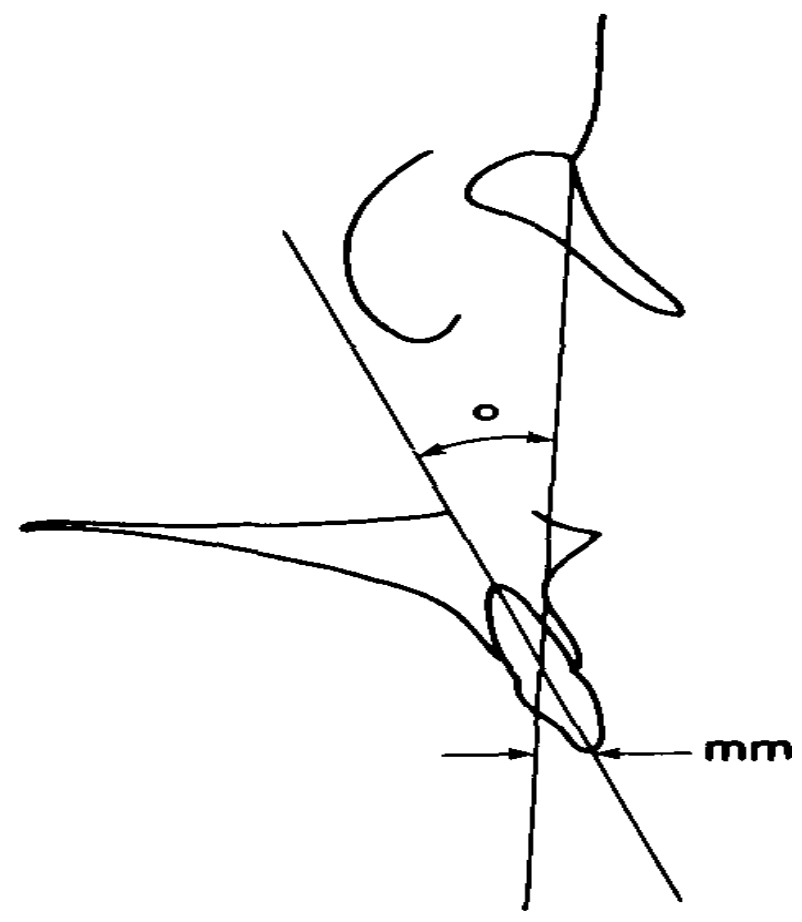

Figure 2: U1/N-A angle [9]

4) U1/ANS-PNS (Fig 3): The angle between the maxillary incisor and the palatal plane (ANS-PNS). It is useful to evaluate the incisor inclination within the maxillary bone.

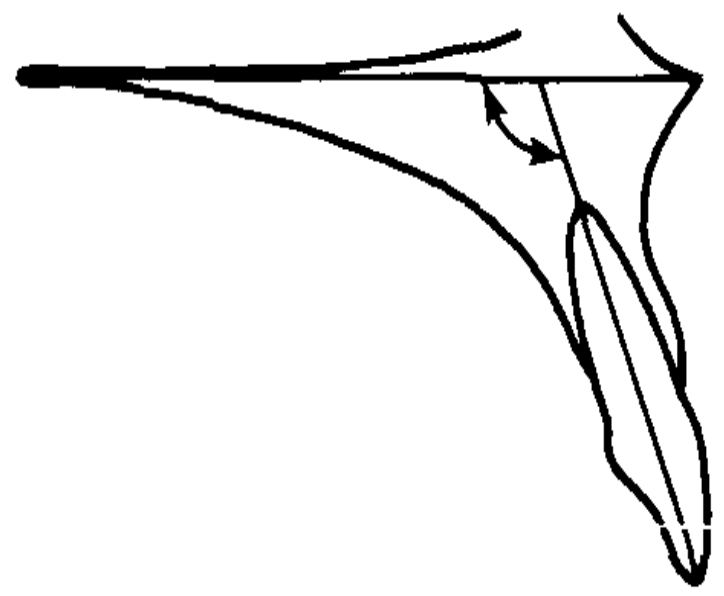

Figure 3: U1/ANS-PNS angle [9] 
5) U1/A-Pog (Fig 4): Distance in millimeters of the incisal edge of the maxillary incisor to the A-Pog line. A protruded maxilla with a protruded mandible, or a retruded maxilla with a retruded mandible, might result in normal measurement of U1/A-Pog even if the incisors are not in a good anteroposterior (AP) position in relation to the cranium [9].

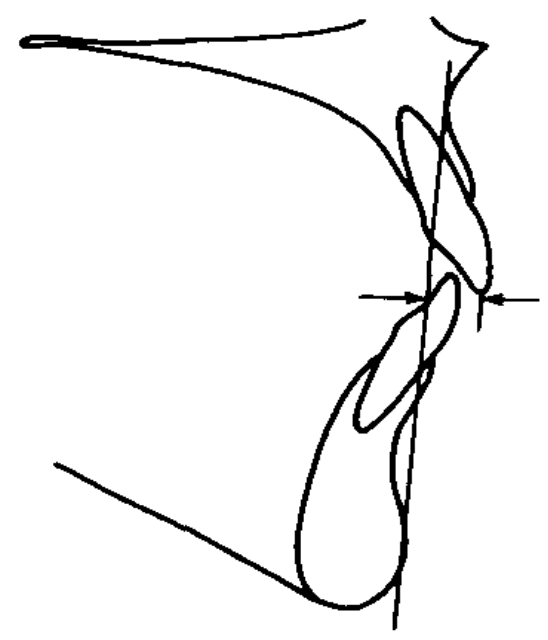

Figure 4: U1/A-Pog [9]

6) U1/N-Pog (Fig 5): Similar to U1/A-Pog in applications. It is the distance of the incisal edge of the maxillary incisor to the N-Pog line. However, it eliminates the use of A point which is one of the highly variable points. Nasion can also be abnormal in position, but it is certainly more constant than the maxilla [9]. 


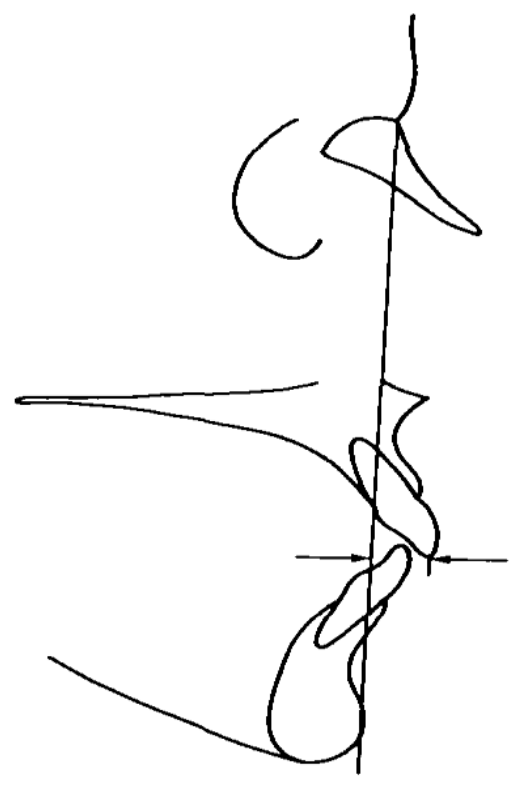

Figure 5: U1/N-Pog [9]

7) U1/A vertical (Fig 6): As defined by McNamara is another way to relate the maxillary incisor to the maxilla. It is the horizontal distance between the facial surface of the maxillary incisor and a perpendicular erected from point A to the Frankfort Horizontal plane [9].

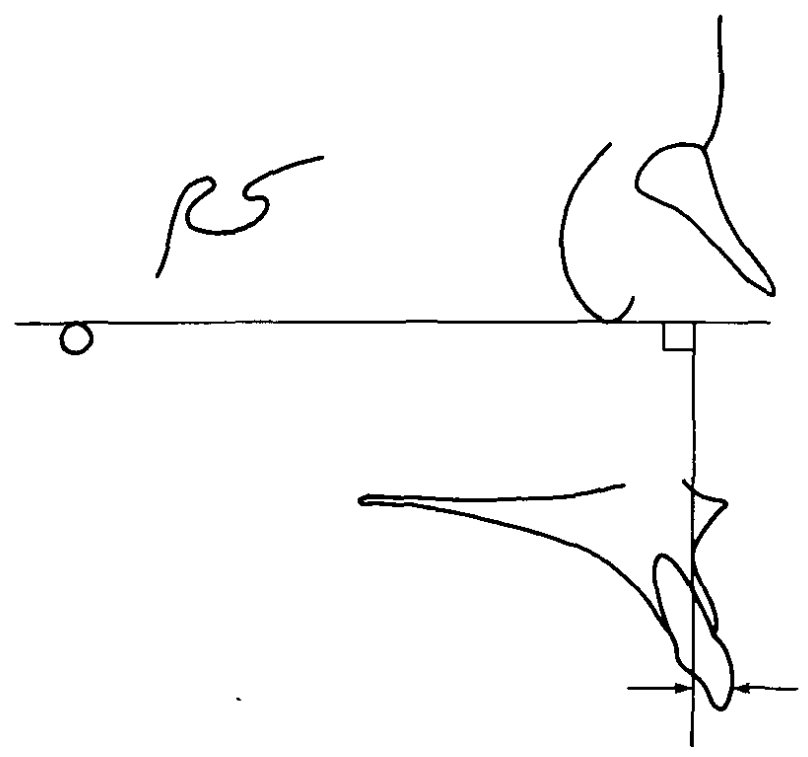

Figure 6: U1/ A vertical [9] 
8) Interincisal angle U1/L1 (Fig 7): This angle was used in literature as an indicator of maxillary and mandibular incisors inclination. The more labially inclined the incisors are, the less the interincisal angle. The more lingually inclined the incisors are, the more the interincisal angle. However, this angle can be affected by the position of the maxillary and mandibular incisors, and the by the relative position of the maxilla and the mandible.

Cephalometric analysis is certainly useful diagnostic and treatment approach, however it can be unreliable and unpredictable to evaluate the optimal anteroposterior (AP) position of the maxillary incisors. The bony landmarks have some variability in their positions. They are internal landmarks that do not represent the external soft tissue. Moreover, good facial esthetics have been shown to exist within a wide range of cephalometric values.

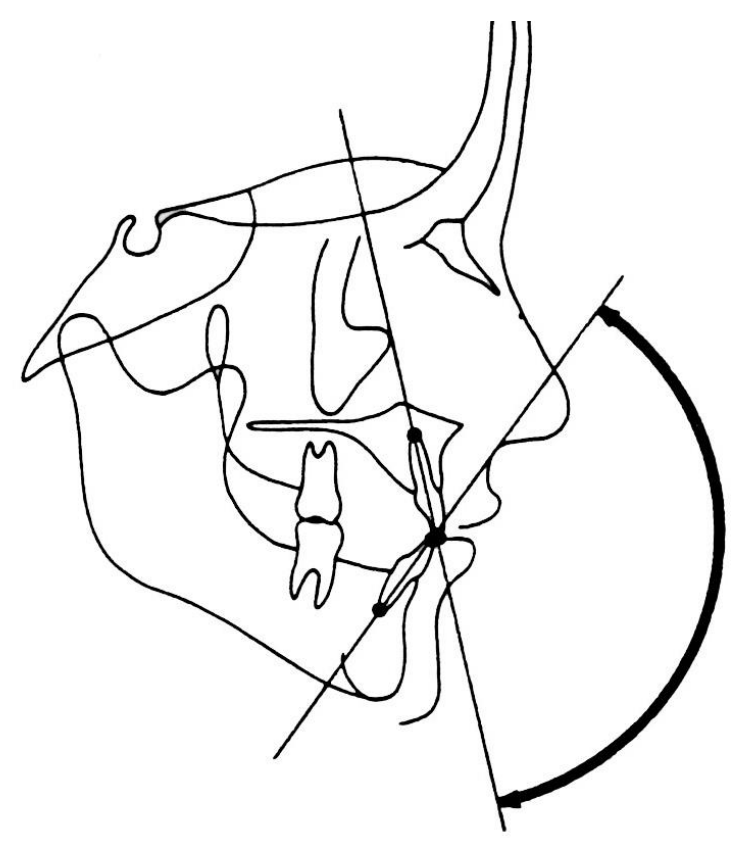

Figure 7: Interincisal angle 


\section{$\underline{\text { Soft Tissue Analysis: }}$}

Some authors have suggested using soft tissue analysis as a reliable guide for orthodontic evaluation and treatment planning. In this method, the overriding key to evaluate the anteroposterior (AP) position of the incisors lies in the clinical perception of the size, shape, and position of the facial tissue parts overlaying the teeth, the lips. Interestingly, facial features are usually studied in profile view. Different authors have defined various soft tissue parameters and landmarks of soft tissue facial analysis. A frequently used soft tissue parameter in orthodontic diagnosis is the nasolabial angle (Fig 8), which Formed by a line tangent to the columella of the nose and a line tangent to the upper lip with an arbitrary range of 90 to 120 degrees is usually stated in the literature. The nasolabial angle fails to tell us weather angle is excessive because the lip slants back, the nose turns up, or both [10].

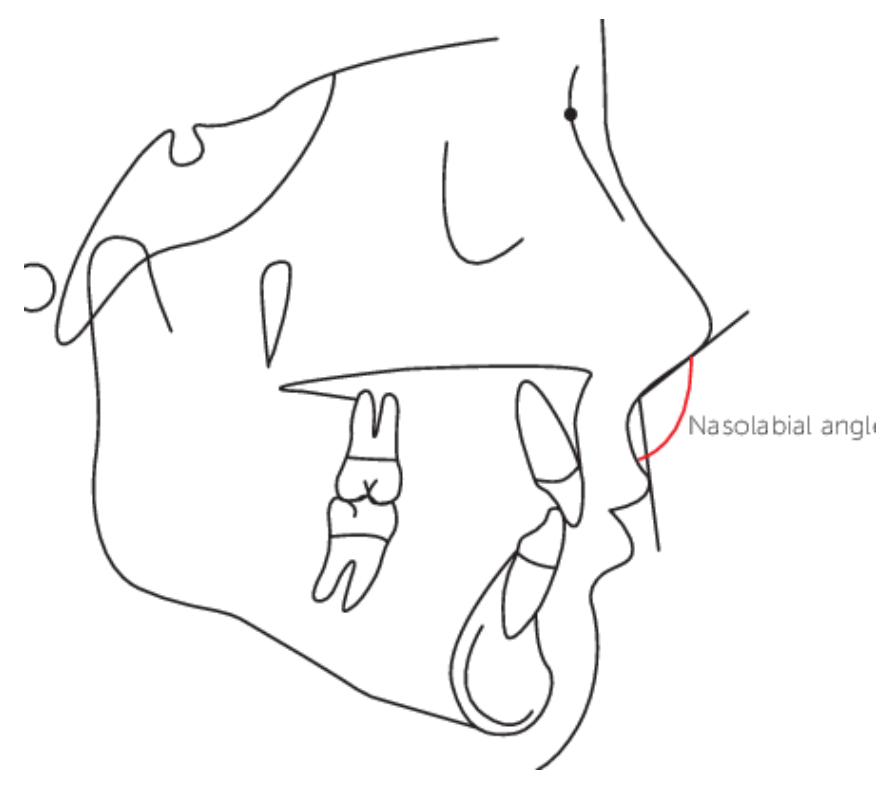

Figure 8: Nasolabial angle 
The concept of having a specific relationship between the nose, lips and chin from a profile perspective goes back to the 1950s and the work of Ricketts. Ricketts established the law of the labial relationship according to the esthetic E-plane. The E line of Ricketts (Fig 9) connects the nose tip to the soft tissue pogonion, and is a reference line used to assess the upper and lower lips. In the average Caucasian face, the lower lip would be 2 mm behind the line, and the upper lip $4 \mathrm{~mm}$ behind the line.

The Steiner's S line (Fig 10) is drawn from midpoint between subnasale and pronasale to soft tissue pogonion and lip prominence with reference to this line is assessed. The $\mathrm{S}$ line has been used cephalometrically but it has not been used on photograph to assess lip prominence. Upper and lower lips distance to $\mathrm{S}$ Line should be ideally $0 \pm 2 \mathrm{~mm}[11]$.

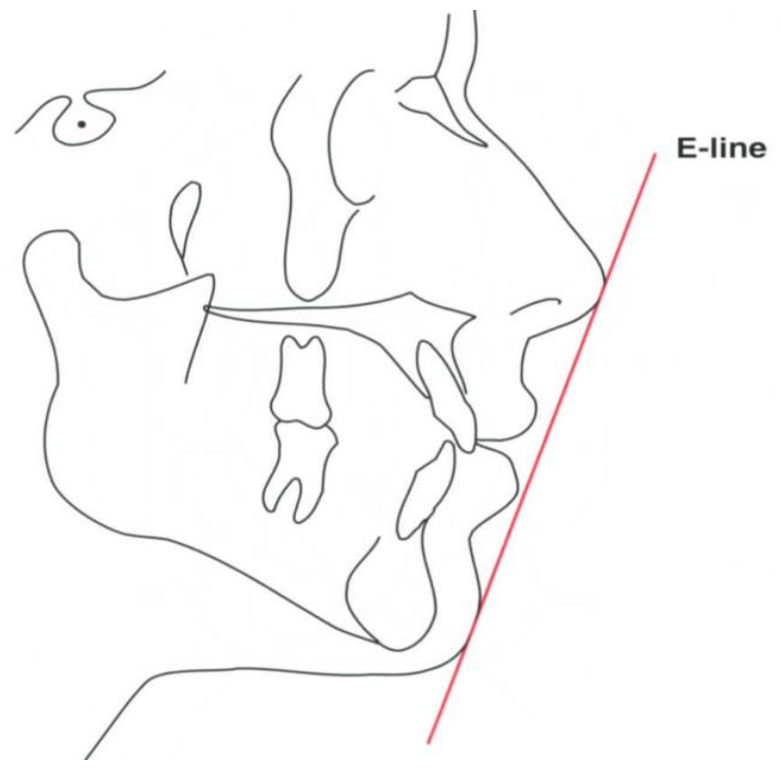

Figure 9: E line (Esthetic Plane) 


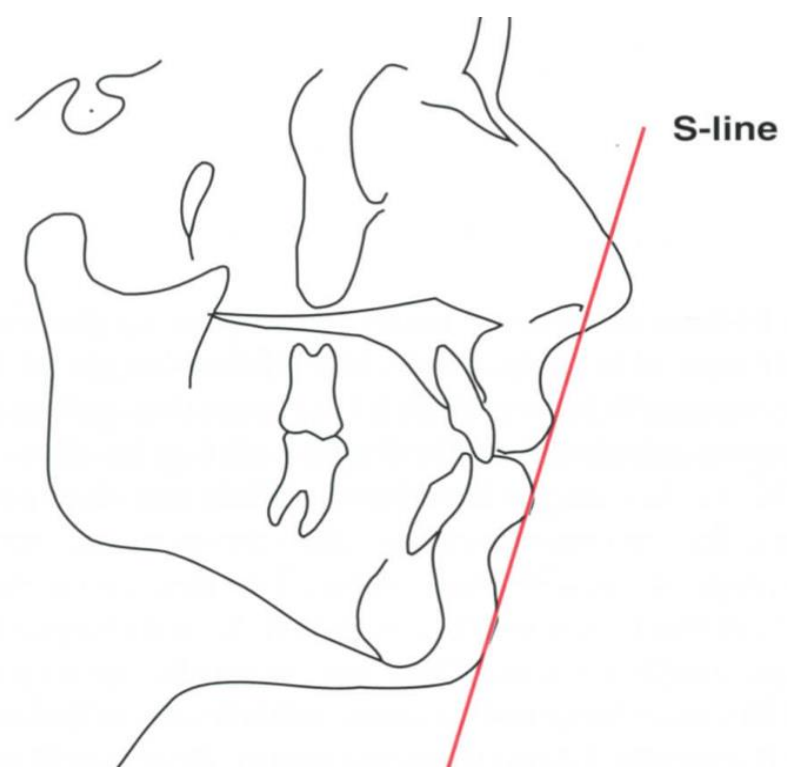

Figure 10: Steiner's S line

In 1981, Holdway presented his soft tissue analysis at the annual meeting of the American Association of Orthodontists (AAO). This analysis included eleven measurements. He introduced the $\mathrm{H}$ line (Harmony line), which is a tangent to chin and upper lip (Fig 11). The H-angle is formed by a line tangent to the chin and upper lip with the Nasion-Pogonion line. Holdaway stated that the ideal face has an H-angle of 7-15 degrees, which is dictated by the patient's skeletal convexity [8]. He also defined norms of the measurements of upper lip thickness, upper lip strain, soft tissue subnasale to the $\mathrm{H}$ line, and the superior sulcus depth. 


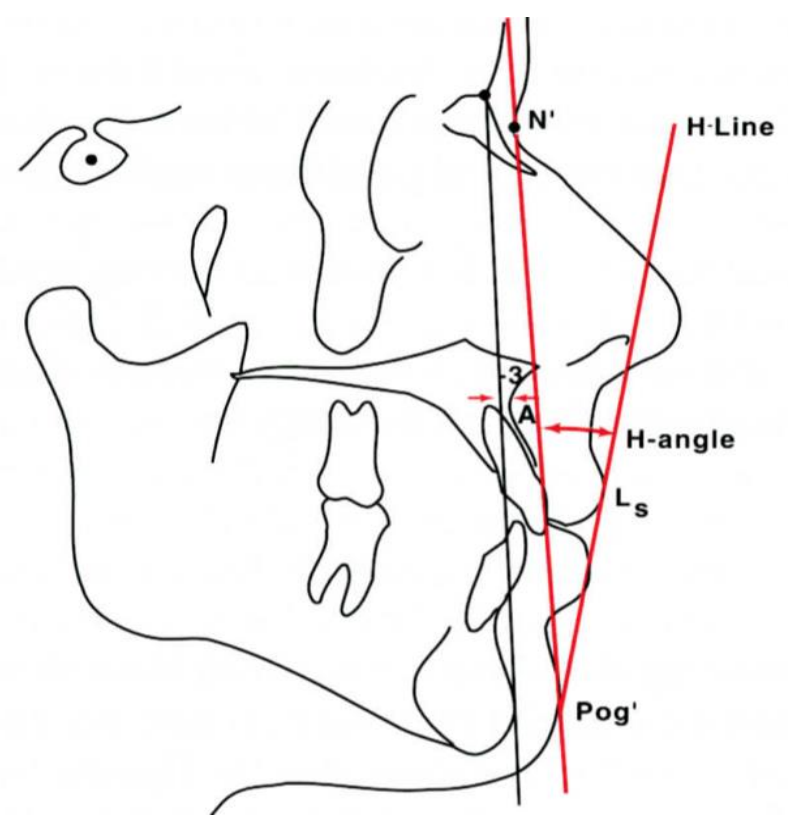

Figure 11: H-angle of Holdway

Burstone used the B line, which connects Subnasale and Pogonion points. He defined the position of the upper lip regarding the $\mathrm{B}$ line to be $3.5 \mathrm{~mm}$ ahead. Arnett and Bergman described an analysis of the soft tissue facial profile on photographic records in natural head position. They studied a small sample of attractive individuals, and described a true vertical line (TVL) passing through subnasale. According to them, the maxillary incisors should be 12.1( \pm 1.8$) \mathrm{mm}$ in males and 9.2( \pm 2.2$) \mathrm{mm}$ behind the TVL in females. In 1991, Bass introduced the position of the upper incisor as a key for orthodontic treatment. He defined the ideal position of the upper incisor, Pogonion, and the upper lip using a perpendicular line to the true horizontal (TH). He also established the exhibition of 2 to 3 $\mathrm{mm}$ of the upper incisor below the interlabial gap [12]. 


\section{The Six Elements Of Orofacial Harmony:}

The Andrews Six Elements of Orofacial Harmony is a classification, diagnostic, and treatment philosophy that describes a clinically relevant method to evaluate and plan the position of the jaws and the teeth. The Six Elements of Orofacial Harmony are the tooth, arch, and jaw characteristics found to be shared by individuals with naturally optimal occlusions and balanced faces [2]. The Six Elements defined by Lawrence F. Andrews as are the optimal orthodontic treatment goals and the six areas for which orthodontists have diagnostic responsibility. The six elements are: Element I) The arch: teeth individually (morphology and positions) and the teeth collectively (arch shape and length); Element II) Anteroposterior (AP) jaws positions; Element III) Jaw widths; Element IV) Jaw heights; Element V) Pogonion prominence and Element VI) Dental occlusion [13]. Andrews defined each element as optimal based on facial esthetics and occlusion of 120 non-treated patients. Dr.Andrews identified referents, landmarks, and objectives to define the optimality of each one of the six elements.

As explained before, the anteroposterior (AP) protrusion of the maxillary incisors in the face can be affected by incisors inclination and teeth anteroposterior (AP) position. According to Dr.Andrews philosophy, Inclination of the maxillary incisors can be evaluated through element I of the Six Elements of Orofacial Harmony. Element I describes the shape and length of the maxillary and mandibular arches. Optimal arches are achieved when teeth sizes are normal, teeth are in the correct inclination, the root of each tooth is centered over basal bone, and the curve of spee is between 0 and $2.5 \mathrm{~mm}$. lateral cephalometric radiograph is used to determine the optimal inclination of the 
incisors. The optimal inclination of the maxillary incisors is identified based on the occlusal plane. The maxillary incisor is defined optimal at $7^{\circ}$ to perpendicular line to the occlusal plane. Maxillary incisors anteroposterior (AP) position is evaluated through Elements II of the Six Elements of Orofacial Harmony. Element II is the optimal anteroposterior (AP) positions of the maxillary and mandibular jaws. Andrews described landmark points on the forehead (trichion, superion, glabella, and FFA). Trichion is located on the superior border of the forehead; located at the hairline. Superion is a point on an angular or rounded forehead representing the superior boundary of the clinical forehead. Glabella is defined as the most inferior aspect of the forehead; a point on the frontal bone above nasion and between the eyebrows. FFA (Forehead FA) is defined as the midpoint between superion and glabella for foreheads with rounded or angular contour. Forehead landmarks are used to create vertical reference plans, FALL line and GALL Line, which can be used to evaluate the anteroposterior (AP) position of the maxillary central incisors in profile. FALL (Face Anterior Limit Line) is a frontal plane of the face passing through the FFA point of the forehead. GALL (Goal Anterior Limit Line) is a frontal plane of the face representing the anterior limit of element II maxillary incisors. The relationship is quantified as the distance in millimeters between the FA point of the maxillary incisor crown and the GALL line. In the past, Andrews defined the optimal anteroposterior (AP) position of the maxilla is when the Element I maxillary incisors are located between the FALL and GALL references. However, in the last years the optimal position was redefined. The anteroposterior (AP) position of the maxilla is optimal when the Facial Axis points (FA point) of Element I maxillary incisors (optimal inclination and position in the basal bone) are on the Goal Anterior Limit Line (GALL). 
The best method for assessing this relationship is clinical judgment [14]. Schlosser, et al. [18] found that Andrews' method of profile assessment was " a useful method to evaluate attractiveness relative to the maxillary incisor position'. In 2015, Tomblyn, et al. found that "Glabella Vertical can be used as a frontal plane for diagnosis and treatment planning. Andrews also suggested using a smiling profile view to evaluate element II of the Six Elements of Orofacial Harmony.

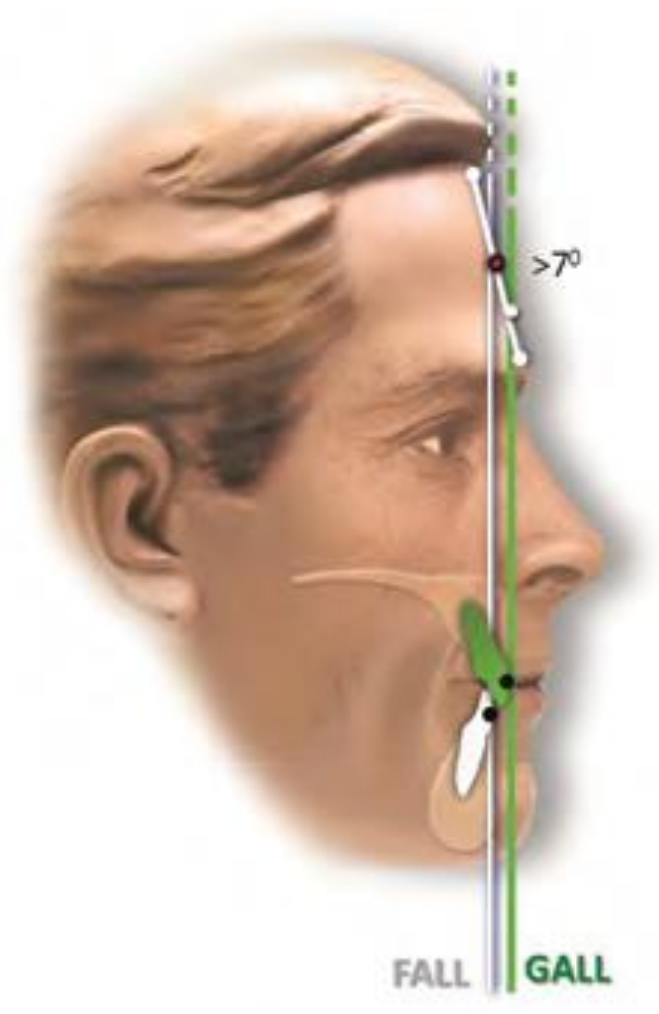

Figure 12: GALL and FALL lines of Andrews

In Six Elements of Orofacial Harmony philosophy, orthodontists can use colors to communicate the anteroposterior (AP) position of the maxillary anterior teeth. Incisors with harmonious position are green. That is when incisors FA point is positioned on the GALL line. Red incisors are teeth that are positioned anterior to the GALL line, and 
black incisors are teeth that are positioned posterior to the GALL line. This color system is very helpful for communication and description, and usually millimeters are used for distances.

\section{Glabella Vertical Plane As A Landmark For Diagnosis And Treatment}

\section{Planning:}

In orthodontics, reference planes are used to relate cranial and facial elements for the purposes of diagnosis, treatment planning and communication. Ideally, a valid reference plane should have the following features: good reliability (low method error), good intraindividual reproducibility, low inter-individual variability, and average orientation close to true horizontal (HOR) or vertical (VER) [15]. In 2015, Tomblyn et al did a study in West Virginia University. The goals of this study were 1) to evaluate the reliability and reproducibility of FALL (Face Anterior Limit Line) and GALL (Goal Anterior Limit Line) as reference planes. 2) to evaluate if Glabella Vertical can be used as a frontal reference plane 3.) to evaluate if $\mathrm{NHO}$ (Natural Head Orientation) is affected by varying chin positions [4]. Tomblyn et al found that FALL and GALL are reliable and reproducible reference planes. They also found that Glabella Vertical can be used as a frontal plane for diagnosis and treatment planning [4].

\section{Anteroposterior Relationship Of The Maxillary Central Incisors To The}

\section{Forehead:}

In the Six Elements philosophy, Andrews suggested using the forehead as a landmark to assess the anteroposterior (AP) position of the maxillary incisors. Andrews defined 
forehead landmarks and observed the correlation between the forehead's prominence and inclination and the position of the maxillary central incisors in individuals with good facial profiles [16]. Using the forehead as a primary landmark for anteroposterior (AP) incisor positioning avoids the potential pitfalls of relying on cephalometric analysis or repose soft tissue analysis [3]. Several studies have been conducted in the past about this subject.

In 2008, Dr.Will Andrews conducted a study to evaluate the anteroposterior (AP) relationship of the maxillary central incisors to the forehead in adult white females. $\mathrm{He}$ compared profile photographs of 94 white females with good facial harmony (as a control group) with photographs of 94 white females seeking orthodontic treatment (as a study group). He found a statistically significant difference in the anteroposterior (AP) position of maxillary incisor between the two groups. The optimal maxillary central incisors position was between the forehead facial axis (FFA) point and glabella in $93 \%$ of the cases in the control group, and only in $21 \%$ of the cases in the study group. He concluded that the forehead is an important landmark for anteroposterior (AP) maxillary incisor positioning for adult white female patients seeking improved facial harmony [16]. In 2013, Adams M, Andrews W, Tremont T, Martin C, Razmus T, Gunel E, and Ngan P repeated the study on adult white males using profile photographs of 101 white male with good facial harmony (as a control group) and photographs of 97 white male seeking orthodontic treatment (as a study group). They came up with the same conclusion that the forehead can be used as an important landmark to locate the optimal anteroposterior (AP) maxillary incisor position for adult white males [17]. 
Some cited studies used computer software to manipulate some facial structures anteroposterior (AP) position to evaluate the effect of such movements on the attractiveness of the face. Schlosser JB, Preston CB, and Lampasso J published a study in 2005. They photographed the facial profile of a white female subject and generated a series of alterations using computer software in which the maxillary incisors were misaligned relative to the GALL in $1 \mathrm{~mm}$ increments to a maximum of $4 \mathrm{~mm}$ forward and backward (Fig 13). The subject had normal soft tissue profile and her maxillary incisors were in an Element II position (on the Glabella Vertical plane). Panels of orthodontists and lay people were asked to score the attractiveness of the photographic variations. Interestingly, they found that orthodontic training did not significantly affect the attractiveness judgement, and that the image with the most retracted anteroposterior (AP) position of the incisors was the least attractive to both orthodontists and laypersons. They concluded that Andrews' Element II provides a useful method to evaluate attractiveness relative to the maxillary incisor position [18].
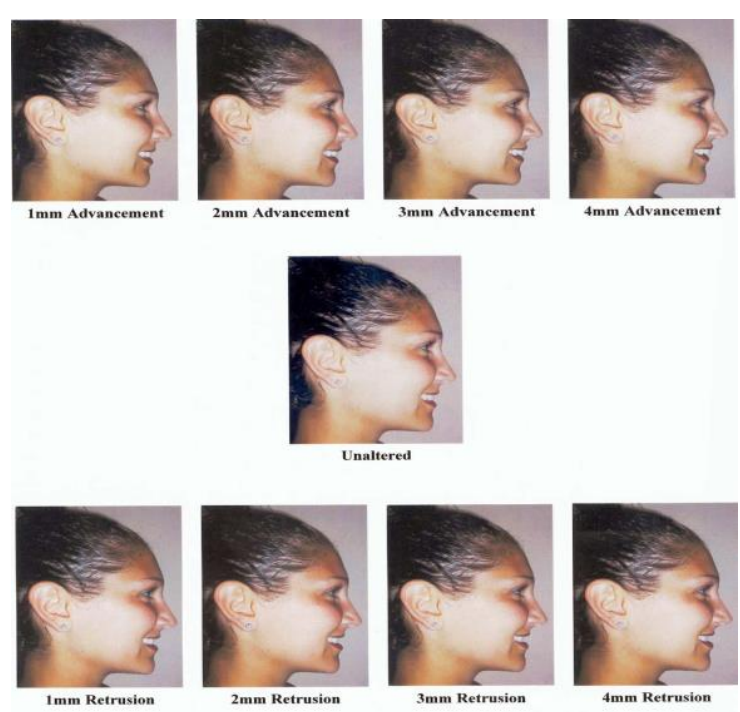

Figure 13: Subject's image set [18] 
Cao, et al. (2011) manipulated photograph of a Chinese woman with a normal profile, a Class I occlusion, and a Class I skeletal pattern. They altered the inclination and the anteroposterior (AP) position of the maxillary incisors to generate a series of photographs that were judged by orthodontic professionals and laypersons (Fig 14). Both maxillary incisor labiolingual inclination and anteroposterior (AP) position found to be essential factors in the attractiveness of the smiling profile. As in the previous study, no significant discrepancy was found between the assessments of the professional and nonprofessional groups. They concluded that Element II of Andrews and Andrews six elements of orofacial harmony is a useful reference to the smiling profile esthetics [19].

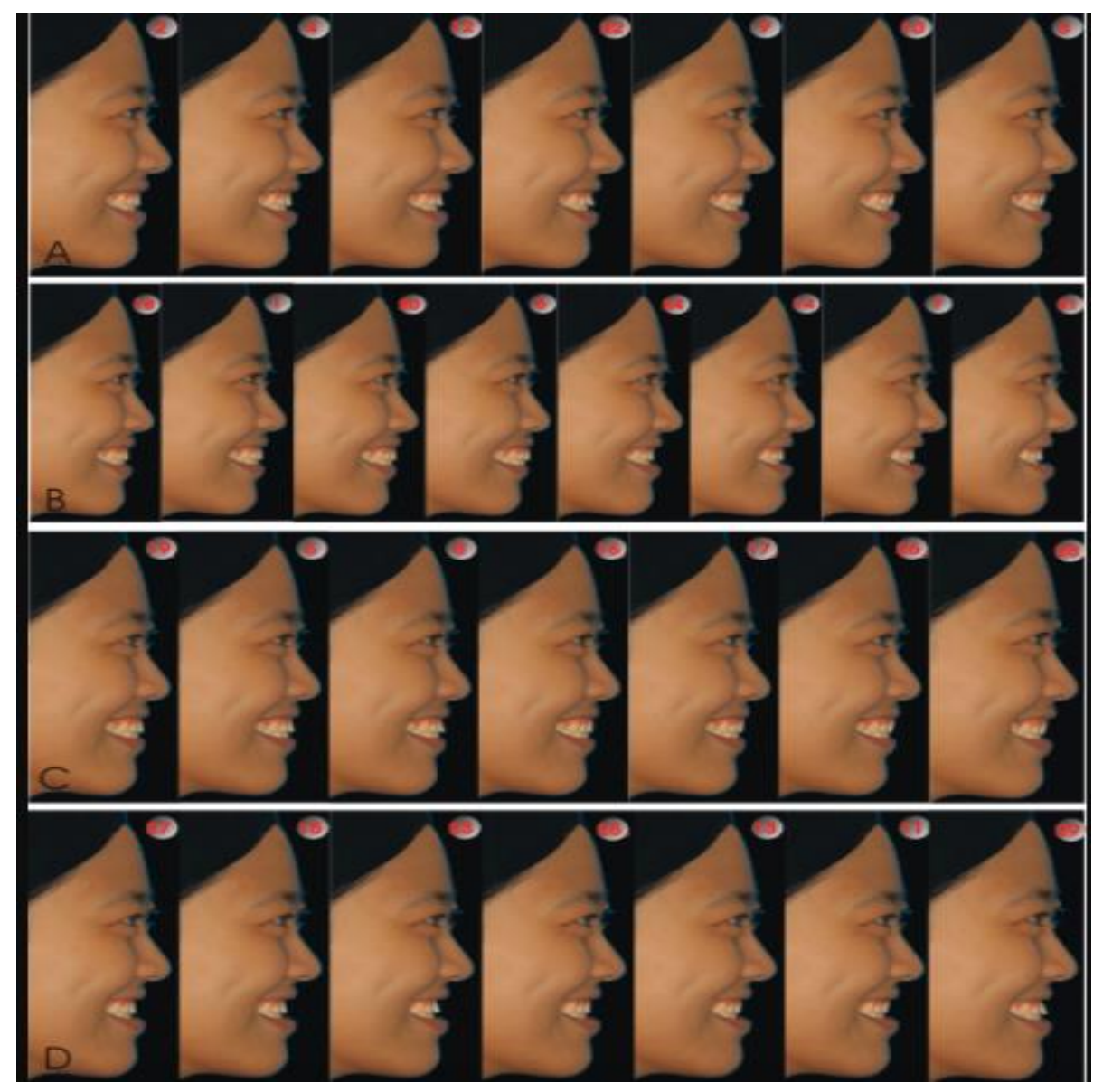

Figure 14: Subject's image set [19] 
However, these two studies only simulated the movement of maxillary section without any movement of mandibular section, which may cause interference with the judgement of attractiveness [20]. Ellis, et al. captured smiling profile photographs of three females from three different racial background (Caucasian, African American, and Asian) and digitally manipulated at the soft tissue glabella to simulate forward movement by 2,4 , and $6 \mathrm{~mm}$ and backward by $2 \mathrm{~mm}$ (Fig 15). They asked dentists and laypersons to judge the attractiveness of the photographs using a 0-100 mm visual analogue scale. Once again, professional and nonprofessional had similar assessment of attractiveness; however dental professionals seemed to have more accurate judgement than laypeople. The study suggests that changes of anteroposterior (AP) position of the glabella affect the appreciation of facial attractiveness [20].

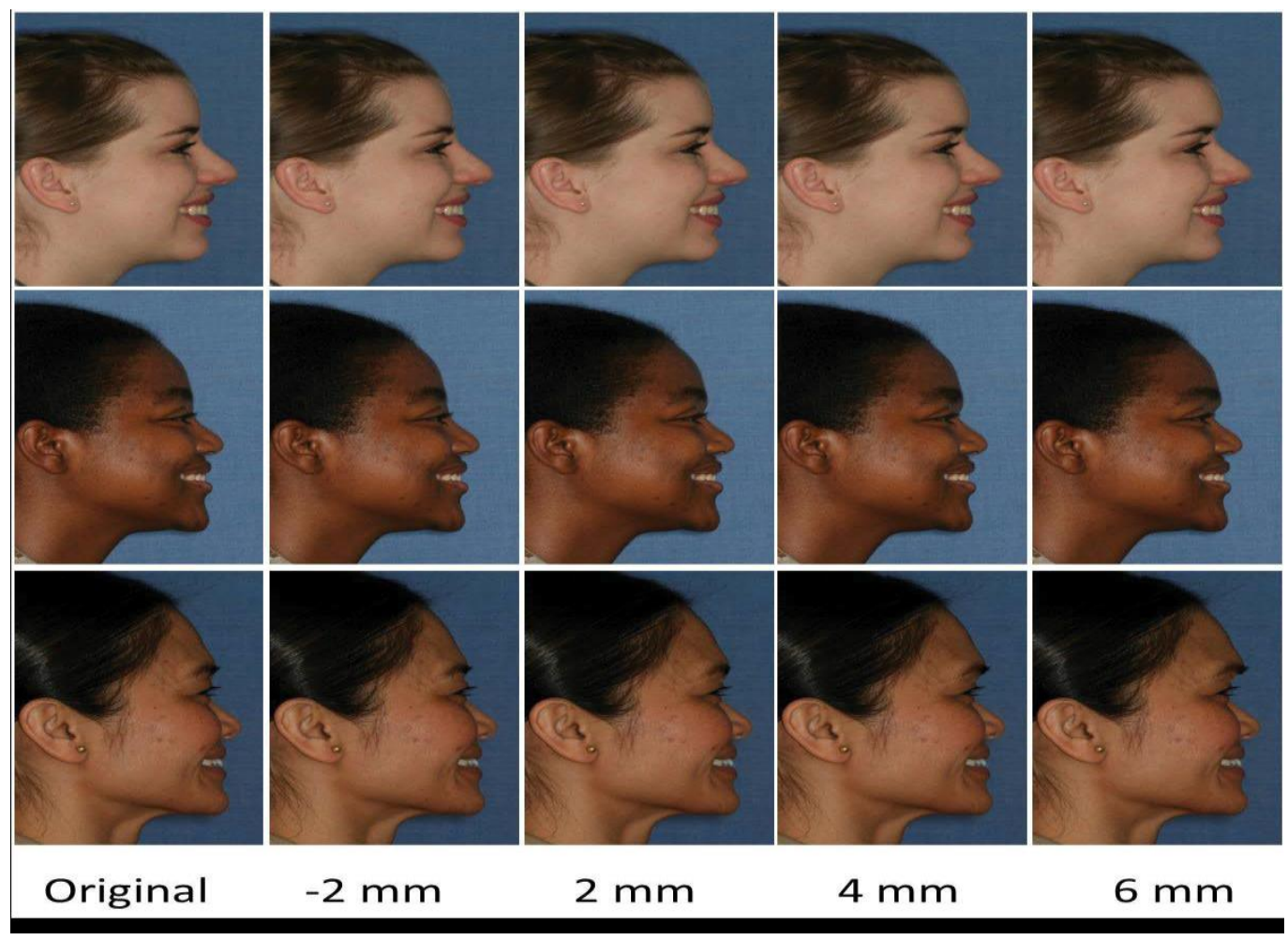

Figure 15: Original photos and simulated photos from Caucasian (upper panel), African American (middle panel), and Asian (lower panel) models [20]. 
Vishal Singh, et al. (2014) evaluated the anteroposterior (AP) position of the maxillary incisors in relation to the soft tissue plane (STP) in young Indian subjects to see if this plane could provide a useful guideline [22]. Soft tissue plane (STP), first defined by Alfaro, is a vertical line drawn passing through the soft tissue nasion (N') and descending perpendicular to the base of the photograph [21]. Vishal Singh, et al. compared profile photographs of 146 subjects with a good facial harmony (as a control group) and of 135 patients seeking orthodontic treatment (as a study group) (Fig 16). They concluded that soft tissue plane (STP) is a useful landmark in evaluating the position of the maxillary central incisors and that most of the young adults $(86.1 \%)$ with good facial harmony had maxillary incisors positioned at of in front of soft tissue plane (STP). Maxillary central incisors were positioned more anteriorly relative to the forehead in males as compared to females [22].

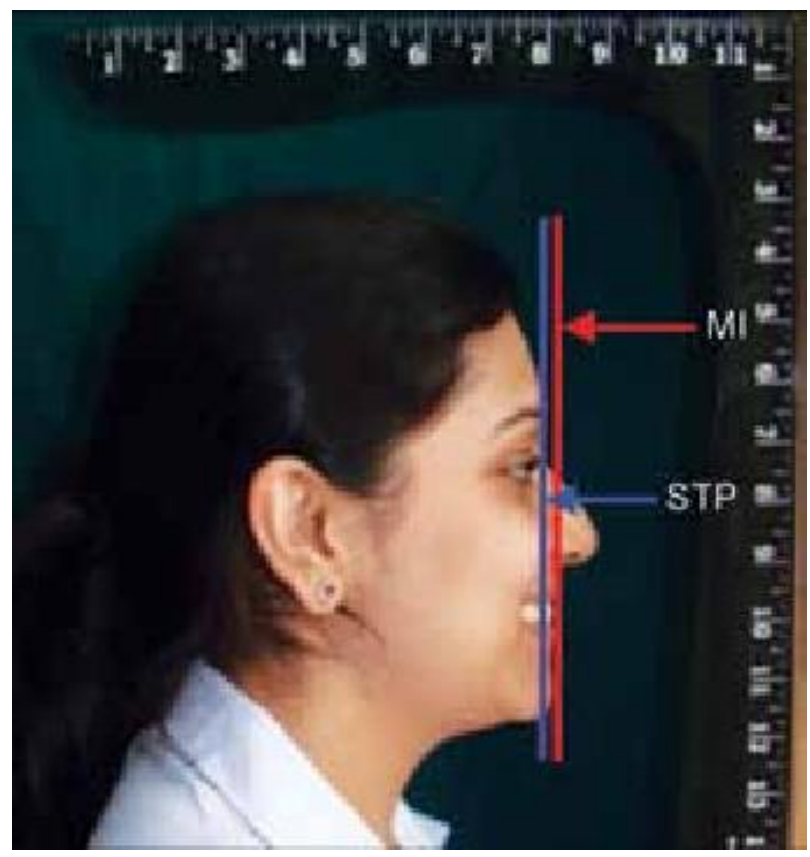

Figure 16: Soft Tissue Plane (STP) [22] 
In 2011, Arqoub SH, et al. did a study to evaluate the influence of changing the anteroposterior (AP) and vertical proportions of the lower face on the judged facial attractiveness. In this study, as the vertical and anteroposterior (AP) dimensions diverged from normal, attractiveness decreased. They also found a significant difference between dentists and lay people in judgment of profile attractiveness [23]. Najafi, et al. (2015) studied a smiling profile photograph of one male subject with normal profile. The photograph was manipulated digitally to obtain 3 different mandibular sagittal positions. In each mandibular position, the inclination of the maxillary incisors was changed labially and lingually. A total of 234 judges from different professional panels (72 senior dental students, 24 orthodontists, 21 maxillofacial surgeons, 25 prosthodontists, and 92 laypeople) were asked to score each photograph. This study showed that a normal incisor inclination is crucial to establish, especially in patients with a mandibular deficiency or excess. They also found that labial inclination is more preferable than lingual inclination. A significant difference in rating was found between different professional panels, and the raters' sex had no effect on their ratings of the images [24]. 

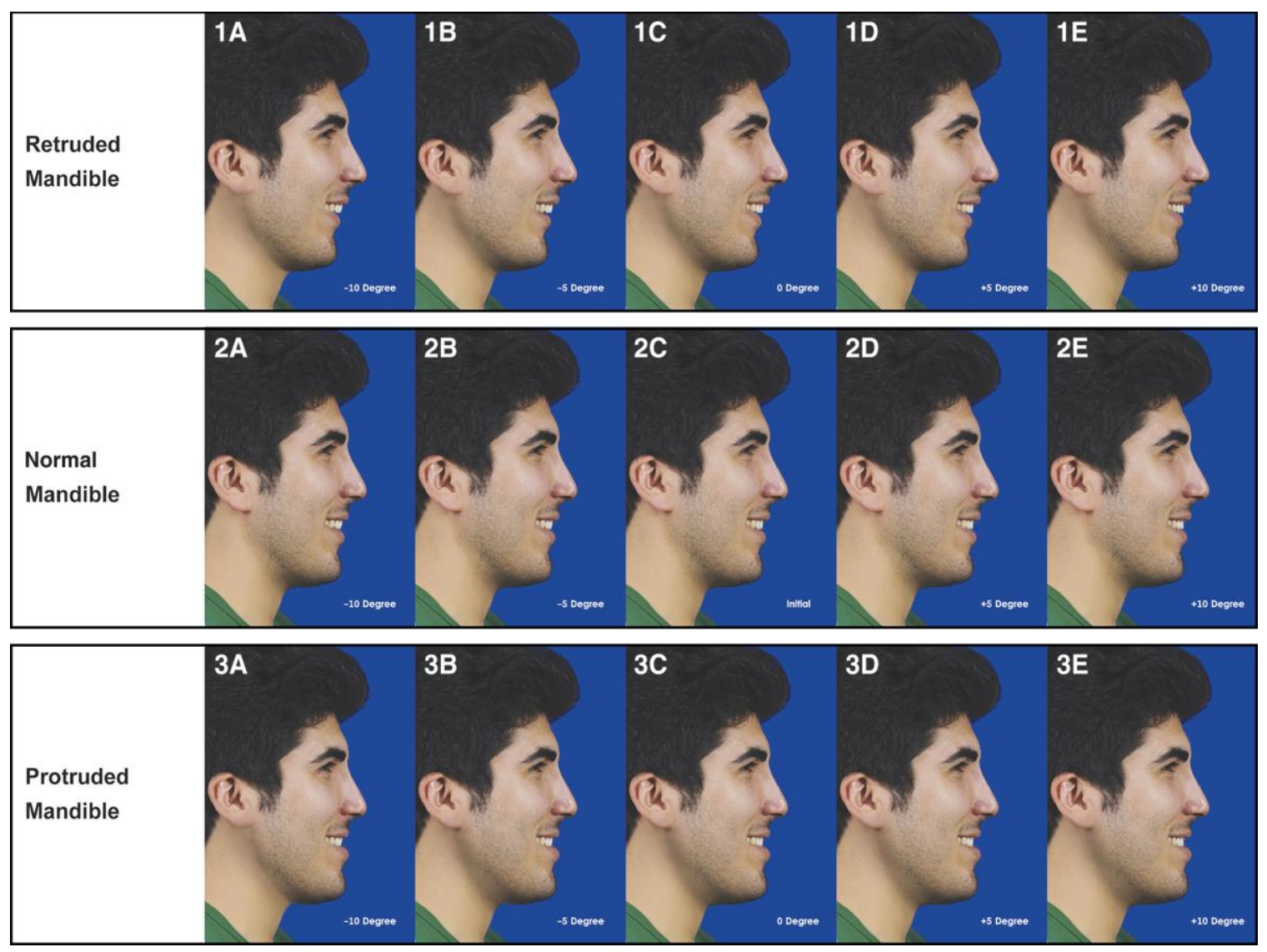

Figure 17: Three sets of altered images with different mandibular positions and incisor inclinations [24].

\section{Adjusted Natural Head Position:}

The idea of using natural head position (NHP) was introduced by Downs [25] and Moorrees [26] in the late 1950's. Borca defined natural head position (NHP) as "When man is standing and his visual axis is horizontal, he is in the natural position" as cited in Solow and Talgren in 1971 [27]. Historically, Natural head position (NHP) has been used by artists, anatomists and anthropologists to study the human face [27]. Natural head position (NHP) has also been widely used in orthodontic clinical diagnosis and research. Natural head position (NHP) is a standardized external reference position that is highly reproducible, accurate, and easy to register. Short and long term intra-observer 
reproducibility studies have been conducted in the past, and these studies have validated the reproducibility of natural head position (NHP). Lundstrom and Lundstrom reported the natural head position (NHP) reproducibility to be close to 2 degrees [28]. Cooke et al. [29-30] conducted and long term studies and reported a variation of 9.24 degrees and 4.8 degrees at 5 years and 15 years respectively, which is significantly less than the variance of intracranial reference planes to the vertical (25 degrees to 36 degrees). However, several physiological, psychological, and pathological factors are involved in the concept described as registered natural head position (NHP) [31]. Registration of natural head position (NHP) may contain an element of unavoidable error that requires correction. Therefore, Lundstrom introduced the concept of adjusted (corrected) natural head position. Adjusted NHP defined as the head position adjusted from the registered natural head position to a position judged to be the natural head orientation by the orthodontist [31].

\section{CHAPTER 3: MATERIAL AND METHODS}

The study was designed as an observational study. An observational study is a study in which investigator observe subjects and measure variables of interest without assigning intervention or treatment to subjects.

\section{IRB Approval:}

An IRB expedited review was obtained from West Virginia University Institutional Review Board prior to the start of this study (see Appendix A). 


\section{Data Collection:}

Study group consists of 30 randomly chosen model subjects and 36 raters (judges).

Subjects were chosen from the patients and visitors of West Virginia University

Orthodontic clinics. Trained orthodontists raters were selected from the faculty members and residents of the West Virginia University Orthodontic Department. Lay raters were selected from the West Virginia University first and second dental school students.

Subjects were asked to participate in the study after explaining potential risks and benefits of the study. Every subject signed a consent form. The model subjects signed the Human Research Protocol of Only Minimal Risk with HIPPAA Consent form. The rater subjects signed the Human Research Protocol of Only Minimal Risk without HIPPAA Consent form.

\section{Sample Description:}

Study group consists of 30 randomly chosen model subjects and 36 raters (judges).

The 32 raters that participated in the study were:

> 6 male trained orthodontists

$>6$ female trained orthodontists

12 male laypeople

12 female Laypeople

Inclusion Criteria for Model Subjects: 
1. Males only.

2. Caucasians only.

3. Subjects of age 18-30 years old only.

4. Subjects with no craniofacial anomalies, face diseases, or developmental deformity.

5. Subjects that have the natural maxillary anterior teeth.

6. Subjects that do not currently have braces, dentures, or any other appliance.

Exclusion Criteria for Model Subjects:

1. Females.

2. Races other than Caucasian

3. Younger than 18 or older than 30 years old.

4. Presence of craniofacial anomalies, face diseases, or developmental deformity.

5. Subjects that do not have their natural maxillary anterior teeth.

6. Subjects that currently have braces, dentures, or any other appliance.

\section{Research Design:}

The study involves the following procedures:

Capturing Photographs Of The Model Subjects:

Upon model subject's approval to participate in the study and signing the Human

Research Protocol of Only Minimal Risk with HIPPAA Consent form, the process of capturing pictures starts. Each subject will be positioned in adjusted natural head position turned to their left side. Black background board was placed behind the subjects. Using laser level, a white robe was added on the right boarder of the board using laser level to simulate the true vertical plane. 


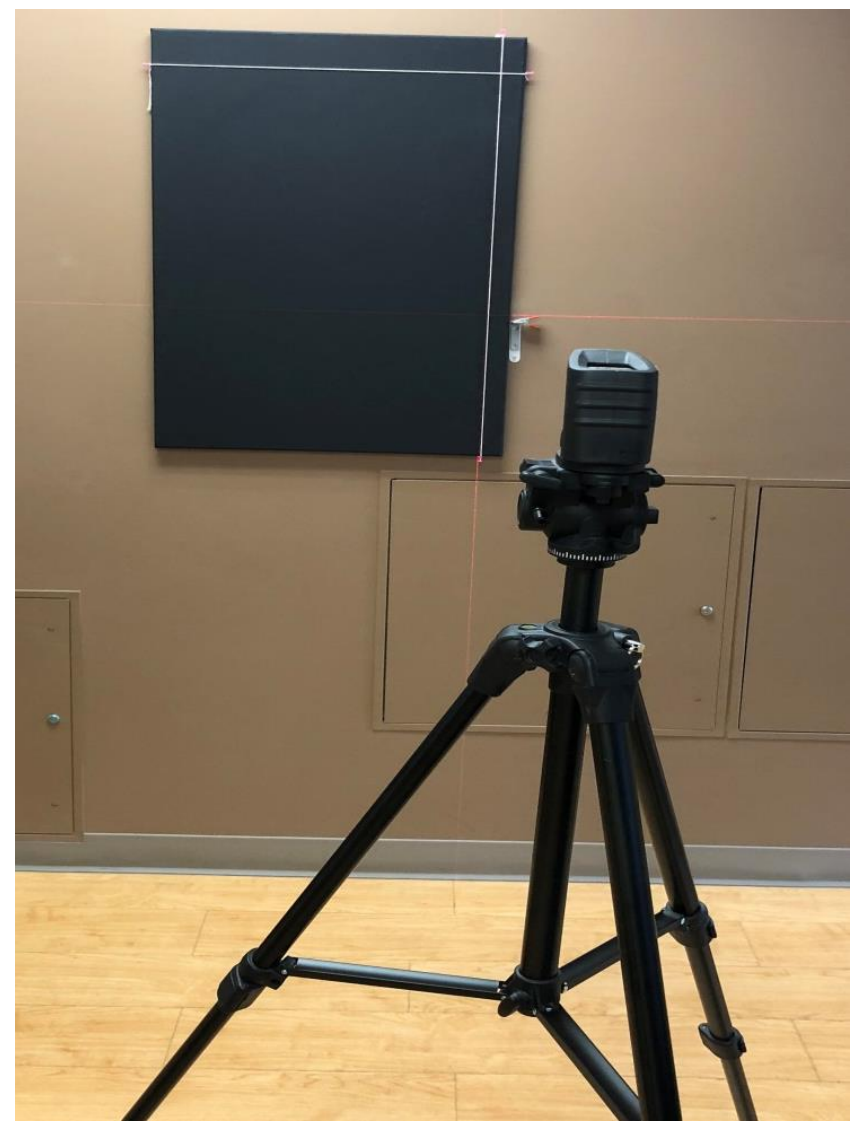

Figure 18: Laser level was used to set a white rope to simulate the true vertical plane A millimeter ruler was positioned on the right side of the board. The ruler position can be adjusted to be on the level of the subject's midsagittal plane. The ruler has 2 black marks with $10 \mathrm{~mm}$ distance between them to digitize the photographs in 1/1 ratio. Using a Nikon D3300 camera with $90 \mathrm{~mm}$ macro lens, two photographs were captured for subject's right profile; one photograph in repose view and one photograph in smiling view. 


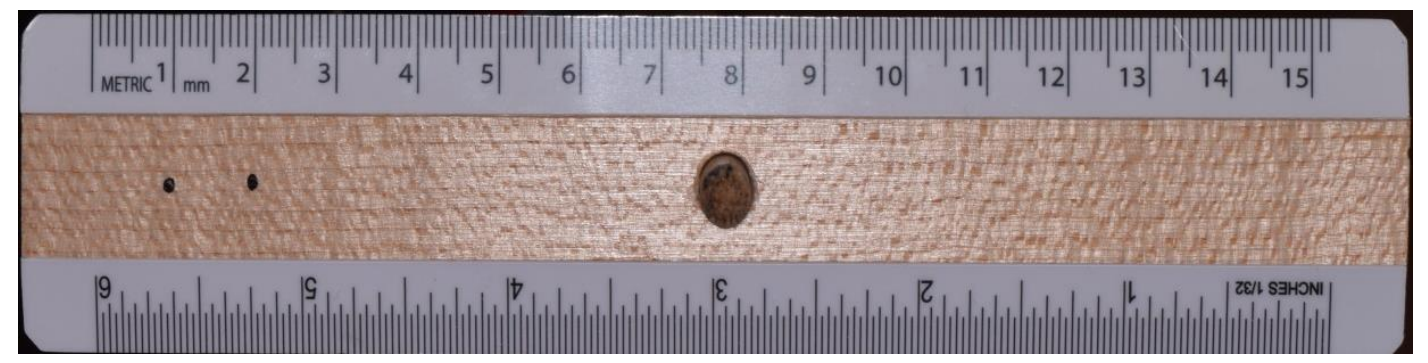

Figure 19: Ruler with $10 \mathrm{~mm}$ apart marks used to caliper the photographs at 1/1 ratio

Figures 20 and 21 show examples of the way we captured photographs in this study. This example model is not one of the subjects recruited for the study. In the actual rated photographs, the white de-identification circles on the eyes where not used since all subjects signed Human Research Protocol of Only Minimal Risk with HIPPAA Consent form.

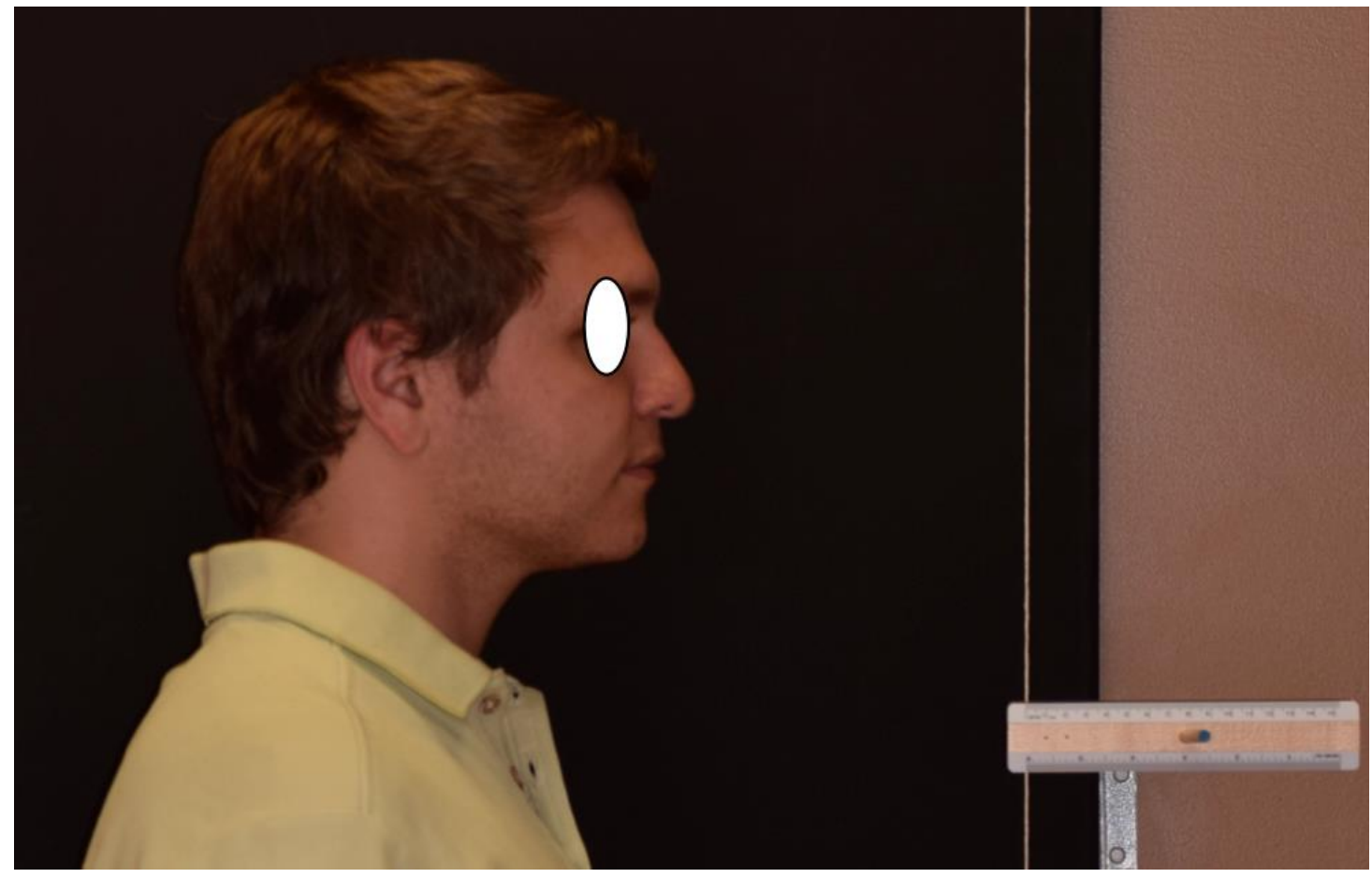

Figure 20: Photographs capturing in repose profile view 


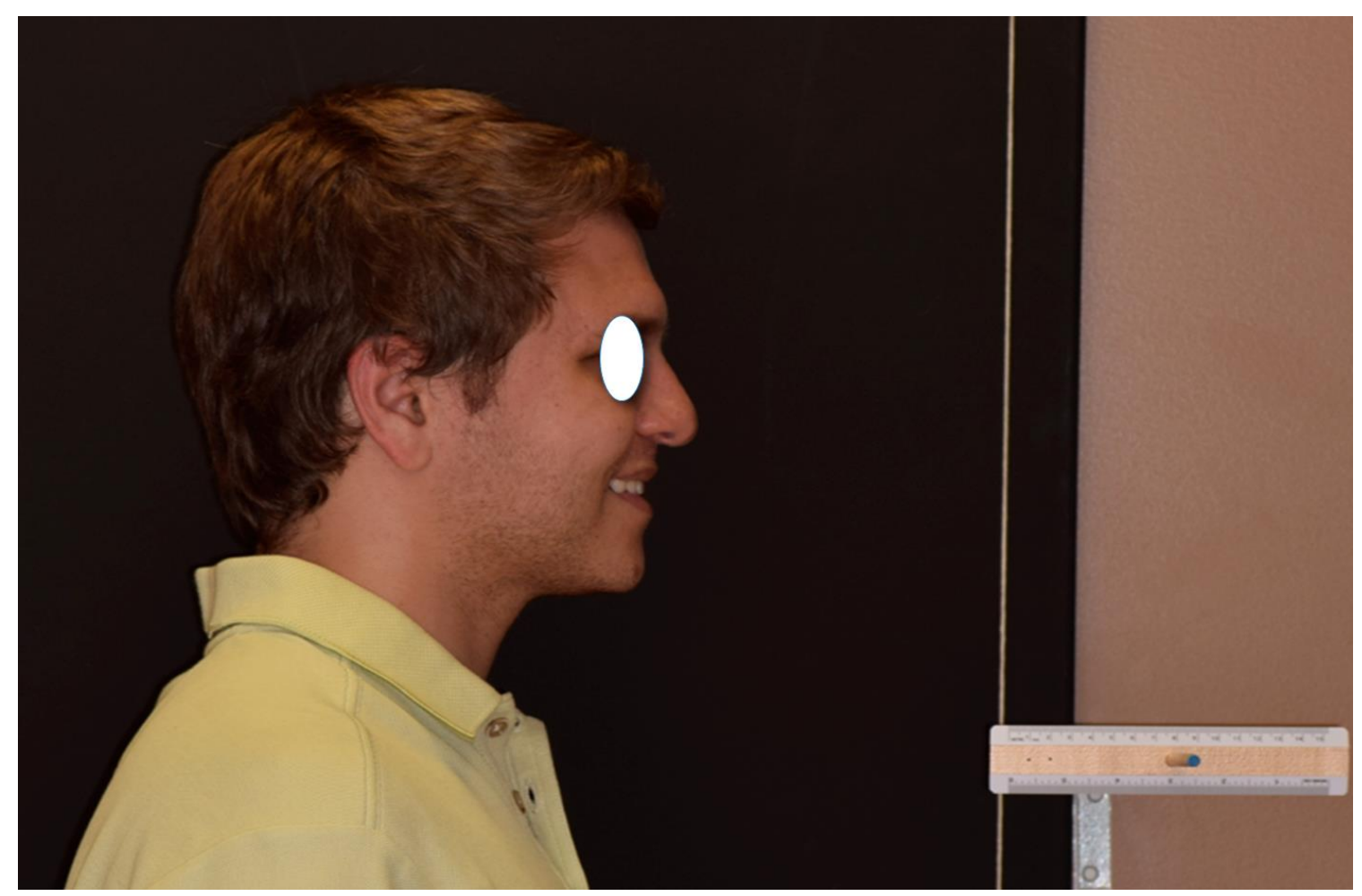

Figure 21: Photographs capturing in smiling profile view

\section{Measuring Anteroposterior (AP) Position Of The Maxillary Incisors:}

Subjects were numbered from 1 to 30 . Photographs were uploaded to Microsoft

PowerPoint program. On the smiling profile photographs, the Glabella Vertical plane was added as a green vertical line that is parallel to the white rope (representing true vertical plane) on the board and touching the soft tissue glabella point on the subject face. Using the marks on the millimeter ruler, a digital ruler was created and callipered to $1 / 1$ ratio to make an accurate measurement. The digital ruler was used to measure the distance of the FA point of the maxillary incisors to the Glabella Vertical line. 


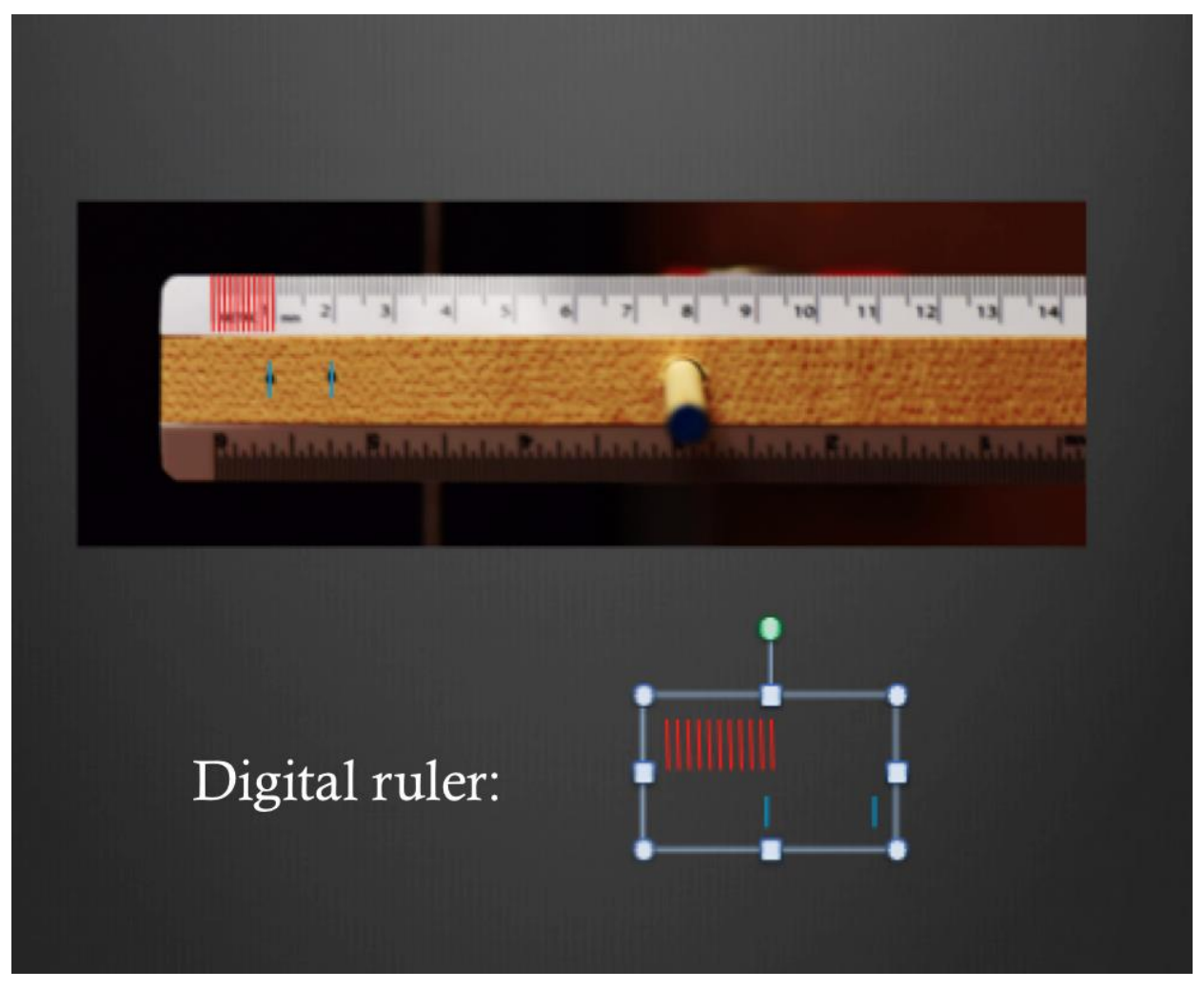

Figure 22: Digital ruler calipered at 1/1 ratio.

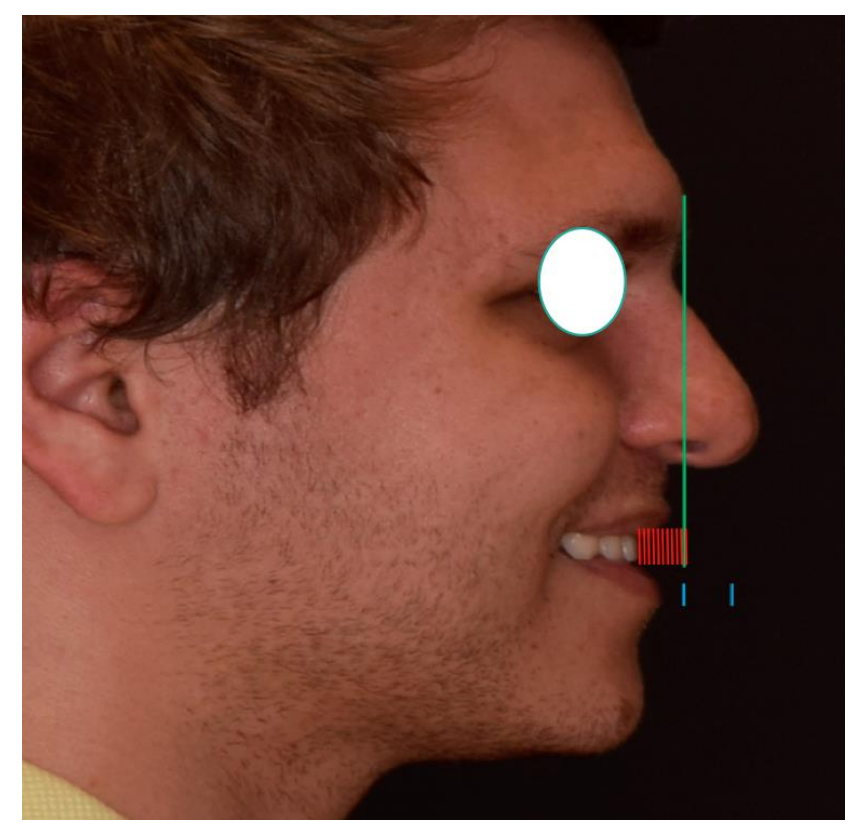

Figure 23: Digital ruler used to measure the distance of the FA point of the maxillary incisors to the Glabella Vertical line. 


\section{Rating Procedure:}

All photographs were uploaded to Microsoft PowerPoint in a randomized order.

Photographs were changed to black and white colors, background was removed, and the vertical lines and ruler were cropped out. Rating slideshow was created that consists of two sections. The first section includes 30 repose photographs, 30 smiling photographs, 10 randomly selected repeated photographs. The 10 repeated photographs were doubled to test the intra-raters reliability of each rater. The second section includes 30 smiling photographs only.

We had 36 raters as described before. Each rater has signed the Human Research Protocol of Only Minimal Risk without HIPPAA Consent form. Each rater received rating form. On the first page of the rating form, raters were asked to about their gender, their age, and if they have any orthodontic training. The rest of rating form consists of two sections in respect with the 2 sections of the slideshow. In the first section, raters were asked to rate the attractiveness of the subject by placing $\mathrm{X}$ mark on the visual analog scale of 1-100 when 0 is the least attractive and 100 is the most attractive. Visual analog scale marks were measured and translated to number (out of 100) for each model subject. On the second section, raters were asked if they like the subject's incisors to move forward, backward, or stay in the same position. The rating procedure instructions were explained verbally and instructions were printed on the first page of the rating form. Copy of the rating form is included in Appendix B. All the data was later entered on Microsoft Excel to be studied by the help of a statistician. 


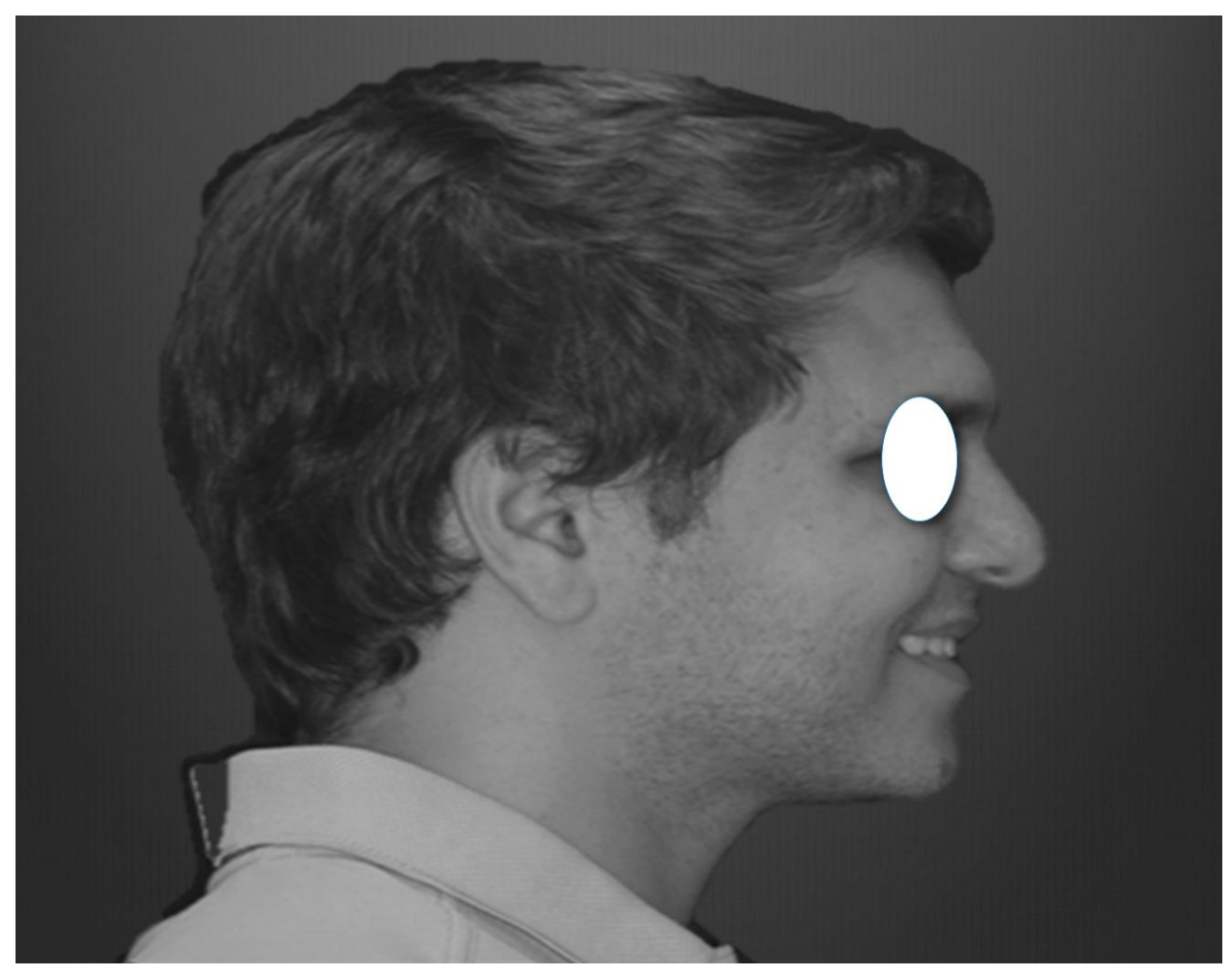

Figure 24: Photograph as appeared in the rating Power Point.

\section{Visual Analog Scale (VAS):}

Visual analog scale (VAS) is an instrument used to measure a characteristic or attitude that is believed to range across a continuum of values and cannot easily be directly measured. It is popular, simple, and inexpensive instrument that is often used in epidemiologic and research. Studies have shown visual analog scale (VAS) to be reliable method to rate esthetic concepts. The simplest visual analog scale (VAS) is a straight horizontal line of fixed length, usually $100 \mathrm{~mm}$. The ends are defined as the extreme limits of the parameter to be measured (facial attractiveness in this case) orientated from the left (worst) to the right (best). The visual analog scale (VAS) score is determined by measuring in millimeters from the left hand end of the line to the point that the patient marks [32]. 


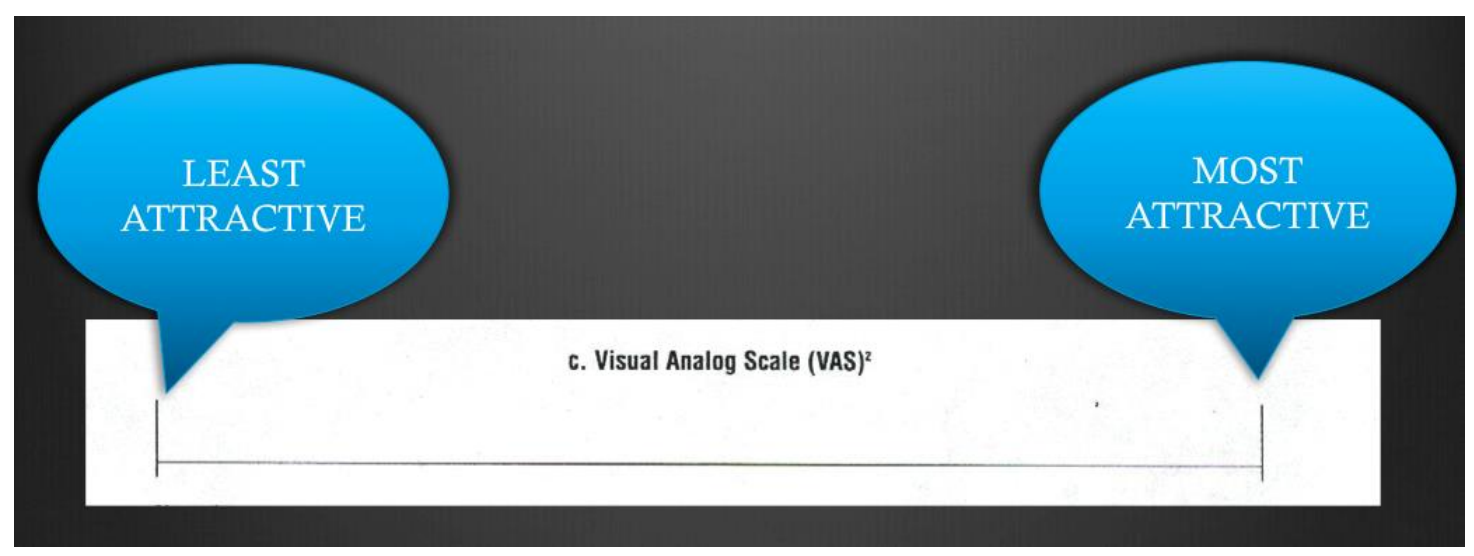

Figure 25: Visual Analog Scale (VAS)

\section{Statistical Analysis:}

All statistical tests were conducted by the statistician (J.X) using SAS (version 9.4, 2013, SAS institute Inc, Cary, NC). To examine the effect of view the patient presented on the perception of attractiveness, we analyzed each patient's ranking scores separately since we assumed the difference in individual facial attractiveness. The mixed model analysis was performed to evaluate the effects of view (repose vs. smile), panel (orthodontist vs. lay-people), gender (male vs. female), and rater nested within panel on perception of attractiveness. We considered rater as a random effect and all others as fixed effects. The interaction between panel and view, and between gender and view were also added to the model as our main focus was on the effect of the view and the two interaction term.

Tukey's test was performed for multiple comparisons after a significant interaction effect. We also run the same mixed model analysis for all patients but adding patient as another random effect. Interaction terms were excluded after non-significant result. Paired t-test was conducted to examine the difference in facial attractiveness ranking scores between 
repose and smile. We examined the mean difference in facial attractiveness between orthodontist and lay-people, male and female using two sample t-test.

To examine the effect of incisors position on the perception of attractiveness, we only use the attractiveness ranking scores on smile pictures and analyzed all patient ranking scores together. The mixed model analysis was performed to evaluate the effects of incisors position (green vs. black vs. red), panel (orthodontist vs. lay-people), gender (male vs. female), rater nested within panel, and patient on perception of attractiveness. Rater and patient were treated as two random effects and all others as fixed effects. Our main interest, the interaction between panel and incisors AP position, and between gender and incisors AP position were also incorporated in the model. We used Tukey's test for multiple comparisons after a significant interaction effect. To compare the mean difference in attractiveness ranking scores among different incisors AP positions for individual raters, one way analysis of variance (ANOVA) test was used and Tukey's test was performed for multiple comparisons after a significant test result.

To analyze the association between incisors AP position and raters' opinion on whether the teeth should be moved backward, forward or stay the same, chi-square analysis was used. The Cochran-Mantel-Haenszel statistic was also utilized to determine the association between GV position and raters' opinion adjusted for different strata.

All statistical tests were two-sided and $p$-values $\leq 0.05$ were considered statistically significant. 


\section{CHAPTER 4: RESULTS}

\section{Model Subjects Sample Distribution:}

The study sample of model subjects included 30 randomly selected Caucasian males. Upon measurements, we found that five model subjects $(16.66 \%)$ have green incisor position. Green incisor position means, as described before, that FA point of the maxillary incisor is located on Glabella Vertical Plane. Eight model subjects (26.66\%) have red incisor position. Red incisor position means that FA point of the maxillary incisor is located anterior to the Glabella Vertical Plane. In this sample, the most anterior position of the maxillary incisors, form the Glabella Vertical line, was $+10 \mathrm{~mm}$. Seventeen model subjects $(56.66 \%)$ have black incisor position, which means that FA point of the maxillary incisor is located posterior to the Glabella Vertical Plane. In this sample, the most posterior position of the maxillary incisors form the Glabella Vertical line was $-14 \mathrm{~mm}$. The table below shows all the model subjects' incisors position measurements.

\begin{tabular}{|c|c|c|}
\hline Model Subject Number & $\begin{array}{c}\text { Incisors AP distance from } \\
\text { the GV }\end{array}$ & Incisors AP Position \\
\hline 1 & 0 & Green \\
\hline 2 & 0 & Green \\
\hline 3 & 0 & Green \\
\hline 4 & 0 & Green \\
\hline 5 & 0 & Green \\
\hline 6 & +1 & Red \\
\hline
\end{tabular}




\begin{tabular}{|c|c|c|}
\hline 7 & +2 & Red \\
\hline 8 & +3 & Red \\
\hline 9 & +4 & Red \\
\hline 10 & +5 & Red \\
\hline 11 & +5 & Red \\
\hline 12 & +6 & Red \\
\hline 13 & +10 & Red \\
\hline 14 & -1 & Black \\
\hline 15 & -2 & Black \\
\hline 16 & -3 & Black \\
\hline 17 & -3 & Black \\
\hline 18 & -3 & Black \\
\hline 19 & -3 & Black \\
\hline 20 & -4 & Black \\
\hline 21 & -5 & Black \\
\hline 22 & -5 & Black \\
\hline 23 & -6 & Black \\
\hline 24 & -6 & Black \\
\hline 25 & -7 & Black \\
\hline 26 & -8 & Black \\
\hline 27 & -9 & Black \\
\hline 28 & -11 & Black \\
\hline 29 & -13 & Black \\
\hline 30 & -14 & Black \\
\hline
\end{tabular}

Table 1: Model subjects' incisors position measurements. 


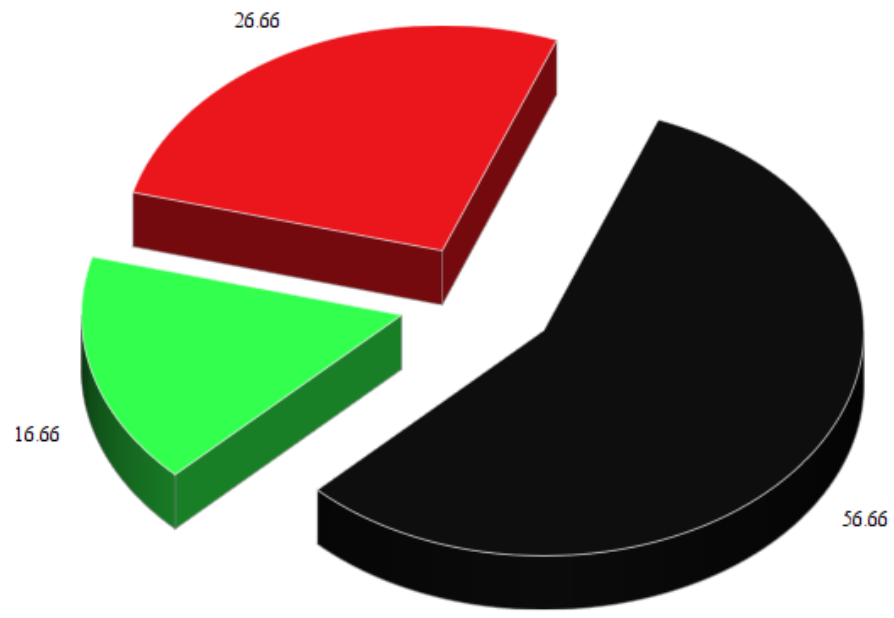

Graph 1: Distribution of the model subjects sample

\section{Effect Of Maxillary Incisors AP Position On The Judged Facial}

\section{Attractiveness From Smiling Profile View:}

From smiling view, the judges in this study gave subjects of the green incisors group the highest mean rating of facial attractiveness (Mean=48.56), while model subjects in the black incisors group had the worst mean rating of facial attractiveness (Mean=38.25), and model subjects in the red incisors group were somewhere in between in term of facial attractiveness (Mean=40.44). Graph 2 below shows the mean rating of attractiveness for each group. 


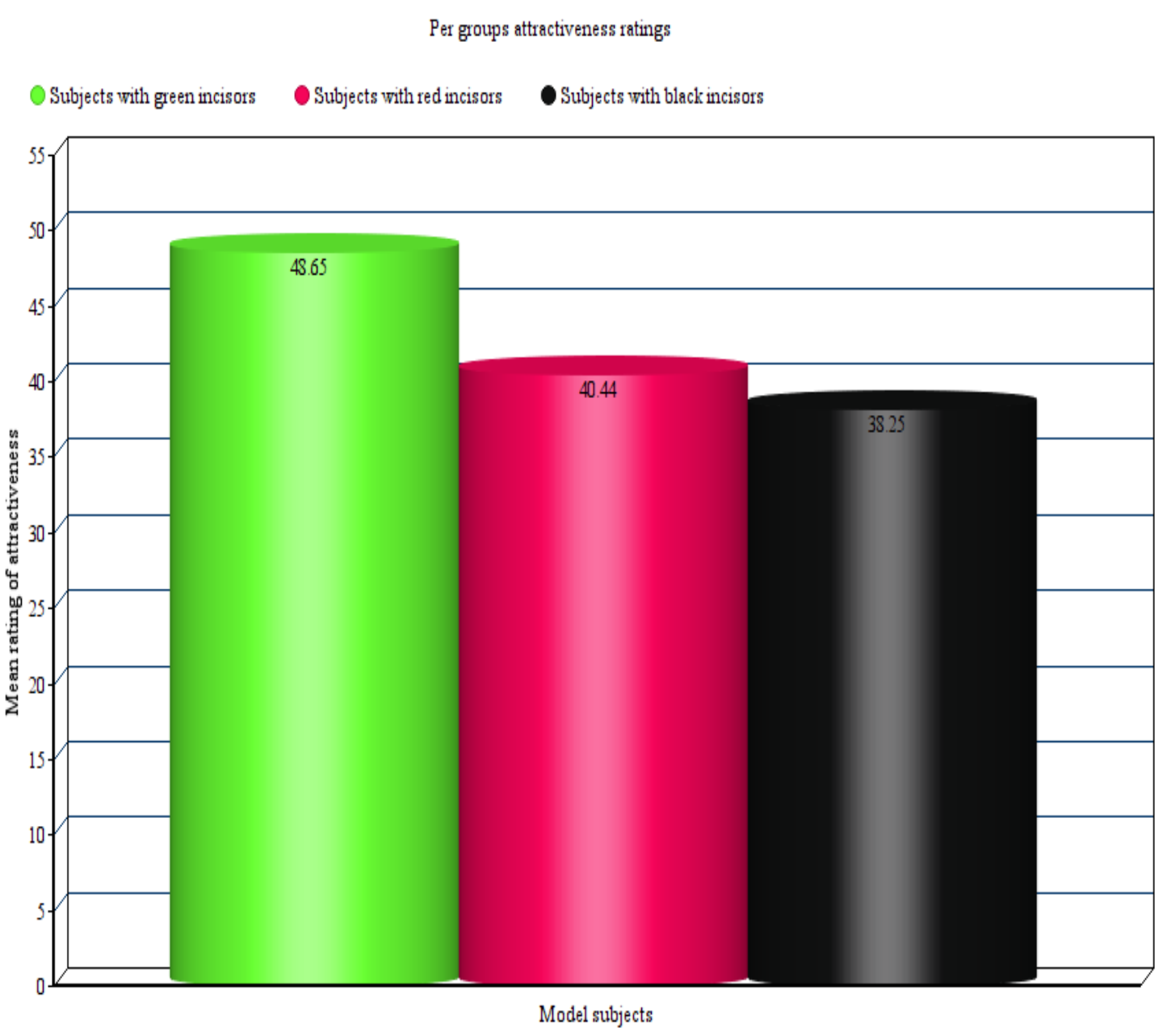

Graph 2: Mean rating of facial attractiveness for each group.

Interestingly, the best mean rating (59.78) of facial attractiveness for individual model subjects has been given to subject \#24, and this subject belongs to the black incisors group and the anteroposterior (AP) position measurement of his maxillary incisors is B6 (FA of the maxillary incisors crowns are positioned $6 \mathrm{~mm}$ posterior to the Glabella Vertical line). The second best rating of facial attractiveness was given to subject \#2 from the green group, and the third highest rating of facial attractiveness was given to subject \#9 from the red group, the anteroposterior (AP) position measurement of his maxillary incisors is R4 (FA of the maxillary incisors crowns are positioned 4mm anterior to the Glabella Vertical line). The worst three mean rating of facial attractiveness have been 
given to subjects \#20,18, and 22. They all belong to the black incisors group (B4, B5, and B3). The table below shows the means of facial attractiveness rating scores for each model subject.

\begin{tabular}{|c|c|c|c|c|}
\hline Patient & AP Position & Position & MEAN & SD \\
\hline 1 & 0 & G & 47.69 & 21.78 \\
\hline 2 & 0 & G & 56.17 & 19.74 \\
\hline 3 & 0 & G & 42.92 & 16.93 \\
\hline 4 & 0 & G & 51.39 & 19.76 \\
\hline 5 & 0 & G & 45.08 & 16.46 \\
\hline 6 & 1 & $\mathrm{R}$ & 41.00 & 18.97 \\
\hline 7 & 2 & $\mathrm{R}$ & 45.50 & 17.76 \\
\hline 8 & 3 & $\mathrm{R}$ & 47.39 & 18.38 \\
\hline 9 & 4 & $\mathrm{R}$ & 54.56 & 23.32 \\
\hline 10 & 5 & $\mathrm{R}$ & 27.44 & 12.24 \\
\hline 11 & 5 & $\mathrm{R}$ & 44.61 & 15.96 \\
\hline 12 & 6 & $\mathrm{R}$ & 34.36 & 20.18 \\
\hline 13 & 10 & $\mathrm{R}$ & 28.69 & 13.64 \\
\hline 14 & -1 & B & 53.47 & 19.75 \\
\hline 15 & -2 & B & 52.44 & 13.67 \\
\hline 16 & -3 & B & 39.75 & 20.79 \\
\hline 17 & -3 & B & 40.19 & 17.93 \\
\hline 18 & -3 & B & 22.81 & 11.97 \\
\hline 19 & -3 & B & 32.39 & 16.17 \\
\hline 20 & -4 & B & 19.00 & 17.23 \\
\hline 21 & -5 & B & 45.89 & 16.63 \\
\hline 22 & -5 & B & 25.58 & 11.12 \\
\hline 23 & -6 & B & 34.25 & 16.45 \\
\hline 24 & -6 & B & 59.78 & 16.62 \\
\hline 25 & -7 & B & 32.61 & 14.46 \\
\hline
\end{tabular}




\begin{tabular}{|c|c|c|c|c|}
\hline 26 & -8 & B & 44.28 & 15.49 \\
\hline 27 & -9 & B & 29.42 & 12.88 \\
\hline 28 & -11 & B & 41.47 & 14.86 \\
\hline 29 & -13 & B & 39.58 & 15.20 \\
\hline 30 & -14 & B & 37.44 & 17.97 \\
\hline
\end{tabular}

Table 2: Means of rating scores for smile by patient.

In this study, we have used 36 judges to rate the facial attractiveness of each one of the model subjects. We studied the mean ranking score for each incisor position group of each one of the 36 raters. Only nine raters $(25 \%)$ showed significant difference in judging the facial attractiveness of models in the different incisors groups (raters \#2, 3, 4, 9, 12, $25,26,35,36)$. In 27 raters $(75 \%)$ the difference was insignificant. Interestingly, those 9 raters always judged models in the green incisors group as the most attractive, and judged models in the black incisors group as the least attractive. The table below shows how the raters scored the subjects in each group.

\begin{tabular}{|c|c|c|c|c|c|c|c|}
\hline \multirow[b]{3}{*}{ Rater } & \multicolumn{6}{|c|}{ Incisors Position Groups } & \multirow[b]{3}{*}{$\mathrm{p}$-value } \\
\hline & \multicolumn{2}{|l|}{ Black } & \multicolumn{2}{|l|}{ Green } & \multicolumn{2}{|l|}{ Red } & \\
\hline & Mean & SD & Mean & SD & Mean & SD & \\
\hline 1 & 27.00 & 17.00 & 36.00 & 6.71 & 23.25 & 19.53 & 0.41 \\
\hline 2 & $19.35^{\mathrm{a}}$ & 14.00 & $42.00^{\mathrm{a}}$ & 19.04 & 29.88 & 14.91 & 0.02 \\
\hline 3 & $20.59^{\mathrm{a}}$ & 16.87 & $41.40^{\mathrm{a}}$ & 12.90 & 31.88 & 17.31 & 0.04 \\
\hline 4 & $25.29^{\mathrm{ac}}$ & 14.48 & $46.40^{\mathrm{a}}$ & 10.60 & $41.00^{c}$ & 12.96 & 0.005 \\
\hline 5 & 32.41 & 19.50 & 31.60 & 8.62 & 21.75 & 16.72 & 0.37 \\
\hline 6 & 26.00 & 16.02 & 35.40 & 19.71 & 33.13 & 18.90 & 0.46 \\
\hline 7 & 29.76 & 18.88 & 19.60 & 15.34 & 23.38 & 16.10 & 0.466 \\
\hline 8 & 29.47 & 18.57 & 25.00 & 12.17 & 30.00 & 10.39 & 0.84 \\
\hline 9 & $20.12^{\mathrm{a}}$ & 12.27 & $47.60^{\mathrm{a}}$ & 7.30 & 31.50 & 18.08 & 0.001 \\
\hline
\end{tabular}




\begin{tabular}{|l|r|r|r|r|r|r|r|}
\hline 10 & 27.88 & 19.25 & 43.00 & 14.11 & 29.00 & 16.59 & 0.26 \\
\hline 11 & 24.47 & 18.11 & 35.00 & 14.42 & 30.50 & 23.63 & 0.51 \\
\hline 12 & $25.41^{\mathrm{a}}$ & 19.46 & $50.40^{\mathrm{ab}}$ & 10.06 & $25.63^{\mathrm{b}}$ & 7.71 & 0.002 \\
\hline 13 & 25.18 & 16.97 & 33.60 & 25.94 & 32.13 & 15.27 & 0.54 \\
\hline 14 & 28.41 & 18.76 & 35.60 & 20.16 & 23.63 & 11.50 & 0.49 \\
\hline 15 & 30.82 & 19.04 & 45.20 & 8.58 & 23.25 & 14.64 & 0.09 \\
\hline 16 & 26.88 & 14.66 & 42.00 & 11.58 & 30.88 & 20.79 & 0.20 \\
\hline 17 & 22.59 & 18.20 & 37.40 & 16.24 & 36.75 & 13.65 & 0.08 \\
\hline 18 & 28.59 & 18.49 & 34.00 & 19.95 & 27.88 & 18.22 & 0.82 \\
\hline 19 & 28.41 & 16.63 & 30.80 & 13.54 & 25.88 & 16.49 & 0.86 \\
\hline 20 & 26.71 & 17.53 & 31.20 & 19.59 & 28.88 & 17.97 & 0.88 \\
\hline 21 & 29.65 & 15.94 & 23.40 & 17.99 & 25.88 & 18.00 & 0.73 \\
\hline 22 & 26.12 & 15.58 & 22.80 & 19.87 & 34.13 & 21.22 & 0.47 \\
\hline 23 & 29.88 & 19.24 & 35.20 & 14.24 & 18.00 & 11.26 & 0.16 \\
\hline 24 & 24.88 & 18.52 & 25.20 & 10.03 & 24.25 & 17.42 & 0.99 \\
\hline 25 & $26.24^{\mathrm{a}}$ & 18.10 & $48.40^{\mathrm{a}}$ & 12.48 & 26.50 & 11.60 & 0.03 \\
\hline 26 & $21.24^{\mathrm{a}}$ & 15.13 & $44.40^{\mathrm{a}}$ & 13.13 & 32.50 & 9.55 & 0.006 \\
\hline 27 & 29.29 & 18.42 & 37.80 & 16.04 & 33.50 & 18.43 & 0.63 \\
\hline 28 & 30.65 & 16.81 & 26.60 & 21.22 & 22.38 & 15.77 & 0.54 \\
\hline 29 & 28.59 & 19.23 & 42.40 & 13.74 & 25.63 & 16.64 & 0.24 \\
\hline 30 & 24.53 & 17.46 & 40.00 & 14.34 & 27.13 & 14.94 & 0.20 \\
\hline 31 & 26.24 & 16.94 & 34.80 & 13.72 & 28.50 & 15.76 & 0.59 \\
\hline 32 & 30.24 & 18.44 & 38.20 & 15.45 & 22.63 & 16.35 & 0.30 \\
\hline 33 & 25.59 & 17.01 & 37.60 & 21.04 & 29.38 & 16.82 & 0.42 \\
\hline 34 & 30.12 & 18.06 & 33.00 & 17.73 & 21.88 & 14.23 & 0.44 \\
\hline 35 & $21.12^{\mathrm{a}}$ & 14.87 & $49.40^{\mathrm{ab}}$ & 10.14 & $27.50^{\mathrm{b}}$ & 18.10 & 0.004 \\
\hline 36 & 17.47 & 14.77 & 36.00 & 18.28 & 29.63 & 14.19 & 0.04 \\
\hline 5 & & & & & & & \\
\hline
\end{tabular}

Significant p-value for multiple comparison of GV position

${ }^{a}$ Black vs. Green position.

${ }^{\mathrm{b}}$ Green vs. Red position

${ }^{\mathrm{c}}$ Black vs. Red position

Table 3: Means of ranking scores for incisors AP position by rater 
The graph below also shows how each one of the judges scored the facial attractiveness for each of the incisor groups.

\section{Mean ranking scores of GV position by rater}

60

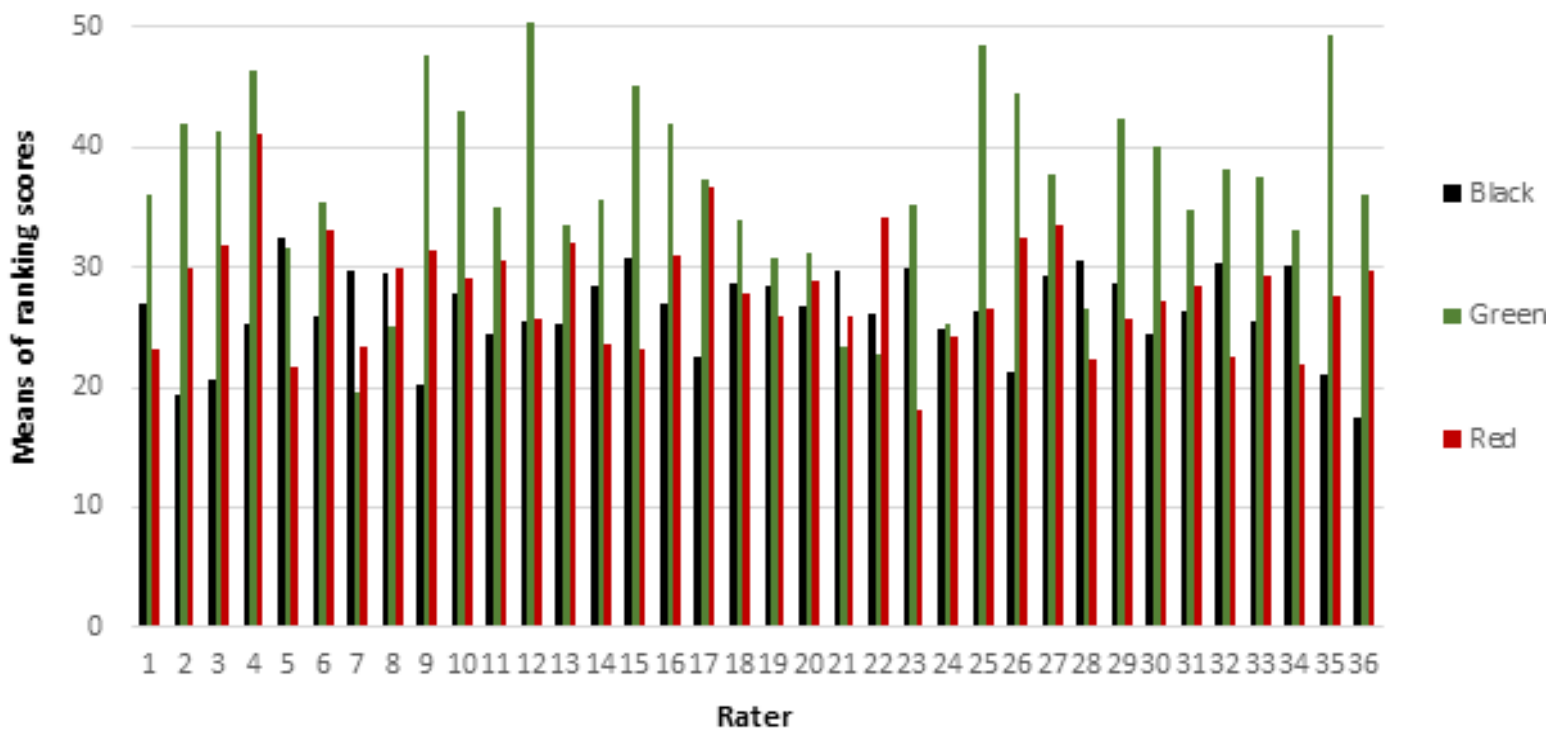

Graph 3: Incisors groups rating per judges

\section{Significance Of Main Effects:}

\begin{tabular}{|c|c|c|c|c|}
\hline source & NDF & DDF & F & Pr $>F$ \\
\hline Fixed Effect & & & & \\
\hline View & 1 & 2092 & 23.54 & $<0.0001^{* * *}$ \\
\hline Panel & 1 & 33 & 0.28 & 0.5937 \\
\hline Sex & 1 & 33 & 0.01 & 0.9395 \\
\hline Panel*View & 1 & 2092 & 1.68 & 0.1954 \\
\hline Sex*View & 1 & 2092 & 1.25 & 0.2640 \\
\hline & & & $Z$ & $\operatorname{Pr}>\mathrm{Z}$ \\
\hline Random & & & & \\
\hline
\end{tabular}




\begin{tabular}{|c|c|c|c|c|}
\hline Effect & & & & \\
\hline Rater(Panel) & & & -31.33 & $<0.0001$ \\
\hline Patient & & & 3.71 & 0.0002 \\
\hline
\end{tabular}

Table 4: Mixed model analysis of ranking scores for all patients. Test of main effects for rater (panel), panel, sex, view, panel* view, sex *view interaction

In this study we have noticed that:

- There was a significant difference in facial attractiveness rating between smiling profile view and repose profile view.

- We found no significant difference in facial attractiveness judgement between orthodontist and layperson panels of judges.

- We found no significant difference in facial attractiveness judgement between male and females judges.

We will try to shed more light on each of those variables in the next few paragraphs.

\section{Repose View VS Smiling View:}

In our sample, we found a significant difference between ratings done on the repose profile view versus ratings done on the smiling profile view. Raters generally gave worse facial attractiveness score in the smiling profile view than in repose profile view.

\begin{tabular}{|c|c|c|c|}
\hline \multicolumn{2}{|l|}{ Repose } & \multicolumn{2}{l|}{ Smile } \\
\hline LS Mean & Std Err & LS Mean & Std Err \\
\hline 31.33 & 1.92 & 28.50 & 1.92 \\
\hline
\end{tabular}

Table 5: Least Square means of ranking scores on view for all patients 
However, the difference was not always significant. We found a significant difference (Pvalue $\leq 0.05$ ) between the facial attractiveness ratings in repose profile view versus smiling profile view in sixteen (16) out of thirty cases (53.33\%). The significant difference was found in one case of the green incisors group (20\%), three cases of the red incisors group (37.50\%), and in twelve cases of the black incisors group (70.58\%). The facial attractiveness rating was better in smiling view than in repose view in four of the sixteen cases (25\%), and facial attractiveness rating was worse in smiling view in twelve of the sixteen cases (75\%). In model subjects with black incisors, when a significant difference is found between the facial attractiveness ratings in repose versus smiling profile views, the rating was worse in smiling view in most cases (nine of the twelve cases or $75 \%$ ). The table below shows all the results for the facial attractiveness ratings in repose versus profile view.

\begin{tabular}{|l|l|l|l|l|l|l|l|}
\hline \multirow{2}{*}{$\begin{array}{l}\text { Model } \\
\text { subject }\end{array}$} & \multirow{2}{*}{$\begin{array}{l}\text { Distance } \\
\text { to GV }\end{array}$} & \multirow{2}{*}{$\begin{array}{l}\text { Teeth } \\
\text { Position }\end{array}$} & \multicolumn{4}{|c|}{ REPOSE } & \multicolumn{2}{|l|}{ SMILE } & $\begin{array}{l}\text { p- } \\
\text { value }\end{array}$ \\
\cline { 4 - 8 } & & & MEAN & SD & MEAN & SD & \\
\hline 1 & 0 & G & 41.9 & 15.5 & 34.0 & 16.5 & .02 \\
\hline 2 & 0 & G & 46.4 & 11.8 & 44.3 & 13.7 & .39 \\
\hline 3 & 0 & G & 37.2 & 11.3 & 30.6 & 17.8 & .06 \\
\hline 4 & 0 & G & 35.3 & 15.7 & 40.0 & 15.9 & .02 \\
\hline 5 & 0 & G & 49.0 & 9.0 & 34.2 & 12.2 & $<.0001$ \\
\hline 6 & +1 & $\mathrm{R}$ & 16.1 & 12.8 & 27.6 & 13.6 & .0004 \\
\hline 7 & +2 & $\mathrm{R}$ & 29.6 & 11.8 & 34.7 & 13.6 & .08 \\
\hline 8 & +3 & $\mathrm{R}$ & 43.4 & 9.6 & 36.3 & 11.9 & .008 \\
\hline 9 & +4 & $\mathrm{R}$ & 44.6 & 13.0 & 40.4 & 16.5 & .13 \\
\hline
\end{tabular}




\begin{tabular}{|l|l|l|l|l|l|l|l|}
\hline 10 & +5 & R & 12.1 & 12.1 & 15.9 & 11.3 & .07 \\
\hline 11 & +5 & R & 24.4 & 14.1 & 32.4 & 13.3 & .002 \\
\hline 12 & +6 & R & 23.1 & 11.7 & 19.9 & 15.1 & .24 \\
\hline 13 & +10 & R & 13.4 & 12.1 & 17.2 & 11.1 & .12 \\
\hline 14 & -1 & B & 30.5 & 13.5 & 40.0 & 14.1 & .002 \\
\hline 15 & -2 & B & 29.3 & 15.8 & 41.9 & 9.6 & $<.0001$ \\
\hline 16 & -3 & B & 37.4 & 15.5 & 28.3 & 20.4 & $<.0001$ \\
\hline 17 & -3 & B & 47.5 & 14.4 & 28.4 & 15.6 & $<.0001$ \\
\hline 18 & -3 & B & 27.6 & 15.2 & 10.1 & 9.6 & $<.0001$ \\
\hline 19 & -3 & B & 21.6 & 10.6 & 19.3 & 10.6 & .28 \\
\hline 20 & -4 & B & 6.2 & 4.3 & 7.9 & 11.7 & .46 \\
\hline 21 & -5 & B & 34.5 & 13.1 & 34.6 & 12.0 & .96 \\
\hline 22 & -5 & B & 24.4 & 13.9 & 12.2 & 8.0 & $<.0001$ \\
\hline 23 & -6 & B & 27.2 & 17.5 & 23.2 & 15.0 & .18 \\
\hline 24 & -6 & B & 54 & 5.5 & 47.6 & 11.4 & .002 \\
\hline 25 & -7 & B & 19.3 & 13.7 & 20.2 & 12.3 & .71 \\
\hline 26 & -8 & B & 41.9 & 13.4 & 33.4 & 16.1 & .0003 \\
\hline 27 & -9 & B & 26.2 & 12.9 & 17.1 & 13.5 & .002 \\
\hline 28 & -11 & B & 40.6 & 13.9 & 29.3 & 13.9 & .002 \\
\hline 29 & -13 & B & 37.3 & 12.0 & 27.2 & 14.3 & .004 \\
\hline 30 & -14 & B & 16.6 & 11.7 & 26.5 & 15.6 & .002 \\
\hline
\end{tabular}

Table 6: Means of ranking scores of views by patient

In the graph below we also see the difference between the attractiveness ratings in repose versus profile view for our sample of model subjects and raters. 


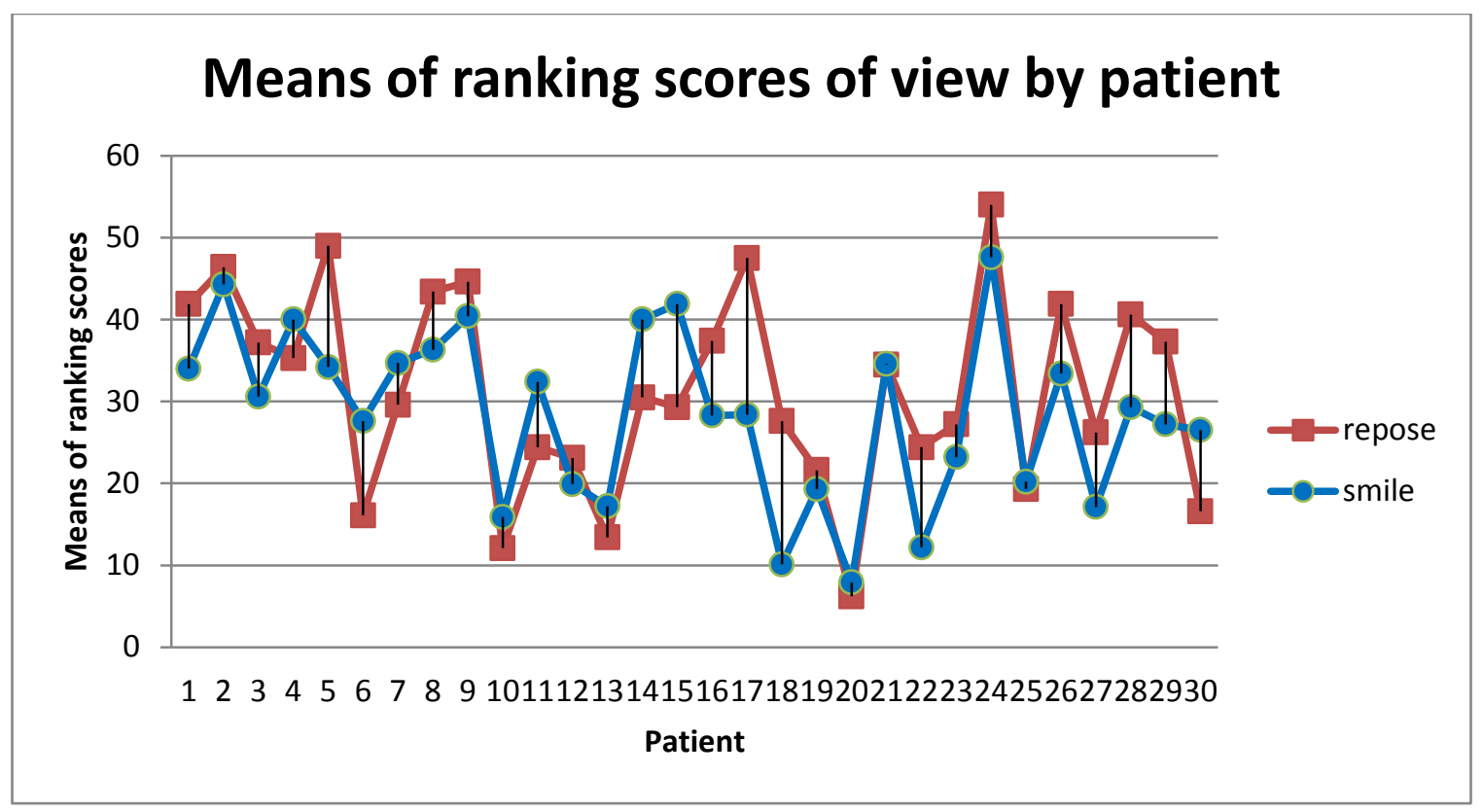

Graph 4: Means of ranking scores of view by patient

\section{Orthodontists VS Layperson Raters:}

In this study, we found that professional and non-professional judges agree upon profile attractiveness judgement. Basically, orthodontic training did not significantly change the facial attractiveness judgement of the raters. Looking at individual model subjects ratings, we noticed a significant difference in the facial attractiveness rating between orthodontist raters and layperson raters in seven cases $(23.33 \%)$. Those cases were distributed as two cases in the green incisors group, one case in the red incisors group, and four cases in the black incisors group. Orthodontist gave higher attractiveness scores than layperson judges in six out of those seven cases $(85.71 \%)$. This difference was statically not significant. The table below shows the difference in facial attractiveness ratings between orthodontically trained raters and layperson raters that did not receive any orthodontic training. 


\begin{tabular}{|c|c|c|c|c|c|c|c|}
\hline \multirow[t]{2}{*}{ Patient } & \multirow{2}{*}{$\begin{array}{c}\text { Distance } \\
\text { to } \mathrm{GV}\end{array}$} & \multirow[t]{2}{*}{ position } & \multicolumn{2}{|c|}{ Orthodontist } & \multicolumn{2}{|c|}{ Lay-people } & \multirow[t]{2}{*}{ P-value* } \\
\hline & & & MEAN & SD & MEAN & SD & \\
\hline 1 & 0 & G & 62.00 & 18.85 & 40.54 & 19.79 & 0.04 \\
\hline 2 & 0 & G & 59.33 & 21.98 & 54.58 & 18.82 & 0.50 \\
\hline 3 & 0 & G & 44.00 & 18.39 & 42.38 & 16.53 & 0.79 \\
\hline 4 & 0 & G & 46.33 & 20.13 & 53.92 & 19.50 & 0.28 \\
\hline 5 & 0 & G & 55.67 & 20.72 & 39.79 & 10.91 & 0.03 \\
\hline 6 & 1 & $\mathrm{R}$ & 41.17 & 17.99 & 40.92 & 19.82 & 0.97 \\
\hline 7 & 2 & $\mathrm{R}$ & 49.67 & 22.80 & 43.42 & 14.76 & 0.33 \\
\hline 8 & 3 & $\mathrm{R}$ & 53.08 & 23.77 & 44.54 & 14.78 & 0.19 \\
\hline 9 & 4 & $\mathrm{R}$ & 68.50 & 19.15 & 47.58 & 22.36 & 0.01 \\
\hline 10 & 5 & $\mathrm{R}$ & 26.75 & 16.01 & 27.79 & 10.24 & 0.81 \\
\hline 11 & 5 & $\mathrm{R}$ & 50.25 & 17.01 & 41.79 & 14.98 & 0.14 \\
\hline 12 & 6 & $\mathrm{R}$ & 42.33 & 19.09 & 30.38 & 19.89 & 0.09 \\
\hline 13 & 10 & $\mathrm{R}$ & 31.08 & 14.67 & 27.50 & 13.25 & 0.47 \\
\hline 14 & -1 & B & 60.00 & 21.35 & 50.21 & 18.50 & 0.16 \\
\hline 15 & -2 & B & 58.75 & 16.80 & 49.29 & 10.88 & 0.05 \\
\hline 16 & -3 & B & 28.75 & 18.33 & 45.25 & 20.06 & 0.02 \\
\hline 17 & -3 & B & 47.42 & 16.74 & 36.58 & 17.73 & 0.09 \\
\hline 18 & -3 & B & 22.33 & 11.67 & 23.04 & 12.36 & 0.87 \\
\hline 19 & -3 & B & 42.00 & 18.25 & 27.58 & 12.89 & 0.01 \\
\hline 20 & -4 & B & 28.67 & 22.85 & 14.17 & 11.35 & 0.06 \\
\hline 21 & -5 & B & 49.83 & 19.28 & 43.92 & 15.20 & 0.32 \\
\hline 22 & -5 & B & 32.17 & 10.33 & 22.29 & 10.16 & 0.01 \\
\hline 23 & -6 & B & 36.42 & 15.42 & 33.17 & 17.16 & 0.58 \\
\hline 24 & -6 & B & 58.08 & 18.67 & 60.63 & 15.85 & 0.67 \\
\hline 25 & -7 & B & 27.33 & 9.15 & 35.25 & 16.01 & 0.12 \\
\hline 26 & -8 & B & 42.00 & 14.46 & 45.42 & 16.16 & 0.54 \\
\hline 27 & -9 & B & 31.67 & 9.12 & 28.29 & 14.44 & 0.47 \\
\hline
\end{tabular}




\begin{tabular}{|l|l|l|r|r|r|r|r|}
\hline 28 & -11 & B & 38.92 & 14.93 & 42.75 & 14.97 & 0.47 \\
\hline 29 & -13 & B & 33.83 & 13.37 & 42.46 & 15.51 & 0.11 \\
\hline 30 & -14 & B & 37.50 & 19.86 & 37.42 & 17.40 & 0.99 \\
\hline
\end{tabular}

Table 7: Means of rating scores (smile) of panel by patient

Also, our result show that orthodontist judges rated models in the green incisors group as most attractive, followed by models in the red incisors group, and models in the black incisors group as least attractive. Laypeople judges also rated models in the green incisors group as most attractive. However, models in the red and black incisors groups got almost the same mean scores for facial attractiveness.

\begin{tabular}{|l|l|l|l|l|l|l|l|l|l|l|l|}
\hline \multicolumn{2}{|l|}{ Orthodontist } & \multicolumn{4}{l|}{ Lay-people } \\
\hline Black & \multicolumn{2}{|l|}{ Green } & \multicolumn{2}{l|}{ Red } & \multicolumn{2}{l|}{ Black } & \multicolumn{2}{l|}{ Green } & \multicolumn{2}{l|}{ Red } \\
\hline LS & Std & LS & Std & LS & Std & LS & Std & LS & Std & LS & Std \\
MEAN & Err & MEAN & Err & MEAN & Err & MEAN & Err & MEAN & Err & MEAN & Err \\
\hline $24.5^{\text {ab }}$ & 2.5 & $36.4^{\mathrm{a}}$ & 4.7 & 30.0 & 3.7 & $27.2^{\mathrm{b}}$ & 2.4 & 36.7 & 4.5 & 27.1 & 3.6 \\
\hline
\end{tabular}

Significant $\mathrm{p}$-value for multiple comparison of panel*GVP

${ }^{a}$ Black vs. Green GV position for orthodontist.

${ }^{\mathrm{b}}$ Orthodontist vs Lay-people for Black GV position

Table 8: Multiple comparison for Panel*incisors position interaction.

\section{Males VS Females Raters:}

In this sample, there was no significant difference in judging facial attractiveness on a smiling profile photograph between male and female judges. Looking at individual model subjects ratings, we found a significant difference in facial attractiveness ratings in only two cases $(6.66 \%)$ of the thirty model subjects we photographed. The difference was insignificant in 28 cases $(93.33 \%)$. In these two cases with significant difference, the 
female judges gave better facial attractiveness score to the subjects. The table below shows the difference in facial attractiveness ratings between male and female raters.

\begin{tabular}{|c|c|c|c|c|c|c|c|}
\hline \multirow[t]{2}{*}{ Patient } & \multirow{2}{*}{$\begin{array}{c}\text { Distance } \\
\text { to } \mathrm{GV}\end{array}$} & \multirow[t]{2}{*}{ position } & \multicolumn{2}{|c|}{ Male } & \multicolumn{2}{|l|}{ Female } & \multirow[t]{2}{*}{ P-value* } \\
\hline & & & MEAN & SD & MEAN & SD & \\
\hline 1 & 0 & G & 48.33 & 22.78 & 47.06 & 21.37 & 0.86 \\
\hline 2 & 0 & $\mathrm{G}$ & 50.17 & 19.83 & 62.17 & 18.25 & 0.07 \\
\hline 3 & 0 & G & 40.94 & 18.59 & 44.89 & 15.37 & 0.49 \\
\hline 4 & 0 & G & 46.56 & 21.93 & 56.22 & 16.54 & 0.14 \\
\hline 5 & 0 & G & 45.00 & 16.60 & 45.17 & 16.79 & 0.98 \\
\hline 6 & 1 & $\mathrm{R}$ & 32.11 & 12.32 & 49.89 & 20.54 & 0.004 \\
\hline 7 & 2 & $\mathrm{R}$ & 42.94 & 17.89 & 48.06 & 17.76 & 0.40 \\
\hline 8 & 3 & $\mathrm{R}$ & 42.61 & 18.18 & 52.17 & 17.79 & 0.12 \\
\hline 9 & 4 & $\mathrm{R}$ & 51.33 & 24.12 & 57.78 & 22.70 & 0.41 \\
\hline 10 & 5 & $\mathrm{R}$ & 24.39 & 12.18 & 30.50 & 11.84 & 0.14 \\
\hline 11 & 5 & $\mathrm{R}$ & 41.50 & 15.25 & 47.72 & 16.47 & 0.25 \\
\hline 12 & 6 & $\mathrm{R}$ & 31.83 & 16.38 & 36.89 & 23.59 & 0.46 \\
\hline 13 & 10 & $\mathrm{R}$ & 24.72 & 13.14 & 32.67 & 13.30 & 0.08 \\
\hline 14 & -1 & B & 47.72 & 21.96 & 59.22 & 15.83 & 0.08 \\
\hline 15 & -2 & B & 51.39 & 14.34 & 53.50 & 13.30 & 0.65 \\
\hline 16 & -3 & B & 39.44 & 23.35 & 40.06 & 18.56 & 0.93 \\
\hline 17 & -3 & B & 38.17 & 15.11 & 42.22 & 20.61 & 0.51 \\
\hline 18 & -3 & B & 20.44 & 9.53 & 25.17 & 13.87 & 0.24 \\
\hline 19 & -3 & B & 28.50 & 14.73 & 36.28 & 17.00 & 0.15 \\
\hline 20 & -4 & B & 14.00 & 8.15 & 24.00 & 22.18 & 0.09 \\
\hline 21 & -5 & B & 43.67 & 17.55 & 48.11 & 15.84 & 0.43 \\
\hline 22 & -5 & B & 23.33 & 8.57 & 27.83 & 13.06 & 0.23 \\
\hline 23 & -6 & B & 34.94 & 17.42 & 33.56 & 15.89 & 0.80 \\
\hline 24 & -6 & B & 54.94 & 16.37 & 64.61 & 15.84 & 0.08 \\
\hline
\end{tabular}




\begin{tabular}{|l|l|l|r|r|r|r|r|}
\hline 25 & -7 & B & 29.78 & 11.04 & 35.44 & 17.07 & 0.25 \\
\hline 26 & -8 & B & 42.67 & 14.08 & 45.89 & 17.04 & 0.54 \\
\hline 27 & -9 & B & 26.00 & 12.21 & 32.83 & 12.94 & 0.11 \\
\hline 28 & -11 & B & 37.22 & 13.16 & 45.72 & 15.59 & 0.09 \\
\hline 29 & -13 & B & 33.89 & 11.37 & 45.28 & 16.68 & 0.02 \\
\hline 30 & -14 & B & 36.83 & 21.75 & 38.06 & 13.82 & 0.84 \\
\hline
\end{tabular}

Table 9: Means of rating scores (smile) of sex by patient

\section{Judges Preference Of Maxillary Incisors AP Position:}

In the last part of the rating procedure, judges were asked how they would like to change the anteroposterior (AP) position of the maxillary incisors for each subject. They were asked if they like the subject's incisors to move forward, backward, or stay in the same position. In the green incisors group, most of the judges (79.4\%) chose to keep the incisors in the current position. In the black incisors group, (60.80\%) of the judges chose to move the incisors forward. In the red incisors group, (62.20\%) of the judges chose to keep the incisors in the same position. The difference was significant for each group. The table below shows the results of this section.

\begin{tabular}{|l|l|l|l|l|}
\hline $\begin{array}{l}\text { Incisors } \\
\text { position }\end{array}$ & $\begin{array}{l}\text { Backward } \\
(\%)\end{array}$ & $\begin{array}{l}\text { Forward } \\
(\%)\end{array}$ & $\begin{array}{l}\text { Stay } \\
(\%)\end{array}$ & -value* \\
\hline B & 2.3 & 60.8 & 36.9 & $<0.0001$ \\
\hline G & 6.7 & 13.9 & 79.4 & $<0.0001$ \\
\hline R & 22.6 & 15.3 & 62.2 & $<0.0001$ \\
\hline
\end{tabular}

Table 10: Contingency table of GV position by Opinion 
The table below shows how orthodontist and layperson judges were different in this part of the rating procedure. In the green incisors group, (86.7\%) of the orthodontist judges and $(75.8 \%)$ of the layperson judges chose to keep the incisors in the same current position. In the red incisors group, $(58.3 \%)$ of the orthodontist judges and $(64.1 \%)$ of the layperson judges chose to keep the incisors in the same current position. Only $(30.2 \%)$ of the orthodontist judges and $(18.8 \%)$ of the layperson judges wanted to move the incisors backward in the red incisors group. In the black incisors group, $(73.5 \%)$ of the orthodontists and (54.4\%) of the layperson judges wanted the incisors to move forward. Only few judges chose to move the teeth back in the black incisors group.

\begin{tabular}{|c|c|c|c|c|c|c|c|c|}
\hline \multirow{2}{*}{$\begin{array}{l}\text { Incisor } \\
\text { Position } \\
\text { Group }\end{array}$} & \multicolumn{3}{|c|}{ Orthodontist } & \multirow[b]{2}{*}{$\begin{array}{l}\text { P- } \\
\text { value* }\end{array}$} & \multicolumn{3}{|c|}{ Lay-people } & \multirow[b]{2}{*}{$\begin{array}{l}\mathrm{P}- \\
\text { value* }\end{array}$} \\
\hline & $\begin{array}{c}\text { Backward } \\
(\%)\end{array}$ & $\begin{array}{l}\text { Forward } \\
(\%)\end{array}$ & $\begin{array}{r}\text { Stay } \\
(\%)\end{array}$ & & Backward & Forward & stay & \\
\hline B & 0 & 73.5 & 26.5 & $<0.0001$ & 3.4 & 54.4 & 42.2 & $<0.0001$ \\
\hline $\mathrm{G}$ & 3.3 & 10.0 & 86.7 & $<0.0001$ & 8.3 & 15.8 & 75.8 & $<0.0001$ \\
\hline $\mathrm{R}$ & 30.2 & 11.5 & 58.3 & $<0.0001$ & 18.8 & 17.2 & 64.1 & $<0.0001$ \\
\hline
\end{tabular}

Table 11: Contingency table of GV position by Opinion by Panel

\section{Intra-Rater Reliability:}

Since all the raters scored 10 photographs twice, the reliability of the ratings was tested using intra-class correlation coefficients: 0.86 indicating a high level of intra-raters reliability. 


\section{CHAPTER 5: DISCUSSION}

\section{Sample Distribution:}

Among the 30 Caucasian males recruited for this study, 5 subjects were categorized with green incisors (their incisors lie on the GV), 8 had red incisors (in front to the GV), and 17 had black incisors (behind the GV line). The fact that there were more subjects having their incisors behind the GV reference agrees with Andrews finding that the optimal AP position of the maxillary central incisors lie between the FALL and GALL line [13]. However, a larger sample is necessary to validate this finding. In addition, the most common AP position can be considered the norm for this population, but not necessarily the most esthetically optimal position that should be considered as an objective for orthodontic treatment.

\section{Effect of AP maxillary incisor position on facial attractiveness:}

No significant differences in rating scores were found among the three groups of photographs by the 36 judges. However, there was a common trend that the judges rated the photographs highest in the following orders: Green incisors > Red incisors > Black incisors. These results reaffirm Element II of Andrews six elements philosophy that the anteroposterior (AP) position of the maxilla is optimal when the Facial Axis points (FA point) of maxillary incisors are on the GALL line [14]. Schlosser, et al. study (2005) studied a Caucasian female and found the least attractive anteroposterior (AP) position of the maxillary incisors is the most retracted position. They concluded that it is preferable 
to leave a normally protrusive maxillary dentition where it is or advance rather than retract them [18]. However, after studying the 36 judges only nine judges (25\%) showed a significant difference in judging the facial attractiveness of models in the different incisors groups. All those nine judges rated the subjects of the green incisors group as the most attractive, and subjects of the black incisors group as the least attractive. It is probably safe to say that maxillary incisors' anteroposterior (AP) position doe s not always affect the facial attractiveness judgement, but when there is a significant difference green is usually the preferred position. The results of the second part of the rating procedure confirm this conclusion. Most judges viewing the photographs preferred green incisors to stay in the same position (79.4\%), and preferred black incisors to move forward toward the Glabella Vertical (60.8\%). In the red incisors group, (62.2\%) of the judges preferred the teeth to stay in the same position showing better toleration of protracted (than retracted) incisors positions.

It was an interesting finding in this study that the subject who received the best mean rating of facial attractiveness had incisors that are located $6 \mathrm{~mm}$ posterior to the Glabella Vertical line. The second best rating was given to a subject from the green incisors group, and the third best rating was given to a subject from the red incisors group. The worst three mean ratings were given to subjects in the black incisors group. We believe that the relationship between the anteroposterior (AP) of the maxillary incisors and facial attractiveness is not a simple linear relationship. Other face features also play a role (For example, hair style, eye shape, skin tone, nose shape, and chin protrusion). The anteroposterior position (AP) of maxillary incisors is only one of those features defining face attractiveness. It is possible that other distracters may have caused some judges to 
miss the target variable (AP incisor position), resulting in a wide range of esthetic opinions and, subsequently a large standard deviation. It has also been reported that background facial attractiveness is more important than the dental condition in attractiveness ratings [34]. We tried in this study to decrease the effect of these features by changing the photographs colors and cropping the background, but removing those variables completely is impossible. Secord and Backman [36] reported that protrusion of the maxillary teeth was a relatively unimportant physical feature that was difficult to remember about a given person. To some observers, the small variations in an unimportant feature might limit the range of their responses [35].

Therefore, the second null hypothesis was accepted. The anteroposterior (AP) of the maxillary incisors is only one of many factors defining facial attractiveness. The AP of the maxillary incisors might not be a crucial factor in judging face attractiveness. However, there is a common trend. The optimal AP position of the maxillary incisors is when the Facial Axis points (FA point) are on the Glabella Vertical reference (green incisors). Incisors positioned anterior to the Glabella Vertical (red incisors) are more preferred than incisors positioned posterior to the Glabella Vertical (black incisors).

\section{Repose View VS Smiling View:}

Contemporary orthodontic diagnosis includes assessing the maxillary incisors display from the frontal view. In profile however, the maxillary incisors are not routinely assessed with regard to how they directly relate to the face. Instead, the soft tissue drape is relied on to reflect their position indirectly despite the potential unreliability of this 
method [22]. In the Six Elements orthodontic philosophy, Andrews stressed the importance of using smiling profile, rather than repose profile, to evaluate the facial esthetics and the optimal AP position of the maxilla. We are not aware of another study that compared the facial attractiveness judgement in smiling profile view versus in repose. This study showed a significantly higher rating score for the photographs in repose versus the smiling photographs. However, if one looks at individual subject ratings, the difference was only significant in about half of the cases (53.33\%). The attractiveness judgement was sometimes better and sometimes worse in the green and the red incisors groups, but the judgement was mostly (75\% of the cases) worse in the black incisors group. We can only assume that the smiling profile view was more accurate to point out the least preferable AP position of the incisors, retracted position.

The null hypothesis was rejected. We concluded that there is a difference in judgment of facial attractiveness when judged from smiling versus repose profile view, especially in patients with retracted maxillary incisors position.

\section{Orthodontists VS Layperson Raters:}

Various studies have tried to shed light on the effects of dental or orthodontic training on facial attractiveness judgement. Many studies reported that professionals and general public evaluate profiles similarly. Romani, et al. (1993) introduced incremental changes in male and female images to simulate the effects of mandibular advancement or setback, maxillary advancement or set-back, and maxillary impaction. A panel of 22 dental clinicians and 22 lay people completed questionnaires evaluating their level of sensitivity 
to changes in the facial profiles and their preferences regarding alternative profiles [34]. Orthodontists and laypeople judges were similarly sensitive to small horizontal changes in maxillary position and nearly identically sensitive to changes of $3 \mathrm{~mm}$ or more [34]. Schlosser, et al. (2005) digitally manipulated a smiling profile picture to simulate maxillary protrusion and retrusion at $1 \mathrm{~mm}$ increments. 20 orthodontist and 20 lay people were asked to score the attractiveness of the altered photographs. They found that orthodontic training did not significantly affect the facial attractiveness rating judgement [18]. Cao, et al. altered the inclination and the anteroposterior (AP) position of the maxillary incisors on a photograph of a Chinese woman with a normal profile to generate a series of photographs that were judged by 21 orthodontic professionals and 66 laypersons. As in the previous study, no significant discrepancy was found [19]. Ellis, et al. have digitally manipulated smiling profile photographs of three females, from three different racial backgrounds, to simulate forward and backward movements of soft tissue glabella. They asked 20 general dentists and 20 laypersons to judge the attractiveness of the photographs. Once again, professional and nonprofessional had similar assessment of attractiveness; however dental professionals seem to have a sharper eye for details than the laypersons [20]. Also in the study by Ghaleb, et al. et al. 3 groups including dentists, orthodontists, and laypeople scored the attractiveness of smiling profile photographs based on maxillary incisor inclinations. They found no significant differences between the professional and nonprofessional groups in terms of their assessments [33]. On the contrary, some researchers reported different assessment. Arqoub, et al. did a study to evaluate the influence of changing the AP and vertical proportions of the lower face on facial attractiveness. They found a significant difference between dentists and lay people 
in judgment of profile attractiveness [23]. In another study Najafi, et al. (2015) studied a smiling profile photograph of one male subject with normal profile. They digitally manipulated mandibular sagittal positions and inclination of the maxillary incisors. 72 senior dental students, 24 orthodontists, 21 maxillofacial surgeons, 25 prosthodontists, and 92 laypeople were asked to score attractiveness of each photograph. This study also showed a significant difference in rating between different professional panels [24].

In the current study, no significant differences were found between orthodontists and laypeople judgement in term of facial attractiveness. However, a significant difference in the facial attractiveness judgement was found between orthodontist and layperson panels in seven cases $(23.33 \%)$. Generally, orthodontists were more likely to give better attractiveness score for subjects than layperson judges. Interestingly, both panels of judges rated subjects of the green incisors groups as the most attractive. The orthodontist judges scored subjects of the red incisors group better than subjects of the black incisors group. Layperson judges were not able to differentiate between subjects in the red and black incisors groups in term of facial attractiveness. The idea that orthodontists are more educated and experienced in profile assessment than the lay public seems to be sound, orthodontists might have sharper eye for noticing profile details. However, the difference is not statistically significant. In the second part of the rating procedure, when the judges asked about their preference to change the AP position of the maxillary incisors, (86.7\%) of the orthodontists and $(75.8 \%)$ of the layperson raters wanted green incisors to stay in the same position. Also, (75.5\%) of the orthodontists and (54.4\%) of the layperson raters wanted black incisors to move forward. These results confirm our conclusion that both 
panels agrees upon preferred maxillary incisors position, and that orthodontically trained people might have better awareness of face details.

This part of null hypothesis was accepted and we concluded that there is no difference in term of facial attractiveness judgment between orthodontically trained raters and laypeople raters.

\section{Males VS Females Raters:}

In orthodontic literature, few studies were found that compared males versus female judges in term of facial attractiveness judgement. Najafi, et al. found no significant differences between the male and female judges in ratings profile images [24]. This finding is similar to the studies of Ghaleb,et al.[33] and Arqoub,et al.[23]. On the other hand, Turkkahraman and Gokalp (2004) concluded that sex had an effect on the profile preferences in the Turkish population, and significant differences were observed between the sexes [37].

In our sample of judges, we randomly selected 18 male and 18 female judges. The attractiveness ratings of the male and female judges trended similarly. Sex of the judge does not seem to have significant effect on the facial attractiveness judgement. The null hypothesis was accepted. We concluded that the concept of profile attractiveness is similar between male and female raters and that judge's sex does not significantly affect the profile attractiveness judgement. 


\section{Intra-Rater Reliability:}

The reliability of the ratings was tested using intra-class correlation coefficients: 0.86 indicating a high level of intra-raters reliability. The profile attractiveness judgement is consistent, reproducible, and reliable.

\section{CHAPTER 6: SUMMARY AND CONCLUSIONS}

\section{Summary:}

The specific aims of this study were to investigate about the most esthetically optimal anteroposterior (AP) position of the maxillary incisors in Caucasian males, and how this position is related to the Glabella Vertical reference. Furthermore, the study tried to analyze the differences in assessing attractiveness from smiling profile view versus repose profile view, orthodontists versus laypeople, and male versus female judges. We photographed 30 model subjects in smiling and repose profile positions, and included 36 judges ( 6 male orthodontists, 6 female orthodontists, 12 male lay judges, and 12 female lay judges) to rate the facial attractiveness in each photograph. Statistical analysis was performed for all the variables, with several variables showing statistical significance.

Findings from the study regarding the Null hypotheses concluded:

1. There is no difference in judged facial attractiveness of Caucasian males between smiling profiles and repose profiles. ACCEPTED 
2. There is no difference in judged facial attractiveness of Caucasian males with various anteroposterior (AP) positions of the maxillary incisors relative to Glabella Vertical (GV). REJECTED

3. There is no difference between male versus female judgment of facial attractiveness of Caucasian males with various anteroposterior (AP) positions of the maxillary incisors relative to Glabella Vertical (GV). ACCEPTED

4. There is no difference between orthodontist versus layperson judgment of facial attractiveness of Caucasian males with various anteroposterior (AP) positions of the maxillary incisors relative to Glabella Vertical (GV). ACCEPTED

\section{Conclusions:}

1. There is no significant difference in facial attractiveness judgement among Caucasian males with various anteroposterior (AP) positions of the maxillary anterior teeth. The AP of the maxillary incisors might not be a crucial factor in judging face attractiveness.

2. There is an esthetically optimal AP position of the maxillary incisors in Caucasian males when evaluated from smiling profile view. The AP position of the maxillary incisors is optimal when the Facial Axis points (FA point) are on the Glabella Vertical reference (green incisors).

3. In Caucasian males, Incisors positioned anterior to the Glabella Vertical (red incisors) are more preferred than incisors positioned posterior to the Glabella Vertical (black incisors). 
4. There is a difference in facial attractiveness judgment when judged from smiling versus repose profile view, especially in patients with retracted maxillary incisors. Smiling profile view is recommended to clinically evaluate profile esthetics.

5. There is no significant difference in term of facial attractiveness judgment between orthodontically trained and laypeople raters.

6. There is no significant difference in term of facial attractiveness judgment between male and female raters. The sex of the rater does not significantly affect the profile esthetic perception.

\section{CHAPTER 7: SUGGESTIONS FOR FUTURE RESEARCH}

There is an obvious need for more research in this area. This study should be repeated with a larger sample in order to see if some of the trends that were observed are significant and failed to reach significance due to small sample size. Moreover, fewer variables must be studied each time to decrease distracters that might affect drawing useful conclusions. Also the study should be repeated with different subject's races and judge's cultural backgrounds, since both are factors that can affect the attractiveness perception of the individual. 


\section{REFERENCES:}

1. Baldwin DC. Appearance And Aesthetics In Oral Health. Community dent oral epidemiol.1980;9:244-56.

2. Andrews LF, Andrews WA. The Six Elements Of Orofacial Harmony. Andrews J. 2000;1:13-22.

3. Ajmera AJ, Toshniwal NG. Assessing the AP Position of Maxillary Central Incisor Using Forhead: A Smiling Profile Photographic Study. The Journal of Indian Orthodontic Society, Oct-Dec 2012;46(4):188-192.

4. Tomblyn.J, Tremont.T, Martin.C, Jurevic.R, Gunel.E. Facial Planes As Landmarks For Diagnosis And Treatment Planning. 2015,1588154

5. The Urban Dictionary

6. Corruccini, RS and Pacciani, E. "Orthodontistry” And Dental Occlusion In Etruscans. Angle Orthod.1989; 59: 61-64.

7. Wahl N. Orthodontics In 3 Millennia. Chapter 1: Antiquity To The Mid-19th Century. Am J Orthod Dentofacial Orthop 2005;127:255-9.

8. Bell WH. Le Fort I Osteotomy For Correction Of Maxillary Deformities. J Oral Surg. 1975;33(6):412-26. 18.

9. Ellis E III, McNamara JA Jr. Cephalometric Evaluation Of Incisor Position. Angle Orthod.1986 Oct;56(4):324-44.

10. Holdaway RA. A Soft-Tissue Cephalometric Analysis And Its Use In Orthodontic Treatment Planning. Part I. Am J Orthod. 1983 Jul;84(1):1-28. 
11. Asad S, Kazmi F, Muhammad M, Aaqil M, Razwan R. Assessment Of AnteroPosterior Position Of Lips: E-Line- S-Line. Pakistan Oral \& Dental Journal. Jun2011, Vol. 31 Issue 1, p82-85. 4p

12. Riveiro P, Suarez-Quintanilla D, Smyth-Chamosa E, Saarez-Cunqueiro M.Linear Photogrammetric Analysis Of The Soft Tissue Facial Profile. American Journal of Orthodontics and Dentofacial Orthopedics, July 2002, 122(1):59-66.

13. Andrews, LF. (1989). Straight Wire: The Concept And Appliance. L.A Wells Co, 2003.

14. Will A. Andrews. Scientific Treatment Goals For Oral And Facial Harmony. AAO Lecture May 7, 2013 Philadelphia, PA

15. Madsen DP, Sampson WJ, Townsend GC. Craniofacial Reference Plane Variation And Natural Head Position. European Journal of Orthodontics, Volume 30, Issue 5, 1 October 2008, Pages 532-540.

16. Will Alan Andrews. AP Relationship Of The Maxillary Central Incisors To The Forehead In Adult White Females. Angle Orthodontist, Vol 78, No 4, 2008. $10.2319 / 071307-329.1$

17. Adams M, Andrews W, Tremont T, Martin C, Razmus T, Gunel E, Ngan P. Anteroposterior Relationship Of The Maxillary Central Incisors To The Forehead In Adult White Males. 2013;14(1):e2-9. DOI: 10.11607/ortho.906

18. Schlosser JB, Preston CB, Lampasso J. The Effects Of Computer-Aided Anteroposterior Maxillary Incisor Movement On Ratings Of Facial Attractiveness. American Journal of Orthodontics and Dentofacial Orthopedics, Volume 127, Number 1, 2005; 127:17-24. 
19. Cao L, Zhang K, Bai D, Jing Y, Tian Y, Guo Y. Effect Of Maxillary Incisor Labiolingual Inclination And Anteroposterior Position On Smiling Profile Esthetics. Angle Orthod. 2011; 81(1):121-129.

20. Heidi S. Ellis, Farid Hamidzadeh, Sennay M. Stefanos, et al. The Effects Of Computer-Aided Anteroposterior Forehead Movement On Ratings Of Facial Attractiveness. J Dent Oral Health (2017), Volume 3, Issue 5, 077. ISSN: 23694475.

21. Alfaro FH. Upper Incisor To Soft Tissue Plane (UI-STP): A New Reference For Diagnosis And Planning In Dentofacial Deformities. Med Oral Patol Oral Cir Bucal. 2010;15(5):779-781.

22. Vishal Singh, Payal Sharma, Piush Kumar, Dinesh Bagga, Rakesh Sharma, Pragya Kumar. Evaluation Of Anteroposterior Relationship Of Maxillary Central Incisors To A Soft Tissue Plane In Profile Analysis. Journal of Indian Orthodontic Society. Volume 48, Number 3, 2014, pp. 180-183(4).

23. Arqoub SH, Al Khateeb SN. Perception Of Facial Profile Attractiveness Of Different Antero-Posterior And Vertical Proportions. Eur J Orthod 2011;33(1):103-11.

24. Hooman Zarif Najafi, Morteza Oshagh, Mohammad Hassan Khalili, and Sepideh Torkan. Esthetic Evaluation Of Incisor Inclination In Smilinig Profiles With Respect To Mandibular Position. Am J Orthod Dentofacial Orthop 2015;148:38795.

25. Downs WB. Analysis Of The Dentofacial Profile. Angle Orthod. 1956; 26: 191212. 
26. Moorrees CF. Natural Head Position-A Revival. Am J Orthod Dentofacial Orthop. 1994;105:512-3.

27. Solow B, Tallgren A. Natural Head Position In Standing Subjects. Acta Odontol Scand. 1971; 29: 591-607.

28. Lundstrom A, Lundstrom. Natural Head Position As A Basis For Cephalometric Analysis. Am J Orthod Dentofacial Orthop.1992 Mar;101(3):244-7.

29. Cooke MS. Five-year reproducibility of natural head posture: a longitudinal study. Am J Orthod Dentofacial Orthop. 1990; 97: 489-494.

30. Peng L, Cooke MS. Fifteen-year reproducibility of natural head posture: a longitudinal study. Am J Orthod Dentofacial Orthop. 1999; 116: 82-85.

31. Lundstrom A, Lundstrom F, Lebret LM, Moorrees CF. Natural head position and natural head orientation: basic considerations in cephalometric analysis. Eur J Orthod. 1995; 17: 111-120.

32. D. Gould et al. Visual Analogue Scale (VAS). Journal of Clinical Nursing 2001; 10:697-706.

33. Ghaleb N, Bouserhal J, Bassil-Nassif N. Aesthetic Evaluation Of Profile Incisor Inclination. Eur J Orthod 2011;33:228-35.

34. Romani KL, Agahi F, Nanda R, Zernik JH. Evaluation Of Horizontal And Vertical Differences In Facial Profiles By Orthodontists And Lay People. Angle Orthod 1993;3:175-82.

35. Shaw WC, Reese G, Dawe M, Charles CR. The Influence Of Dentofacial Appearance On The Social Attractiveness Of Young Adults. Am J Orthod $1985 ; 87: 21-6$ 
36. Secord PF, Backman CW. Malocclusion And Psychological Factors. J Am Dent Assoc 1959;59:931-8.

37. Turkkahraman H, Gokalp H. Facial Profile Preferences Among Various Layers Of Turkish Population. Angle Orthod 2004;74:640-7. 


\section{$\underline{\text { APPENDICES }}$}

\section{APPENDIX A- IRB Approval:}

\section{W. West VruginiaUniversity. \\ Office of Research Integrity and Compliance \\ QSG CHESNUT RIDGE ROAD MORGANTOWN, WV 26500}

Approval of Human Research Protocol

$10 / 19 / 2017$

To: Peter Ngan

From: WVU Office of Research Integrity \& Compliance

Protocol Type: Expedited

Approval Date: 10/19/2017

Submission Type: Initial

Expiration Date: 10/18/2018

Funding: N/A

WVU Protocol \#: 1708703095

Protocol Title: The optimal anterior-posterior position of maxillary incisors in Caucasian males as viewed from smiling profile.

The West Virginia University Institutional Review Board has reviewed and granted your request for approval of Expedited protocol 1708703095, in accordance with the Federal regulations 45 CFR 46, 21 CFR 50, and 21 CFR 56 (when applicable). Additional details concerning the review are below:

- Category 6. Collection of data from voice, video, digital, or image recordings made for research purposes.

The following documents were reviewed and approved for use as part of this submission. Only the documents listed below may be used in the research. Please access and print the files in the Notes \& Attachments section of your approved protocol.

- Consent-only-minimal-risk With HIPPA.pdf

- Consent-only-minimal-risk wo HIPAA.pdf

WVU IRB approval of protocol 1708703095 will expire on 10/18/2018. 
If any study related activities are to continue beyond the expiration date, a renewal application should be submitted no later than four (4) weeks prior to the expiration date. It is your responsibility to submit your protocol for continuing review.

Once you begin your human subjects research, the following regulations apply:

1. Unanticipated or serious adverse events and/or side effects encountered in this research study must be reported to the IRB within five (5) days using the Notify IRB action in the electronic protocol.

2. Any modifications to the study protocol or informed consent form must be reviewed and approved by the IRB prior to implementation. These modifications should be submitted as an amendment.

3. You may not use a modified informed consent form until it has been reviewed and approved by the WVU IRB. Only consent forms with the WVU+kc watermark may be used to obtain informed consent from participants.

The Office of Research Integrity and Compliance will be glad to provide assistance to you throughout the research process. Please feel free to contact us by phone, at 304.293 .7073 or by email at IRB@mail.wvu.edu.

Sincerely,

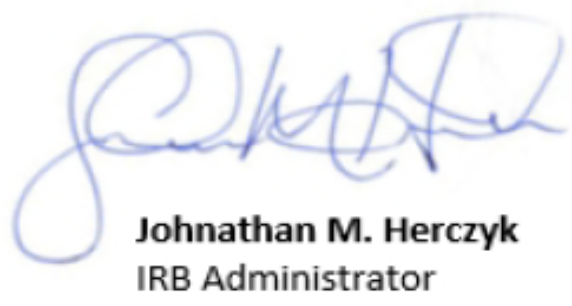




\title{
APPENDIX B- Only minimal risk consents information and HIPAA form:
}

\section{W- WestViriginiaUniversity.}

Human Research Protocol

Only Minimal Risk Consent Form

(With HIPAA)

\author{
Only Minimal Risk \\ Consent Information and HIPAA Form \\ Principal Investigator \\ Peter Ngan, DMD, MS \\ Department \\ Orthodontics \\ Protocol Number \\ 1708703095 \\ Study Title \\ The optimal anterior-posterior position of maxillary incisors in Caucasian males \\ as viewed from smiling profile. \\ Co-Investigator(s) \\ Amer Shammaa, DDS \\ Contact Persons
}

In the event you experience any side effects or injury related to this research, you should contact Dr. Amer Shammaa at (304) 293-0204. If you have any questions, concerns, or complaints about this research, you can contact Dr. Peter Ngan at (304) 293-3222.

For information regarding your rights as a research subject, to discuss problems, concerns, or suggestions related to the research, to obtain information or offer input about the research, contact the Office of Research Compliance at (304) 293-7073.

In addition if you would like to discuss problems, concerns, have suggestions related to research, or would like to offer input about the research, contact the Office of Research Integrity and Compliance at 304-293-7073.

\section{Introduction}

You, have been asked to participate in this research study, which has been explained to you by Dr. Amer Shammaa. This study is being conducted by Dr. Peter Ngan and Dr.Amer Shammaa in the Department of Orthodontics at West Virginia University.

\section{Purpose(s) of the Study}

The purpose of this study is to identify the most aesthetically optimal anterior-posterior position of the upper front teeth in Caucasian males from a smiling profile view relative to a landmark on the person's forehead, as judged by orthodontists and by lay people judges. We are using first and second year dental students as lay people judges. Also, we are trying to discover if there is any difference in judgment of attractiveness when comparing smiling and nonsmiling profiles.

This research could potentially help orthodontists in identifying the anterior-posterior position of the upper front teeth in Caucasian males and provide standards to compare patients and determine how to move teeth. This could potentially help orthodontists in diagnosing and treatment planning orthodontic patients.

\begin{tabular}{r|lr} 
& Chestnut Ridge Research Building & P a g e | 1 \\
Phone: 304-293-7073 & 886 Chestnut Ridge Road & Subject's Initials__ \\
Fax: 304-293-3098 & PO Box 6845 & Date__
\end{tabular}




\section{WWestVirginiaUniversity.}

Human Research Protocol Only Minimal Risk Consent Form

(With HIPAA)

\section{Description of Procedures}

This study involves taking profile photographs of your face in smiling and non-smiling positions and this will take approximately few minutes to complete. On the photographs, we will measure the distance from the upper front teeth to a point on your forehead called Glabella. WVU orthodontic faculty, orthodontic residents, and dental students will be shown the photographs in a secure location at the WVU School of Dentistry-Orthodontic Department and they will be asked to rate them on the base of attractiveness.

\section{Discomforts}

There are no known or expected risks from participating in this study, except for the mild frustration associated with taking photographs.

\section{Alternatives}

You do not have to participate in this study.

\section{Benefits}

You may not receive any direct benefit from this study. The knowledge gained from this study may eventually benefit others.

\section{Financial Considerations}

You will not be paid to participate in this study.

\section{Confidentiality}

Any information about you that is obtained as a result of your participation in this research will be kept as confidential as legally possible. Your research records and test results, just like hospital records, may be subpoenaed by court order or may be inspected by the study sponsor or federal regulatory authorities without your additional consent.

In any publications that result from this research, neither your name nor any information from which you might be identified will be published without your consent.

\section{HIPAA}

We know that information about you and your health is private. We are dedicated to protecting the privacy of that information. Because of this promise, we must get your written authorization (permission) before we may use or disclose your protected health information or share it with others for research purposes.

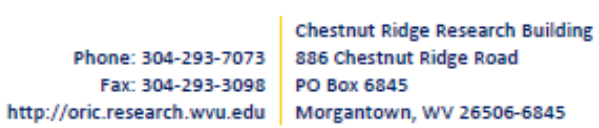

$P$ a ge $\mid 2$

Subject's Initials

Date 
You can decide to sign or not to sign this authorization section. However, if you choose not to sign this authorization, you will not be able to take part in the research study. Whatever choice you make about this research study will not have an effect on your access to medical care.

\section{Persons/Organizations Providing the Information}

Subjects/West Virginia University Hospitals

\section{Persons/Organizations Receiving the Information}

- The research site carrying out this study. This includes UHA or UHA Affiliated, WVU, WVU Medicine, or the covered entities under the purview of West Virginia University, collaborating institutions, affiliate institutions, and component institutions. It also includes each site's research staff and medical staff.

- Dental students, Orthodontic residents, and Orthodontic faculty of the WVU School of Dentistry.

- The members and staff of any Institutional Review Board (IRB) that oversees this research study. West Virginia University Office of Research Compliance and Office of Sponsored Programs.

The Following Information Will Be Use

- Smiling and Repose profile photographs of the face.

The Information is Being Disclosed for the Following Reasons

- Help the comprehensive examination process of future orthodontic patients.

- Help identifying of the most esthetically optimal anterior-posterior position of the maxillary incisors.

- Publication and lectures given that reveal the study results.

\section{You May Cancel this Authorization at Any Time by Writing to the Principal} Investigator.

Peter Ngan DMD, MS

451 Suncrest Town Centre Drive

Morgantown, WV 26505

If you cancel this authorization, any information that was collected already for this study cannot be withdrawn. Once information is disclosed, according to this authorization, the recipient may re-disclose it and then the information may no longer be protected by federal regulations.

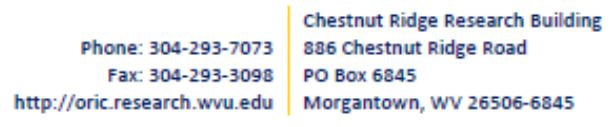

Page 13

Subject's Initials

Date 


\section{W-WestViriniauniversity.}

Human Research Protocol Only Minimal Risk Consent Form

(With HIPAA)

You have a right to see and make copies of your medical records. You will not be able to see or copy your records related to the study until the sponsor has completed all work related to the study. At that time you may ask to see the study doctor's files related to your participation in the study and have the study doctor correct any information about you that is wrong.

This authorization will expire at the end of the study unless you cancel it before that time.

\section{Voluntary Participation}

Participation in this study is voluntary. You are free to withdraw your consent to participate in this study at any time.

Refusal to participate or withdrawal will not affect you and will involve no penalty to you. Refusal to participate or withdrawal will not affect your future care, or your employee status at West Virginia University.

In the event new information becomes available that may affect your willingness to participate in this study, this information will be given to you so that you can make an informed decision about whether or not to continue your participation.

You have been given the opportunity to ask questions about the research, and you have received answers concerning areas you did not understand.

Upon signing this form, you will receive a copy.

I willingly consent to participate in this research.

\section{Signatures}

Signature of Subject

\begin{tabular}{lll}
\hline Printed Name & Date & Time \\
\hline
\end{tabular}

The participant has had the opportunity to have questions addressed. The participant willingly agrees to be in the study.

Signature of Investigator or Co-Investigator

\begin{tabular}{|c|c|c|c|}
\hline Printed Name & Date & Time & \\
\hline $\begin{array}{l}\text { Phone: 304-293-7073 } \\
\text { Fax 304-293-3098 }\end{array}$ & $\begin{array}{l}\text { Chestnut Ridge Research Building } \\
\text { 886 Chestnut Ridge Road } \\
\text { PO Box } 6845\end{array}$ & & $\mathrm{Page} \mid 4$ \\
\hline $\begin{array}{r}\text { Fax. 304-293-3098 } \\
\text { http://oric.research.wvu.edu }\end{array}$ & $\begin{array}{l}\text { PO Box } 6845 \\
\text { Morgantown, WV 26506-6845 }\end{array}$ & $\begin{array}{l}\text { Subject's Initials_ } \\
\text { Date }\end{array}$ & \\
\hline
\end{tabular}




\title{
APPENDIX C- Only minimal risk consents information form (without HIPAA):
}

\section{W- WestVirginiaUniversity.}

Human Research Protocol

Only Minimal Risk Consent Form

Without HIPAA

\author{
Only Minimal Risk \\ Consent Information Form (without HIPAA) \\ Principal Investigator \\ Peter Ngan, DMD, MS \\ Department \\ Orthodontics \\ Protocol Number \\ 1708703095 \\ Study Title \\ The optimal anterior-posterior position of maxillary incisors in Caucasian males \\ as viewed from smiling profile. \\ Co-Investigator(s) \\ Amer Shammaa, DDS

\section{Contact Persons}

In the event you experience any side effects or injury related to this research, you should contact Dr. Amer Shammaa at (304) 293-0204. If you have any questions, concerns, or complaints about this research, you can contact Dr. Peter Ngan at (304) 293-3222.

For information regarding your rights as a research subject, to discuss problems, concerns, or suggestions related to the research, to obtain information or offer input about the research, contact the Office of Research Compliance at (304) 293-7073.

In addition if you would like to discuss problems, concerns, have suggestions related to research, or would like to offer input about the research, contact the Office of Research Integrity and Compliance at 304-293-7073.

\section{Introduction}

You, , have been asked to participate in this research study, which has been explained to you by Dr. Amer Shammaa. This study is being conducted by Dr. Peter Ngan and Dr.Amer Shammaa in the Department of Orthodontics at West Virginia University.

\section{Purpose(s) of the Study}

The purpose of this study is to identify the most esthetically optimal anterior-posterior position of the upper front teeth in Caucasian males from a smiling profile view relative to a landmark on the person's forehead, as judged by orthodontists and by lay people judges. We are using first and second year dental students as lay people judges. Also, we are trying to discover if there is any difference in judgment of attractiveness when comparing smiling and nonsmiling profiles.

This research could potentially help orthodontists in identifying the anterior-posterior position of the upper front teeth in Caucasian males and provide standards to compare patients and determine how to move teeth. This could potentially help orthodontists in diagnosing and treatment planning orthodontic patients.

\begin{tabular}{r|l} 
& Chestnut Ridge Research Building \\
Phone: 304-293-7073 & 886 Chestnut Ridge Road \\
Fax: 304-293-3098 & PO Box 6845 \\
http://oric.research.wvu.edu & Morgantown, WV 26506-6845
\end{tabular}

Page | 1

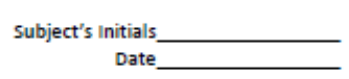




\section{Description of Procedures}

In this study, you will be shown on a TV screen 70 profile photographs of subject's faces in smiling and non-smiling positions. Ten of those pictures are repeats. Each photograph will be displayed for 20 seconds and some pictures are repeated. This will take place in a secure location at the WVU School of Dentistry-Orthodontic Department. You will be asked to rate them on the base of attractiveness. You will be given a paper with 70 lines with least attractive on the left and most attractive on the right. For each photograph you will be asked to mark on " $X$ " on the line as to how attractive you rate the position of the upper front teeth. This will take will take approximately 30 minutes of your time to complete.

\section{Discomforts}

There are no known or expected risks from participating in this study, except for the mild frustration associated with looking at photographs on a TV screen and judging the attractiveness of the subject's position of the upper front tooth..

\section{Alternatives}

You do not have to participate in this study.

\section{Benefits}

You may not receive any direct benefit from this study. The knowledge gained from this study may eventually benefit others.

\section{Financial Considerations}

You will not be paid to participate in this study.

\section{Confidentiality}

Any information about you that is obtained as a result of your participation in this research will be kept as confidential as legally possible. Your research records and test results, just like hospital records, may be subpoenaed by court order or may be inspected by the study sponsor or federal regulatory authorities (including the FDA if applicable) without your additional consent.

In addition, there are certain instances where the researcher is legally required to give information to the appropriate authorities. These would include mandatory reporting of infectious diseases, mandatory reporting of information about behavior that is imminently dangerous to your child or to others, such as suicide, child abuse, etc.

In any publications that result from this research, neither your name nor any information from which you might be identified will be published without your consent.

\begin{tabular}{r|l} 
& Chestnut Ridge Research Building \\
Phone: 304-293-7073 & 886 Chestnut Ridge Road \\
Fax. 304-293-3098 & PO Box 6845 \\
http://oric.research.wvu.edu & Morgantown, WV 26506-6845
\end{tabular}

P a ge | 2

Subject's Initials

Date 


\section{W- WestVliginiaUniversity,}

Human Research Protocol Only Minimal Risk Consent Form Without HIPAA

\section{Voluntary Participation}

Participation in this study is voluntary. You are free to withdraw your consent to participate in this study at any time.

Refusal to participate or withdrawal will not affect you and will involve no penalty to you. Refusal to participate or withdrawal will not affect your future care, or your employee status at West Virginia University.

In the event new information becomes available that may affect your willingness to participate in this study, this information will be given to you so that you can make an informed decision about whether or not to continue your participation.

You have been given the opportunity to ask questions about the research, and you have received answers concerning areas you did not understand.

Upon signing this form, you will receive a copy.

I willingly consent to participate in this research.

Signatures

Signature of Subject

Printed Name

Date

Time

The participant has had the opportunity to have questions addressed. The participant willingly agrees to be in the study.

Signature of Investigator or Co-Investigator

Printed Name

Date

Time

\begin{tabular}{r|l} 
& Chestnut Ridge Research Building \\
Phone: 304-293-7073 & 886 Chestnut Ridge Road \\
Fax: 304-293-3098 & PO Box 6845 \\
http://oric.research.wvu.edu & Morgantown, WV 26506-6845
\end{tabular}

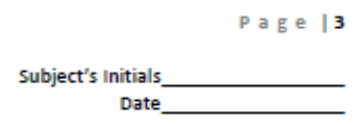




\section{APPENDIX D-Raw Data:}

Table1 Means of ranking scores of views by patient

\begin{tabular}{|c|c|c|c|c|c|c|c|}
\hline \multirow[t]{2}{*}{ Patient } & \multirow[t]{2}{*}{ GV } & \multirow[t]{2}{*}{ position } & \multicolumn{2}{|c|}{ REPOSE } & \multicolumn{2}{|l|}{ SMILE } & \multirow{2}{*}{$\begin{array}{l}p- \\
\text { value* }\end{array}$} \\
\hline & & & MEAN & SD & MEAN & SD & \\
\hline 1 & 0 & G & 41.9 & 15.5 & 34.0 & 16.5 & .02 \\
\hline 2 & 0 & G & 46.4 & 11.8 & 44.3 & 13.7 & .39 \\
\hline 3 & 0 & $G$ & 37.2 & 11.3 & 30.6 & 17.8 & .06 \\
\hline 4 & 0 & G & 35.3 & 15.7 & 40.0 & 15.9 & .07 \\
\hline 5 & 0 & $\mathrm{G}$ & 49.0 & 9.0 & 34.2 & 12.2 & $<.0001$ \\
\hline 6 & 1 & $\mathrm{R}$ & 16.1 & 12.8 & 27.6 & 13.6 & .0004 \\
\hline 7 & 2 & $\mathrm{R}$ & 29.6 & 11.8 & 34.7 & 13.6 & .08 \\
\hline 8 & 3 & $\mathrm{R}$ & 43.4 & 9.6 & 36.3 & 11.9 & .008 \\
\hline 9 & 4 & $\mathrm{R}$ & 44.6 & 13.0 & 40.4 & 16.5 & .13 \\
\hline 10 & 5 & $\mathrm{R}$ & 12.1 & 12.1 & 15.9 & 11.3 & .07 \\
\hline 11 & 5 & $R$ & 24.4 & 14.1 & 32.4 & 13.3 & .002 \\
\hline 12 & 6 & $R$ & 23.1 & 11.7 & 19.9 & 15.1 & .24 \\
\hline 13 & 10 & $\mathrm{R}$ & 13.4 & 12.1 & 17.2 & 11.1 & .12 \\
\hline 14 & -1 & B & 30.5 & 13.5 & 40.0 & 14.1 & .002 \\
\hline 15 & -2 & $B$ & 29.3 & 15.8 & 41.9 & 9.6 & $<.0001$ \\
\hline 16 & -3 & B & 37.4 & 15.5 & 28.3 & 20.4 & $<.0001$ \\
\hline 17 & -3 & $B$ & 47.5 & 14.4 & 28.4 & 15.6 & $<.0001$ \\
\hline 18 & -3 & B & 27.6 & 15.2 & 10.1 & 9.6 & $<.0001$ \\
\hline 19 & -3 & B & 21.6 & 10.6 & 19.3 & 10.6 & .28 \\
\hline 20 & -4 & B & 6.2 & 4.3 & 7.9 & 11.7 & .40 \\
\hline 21 & -5 & $B$ & 34.5 & 13.1 & 34.6 & 12.0 & .96 \\
\hline 22 & -5 & B & 24.4 & 13.9 & 12.2 & 8.0 & $<.0001$ \\
\hline 23 & -6 & $B$ & 27.2 & 17.5 & 23.2 & 15.0 & .18 \\
\hline 24 & -6 & B & 54 & 5.5 & 47.6 & 11.4 & .002 \\
\hline 25 & -7 & B & 19.3 & 13.7 & 20.2 & 12.3 & .71 \\
\hline 26 & -8 & $B$ & 41.9 & 13.4 & 33.4 & 16.1 & .0003 \\
\hline 27 & -9 & B & 26.2 & 12.9 & 17.1 & 13.5 & .001 \\
\hline 28 & -11 & B & 40.6 & 13.9 & 29.3 & 13.9 & .002 \\
\hline 29 & -13 & B & 37.3 & 12.0 & 27.2 & 14.3 & .004 \\
\hline 30 & -14 & B & 16.6 & 11.7 & 26.5 & 15.6 & .0002 \\
\hline
\end{tabular}

*P-value from paired t-test analysis 
Table2 Means of ranking scores of panel by patient

\begin{tabular}{|c|c|c|c|c|c|c|c|}
\hline \multirow[t]{2}{*}{ Patient } & \multirow[t]{2}{*}{ GV } & \multirow[t]{2}{*}{ position } & \multicolumn{2}{|c|}{ Orthodontist } & \multicolumn{2}{|c|}{ Lay-people } & \multirow[t]{2}{*}{$\begin{array}{l}\mathrm{p}- \\
\text { value* }\end{array}$} \\
\hline & & & MEAN & SD & MEAN & SD & \\
\hline 1 & 0 & G & 47.42 & 10.73 & 33.27 & 16.79 & 0.0001 \\
\hline 2 & 0 & G & 45.79 & 13.56 & 45.13 & 12.47 & 0.84 \\
\hline 3 & 0 & G & 36.17 & 15.65 & 32.77 & 14.94 & 0.37 \\
\hline 4 & 0 & G & 26.38 & 16.67 & 43.27 & 12.20 & $<0.0001$ \\
\hline 5 & 0 & $\mathrm{G}$ & 47.42 & 13.20 & 39.42 & 12.60 & 0.01 \\
\hline 6 & 1 & $\mathrm{R}$ & 18.54 & 12.23 & 23.50 & 15.14 & 0.17 \\
\hline 7 & 2 & $\mathrm{R}$ & 33.33 & 13.26 & 31.58 & 12.85 & 0.60 \\
\hline 8 & 3 & $\mathrm{R}$ & 40.96 & 12.47 & 39.31 & 10.83 & 0.57 \\
\hline 9 & 4 & $\mathrm{R}$ & 50.50 & 10.22 & 38.54 & 15.35 & 0.001 \\
\hline 10 & 5 & $\mathrm{R}$ & 14.33 & 12.40 & 13.85 & 11.53 & 0.88 \\
\hline 11 & 5 & $\mathrm{R}$ & 33.46 & 11.54 & 25.92 & 14.78 & 0.03 \\
\hline 12 & 6 & $\mathrm{R}$ & 27.08 & 13.58 & 18.69 & 12.76 & 0.01 \\
\hline 13 & 10 & $\mathrm{R}$ & 17.21 & 13.10 & 14.31 & 10.96 & 0.33 \\
\hline 14 & -1 & $\mathrm{~B}$ & 38.38 & 13.09 & 33.65 & 15.05 & 0.19 \\
\hline 15 & -2 & B & 30.42 & 16.77 & 38.19 & 12.52 & 0.03 \\
\hline 16 & -3 & $\mathrm{~B}$ & 23.08 & 17.45 & 37.75 & 17.27 & 0.001 \\
\hline 17 & -3 & $B$ & 36.92 & 16.20 & 38.46 & 18.56 & 0.73 \\
\hline 18 & -3 & B & 18.63 & 14.08 & 18.98 & 16.08 & 0.93 \\
\hline 19 & -3 & $B$ & 25.17 & 9.43 & 18.08 & 10.47 & 0.007 \\
\hline 20 & -4 & B & 10.04 & 10.99 & 5.60 & 7.12 & 0.08 \\
\hline 21 & -5 & $\mathrm{~B}$ & 37.38 & 13.13 & 33.17 & 12.05 & 0.18 \\
\hline 22 & -5 & $B$ & 24.38 & 13.41 & 15.27 & 11.47 & 0.003 \\
\hline 23 & -6 & $\mathrm{~B}$ & 24.75 & 11.36 & 25.42 & 18.40 & 0.85 \\
\hline 24 & -6 & $B$ & 47.25 & 13.03 & 52.58 & 6.59 & 0.02 \\
\hline 25 & -7 & $B$ & 11.54 & 8.70 & 23.81 & 12.80 & $<0.0001$ \\
\hline 26 & -8 & B & 31.00 & 15.94 & 40.94 & 14.02 & 0.009 \\
\hline 27 & -9 & $B$ & 23.00 & 14.19 & 20.96 & 13.79 & 0.56 \\
\hline 28 & -11 & $\mathrm{~B}$ & 30.17 & 16.00 & 37.38 & 13.96 & 0.05 \\
\hline 29 & -13 & $\mathrm{~B}$ & 28.38 & 15.31 & 34.17 & 13.15 & 0.10 \\
\hline 30 & -14 & $B$ & 19.13 & 15.26 & 22.77 & 14.19 & 0.32 \\
\hline
\end{tabular}

*P-value from two sample t-test analysis 
Table 3 Means of ranking scores of sex by patient

\begin{tabular}{|l|l|l|r|r|r|r|r|}
\hline Patient & GV & position & \multicolumn{2}{l|}{ Male } & \multicolumn{2}{l|}{ Female } & \multicolumn{2}{l|}{$\begin{array}{l}\text { - } \\
\text { value* }\end{array}$} \\
\cline { 3 - 9 } & & & \multicolumn{1}{l}{ MEAN } & \multicolumn{1}{l|}{ SD } & \multicolumn{1}{l|}{ MEAN } & SD & \\
\hline 1 & 0 & G & 39.25 & 13.91 & 36.72 & 18.67 & 0.52 \\
\hline 2 & 0 & G & 43.83 & 13.89 & 46.86 & 11.49 & 0.32 \\
\hline 3 & 0 & G & 33.42 & 16.35 & 34.39 & 14.08 & 0.79 \\
\hline 4 & 0 & G & 37.58 & 15.16 & 37.69 & 16.82 & 0.98 \\
\hline 5 & 0 & G & 42.61 & 12.36 & 41.56 & 14.27 & 0.74 \\
\hline 6 & 1 & R & 18.36 & 11.22 & 25.33 & 16.32 & 0.04 \\
\hline 7 & 2 & R & 30.94 & 12.87 & 33.39 & 13.03 & 0.43 \\
\hline 8 & 3 & R & 39.94 & 12.18 & 39.78 & 10.62 & 0.95 \\
\hline 9 & 4 & R & 44.03 & 15.00 & 41.03 & 14.86 & 0.40 \\
\hline 10 & 5 & R & 13.06 & 10.64 & 14.97 & 12.83 & 0.49 \\
\hline 11 & 5 & R & 28.42 & 14.27 & 28.44 & 14.27 & 0.99 \\
\hline 12 & 6 & R & 21.94 & 13.92 & 21.03 & 13.33 & 0.78 \\
\hline 13 & 10 & R & 13.67 & 9.31 & 16.89 & 13.64 & 0.25 \\
\hline 14 & -1 & B & 33.28 & 14.79 & 37.17 & 14.16 & 0.26 \\
\hline 15 & -2 & B & 40.75 & 12.79 & 30.44 & 14.31 & 0.002 \\
\hline 16 & -3 & B & 33.81 & 19.95 & 31.92 & 17.29 & 0.67 \\
\hline 17 & -3 & B & 36.89 & 16.87 & 39.00 & 18.69 & 0.62 \\
\hline 18 & -3 & B & 17.14 & 13.41 & 20.58 & 17.07 & 0.34 \\
\hline 19 & -3 & B & 20.44 & 10.95 & 20.44 & 10.42 & 1.00 \\
\hline 20 & -4 & B & 5.17 & 4.48 & 9.00 & 11.35 & 0.07 \\
\hline 21 & -5 & B & 32.53 & 13.61 & 36.61 & 11.07 & 0.17 \\
\hline 22 & -5 & B & 16.58 & 12.20 & 20.03 & 13.33 & 0.26 \\
\hline 23 & -6 & B & 32.56 & 17.22 & 17.83 & 11.48 & 0.0001 \\
\hline 24 & -6 & B & 49.50 & 9.82 & 52.11 & 9.11 & 0.25 \\
\hline 25 & -7 & B & 19.72 & 10.89 & 19.72 & 14.84 & 1.00 \\
\hline 26 & -8 & B & 40.53 & 13.85 & 34.72 & 16.34 & 0.11 \\
\hline 27 & -9 & B & 19.64 & 13.30 & 23.64 & 14.30 & 0.22 \\
\hline 28 & -11 & B & 35.50 & 14.17 & 34.44 & 15.89 & 0.77 \\
\hline 29 & -13 & B & 34.14 & 14.73 & 30.33 & 13.31 & 0.25 \\
\hline 30 & -14 & B & 21.89 & 15.33 & 21.22 & 13.94 & 0.85 \\
\hline & & & & & & \\
\hline
\end{tabular}

*P-value from two sample t-test analysis 
Table 4 Mixed model analysis of ranking scores by patient. Test of main effects for rater (panel), panel, sex, view, panel* view, sex *view interaction

\begin{tabular}{|c|c|c|c|c|c|c|c|c|c|c|c|c|}
\hline & \multicolumn{2}{|c|}{$\begin{array}{l}\text { View } \\
(D F=1)\end{array}$} & \multicolumn{2}{|c|}{$\begin{array}{l}\text { Group } \\
(D F=1)\end{array}$} & \multicolumn{2}{|c|}{$\begin{array}{c}\text { Sex } \\
(D F=1)\end{array}$} & \multicolumn{2}{|c|}{$\begin{array}{l}\text { Group*view } \\
(D F=1)\end{array}$} & \multicolumn{2}{|c|}{$\begin{array}{c}\text { Sex*view } \\
(D F=1)\end{array}$} & \multicolumn{2}{|c|}{ Rater(Group) } \\
\hline $\begin{array}{l}\text { patien } \\
\mathrm{t}\end{array}$ & $F$ & $\mathrm{P}$ & $\mathrm{F}$ & $\mathrm{P}$ & $\mathrm{F}$ & $\mathrm{P}$ & $F$ & $P$ & $\mathrm{~F}$ & $P$ & Z & $P$ \\
\hline 1 & 5.77 & 0.02 & $\begin{array}{r}12.2 \\
4 \\
\end{array}$ & 0.001 & 0.44 & 0.51 & $\begin{array}{r}0.00 \\
04 \\
\end{array}$ & 0.99 & 1.45 & 0.24 & 1.12 & 0.26 \\
\hline 2 & 1.89 & 0.18 & 0.03 & 0.86 & 0.73 & 0.40 & 2.66 & 0.11 & 0.03 & 0.86 & 1.95 & 0.05 \\
\hline 3 & 8.02 & 0.008 & 0.73 & 0.40 & 0.07 & 0.80 & 6.33 & 0.02 & 0.45 & 0.51 & 1.05 & 0.30 \\
\hline 4 & 4.28 & 0.04 & $\begin{array}{r}16.7 \\
7 \\
\end{array}$ & 0.0003 & 0.001 & 0.98 & 0.64 & 0.43 & 3.75 & 0.06 & 2.29 & 0.02 \\
\hline 5 & 49.83 & $\begin{array}{l}<0.000 \\
1\end{array}$ & 8.53 & 0.006 & 0.17 & 0.69 & 0.02 & 0.88 & 4.76 & 0.04 & 1.11 & 0.27 \\
\hline 6 & 15.54 & 0.0004 & 2.40 & 0.13 & 5.33 & 0.03 & 0.25 & 0.62 & 3.76 & 0.06 & 0.27 & 0.79 \\
\hline 7 & 1.65 & 0.21 & 0.27 & 0.61 & 0.59 & 0.45 & 1.38 & 0.25 & 0.79 & 0.38 & 0.57 & 0.57 \\
\hline 8 & 7.79 & 0.009 & 0.36 & 0.55 & 0.004 & 0.95 & 0.08 & 0.78 & 3.09 & 0.09 & 0.15 & 0.88 \\
\hline 9 & 1.92 & 0.17 & 9.02 & 0.005 & 0.64 & 0.43 & 0.03 & 0.85 & 0.98 & 0.33 & 1.66 & 0.10 \\
\hline 10 & 2.32 & 0.14 & 0.02 & 0.89 & 0.32 & 0.57 & 0.30 & 0.59 & 0.17 & 0.68 & 2.32 & 0.02 \\
\hline 11 & 7.19 & 0.01 & 3.40 & 0.07 & 0.00 & 0.99 & 3.54 & 0.07 & 0.28 & 0.60 & 2.53 & 0.01 \\
\hline 12 & 1.34 & 0.26 & 5.24 & 0.03 & 0.07 & 0.79 & 0.02 & 0.88 & 0.19 & 0.67 & 1.23 & 0.22 \\
\hline 13 & 2.86 & 0.10 & 0.79 & 0.38 & 1.10 & 0.30 & 0.45 & 0.51 & 0.03 & 0.86 & 1.29 & 0.20 \\
\hline 14 & 7.28 & 0.01 & 1.55 & 0.22 & 1.18 & 0.29 & 2.08 & 0.16 & 0.33 & 0.57 & 1.32 & 0.19 \\
\hline 15 & 61.21 & $\begin{array}{l}<0.000 \\
1\end{array}$ & 6.01 & 0.02 & 11.89 & 0.002 & $\begin{array}{r}20.1 \\
9\end{array}$ & 0.0001 & 6.41 & 0.02 & 2.29 & 0.02 \\
\hline 16 & 25.61 & $\begin{array}{l}<0.000 \\
1\end{array}$ & 6.68 & 0.01 & 0.12 & 0.73 & 0.42 & 0.52 & 10.75 & $\begin{array}{r}0.00 \\
2 \\
\end{array}$ & 3.60 & 0.0003 \\
\hline 17 & 24.28 & $\begin{array}{l}<0.000 \\
1\end{array}$ & 0.14 & 0.71 & 0.31 & 0.58 & 3.49 & 0.07 & 0.40 & 0.53 & 0.93 & 0.35 \\
\hline 18 & 35.77 & $\begin{array}{l}<0.000 \\
1\end{array}$ & 0.01 & 0.92 & 1.12 & 0.30 & 0.14 & 0.71 & 0.02 & 0.89 & 0.84 & 0.40 \\
\hline 19 & 0.72 & 0.40 & 6.09 & 0.02 & 0.00 & 1.00 & 0.30 & 0.58 & 0.22 & 0.64 & 1.30 & 0.19 \\
\hline 20 & 2.97 & 0.09 & 4.47 & 0.04 & 3.75 & 0.06 & 6.17 & 0.02 & 3.50 & 0.07 & 0.50 & 0.61 \\
\hline 21 & 0.18 & 0.67 & 1.59 & 0.22 & 1.69 & 0.20 & 2.08 & 0.16 & 4.02 & 0.05 & 1.13 & 0.26 \\
\hline 22 & 26.39 & $\begin{array}{l}<0.000 \\
1\end{array}$ & $\begin{array}{r}12.5 \\
0 \\
\end{array}$ & 0.001 & 2.01 & 0.17 & 2.25 & 0.14 & 0.52 & 0.48 & -0.11 & 0.91 \\
\hline 23 & 2.07 & 0.16 & 0.03 & 0.88 & 13.74 & 0.0008 & 0.07 & 0.79 & 5.94 & 0.02 & 1.90 & 0.06 \\
\hline 24 & 22.47 & $\begin{array}{l}<0.000 \\
1\end{array}$ & 5.32 & 0.03 & 1.44 & 0.24 & $\begin{array}{r}11.3 \\
7 \\
\end{array}$ & 0.002 & 0.94 & 0.34 & 1.46 & 0.14 \\
\hline 25 & 0.34 & 0.56 & $\begin{array}{r}13.7 \\
6 \\
\end{array}$ & 0.0008 & 0.00 & 1.00 & 0.53 & 0.47 & 0.17 & 0.69 & 1.31 & 0.19 \\
\hline 26 & 12.52 & 0.0012 & 5.03 & 0.03 & 1.93 & 0.17 & 0.31 & 0.58 & 0.12 & 0.73 & 2.88 & 0.004 \\
\hline 27 & 13.13 & 0.001 & 0.29 & 0.59 & 1.27 & 0.27 & 1.41 & 0.24 & 0.03 & 0.87 & 1.57 & 0.12 \\
\hline 28 & 10.84 & 0.002 & 4.68 & 0.04 & 0.11 & 0.74 & 0.10 & 0.75 & 0.80 & 0.38 & -0.38 & 0.71 \\
\hline
\end{tabular}




\begin{tabular}{|l|l|l|l|l|l|l|l|l|l|l|l|l|}
\hline 29 & 16.92 & 0.0002 & 3.90 & 0.06 & 1.89 & 0.18 & 5.85 & 0.02 & 7.48 & 0.01 & -0.22 & 0.82 \\
\hline 30 & 15.23 & 0.0004 & 0.75 & 0.39 & 0.03 & 0.87 & 0.21 & 0.65 & 0.04 & 0.84 & 2.33 & 0.02 \\
\hline
\end{tabular}

Table 52 Adjusted multiple comparison of Least square (LS) means of ranking scores for patient with significant panel * view interaction

\begin{tabular}{|c|c|c|c|c|c|c|c|c|}
\hline \multirow{3}{*}{$\begin{array}{l}\text { Patien } \\
\mathrm{t}\end{array}$} & \multicolumn{4}{|c|}{ ORTHODONTIST } & \multicolumn{4}{|c|}{ LAYPEOPLE } \\
\hline & \multicolumn{2}{|c|}{ REPOSE } & \multicolumn{2}{|l|}{ SMILE } & \multicolumn{2}{|l|}{ REPOSE } & \multicolumn{2}{|l|}{ SMILE } \\
\hline & $\begin{array}{l}\text { LS } \\
\text { MEAN }\end{array}$ & Std Err & $\begin{array}{l}\text { LS } \\
\text { MEAN }\end{array}$ & $\begin{array}{l}\text { Std } \\
\text { Err }\end{array}$ & $\begin{array}{l}\text { LS } \\
\text { MEAN }\end{array}$ & $\begin{array}{l}\text { Std } \\
\text { Err }\end{array}$ & $\begin{array}{l}\text { LS } \\
\text { MEAN }\end{array}$ & $\begin{array}{l}\text { Std } \\
\text { Err }\end{array}$ \\
\hline 3 & $45.00^{\mathrm{ac}}$ & 4.23 & $27.33^{a}$ & 4.23 & $33.29^{c}$ & 2.99 & 32.25 & 2.99 \\
\hline 15 & $18.17^{\mathrm{ac}}$ & 3.06 & $42.67^{\mathrm{a}}$ & 3.06 & $34.88^{\mathrm{bc}}$ & 2.16 & $41.50^{b}$ & 2.16 \\
\hline 20 & $6.00^{\mathrm{a}}$ & 2.32 & $14.08^{\text {ad }}$ & 2.32 & 6.33 & 1.64 & $4.88^{d}$ & 1.64 \\
\hline 24 & $54.42^{\mathrm{a}}$ & 2.38 & $40.08^{\text {ad }}$ & 2.38 & 53.79 & 1.68 & $51.38^{d}$ & 1.68 \\
\hline 29 & $38.33^{a}$ & 3.45 & $18.42^{\mathrm{ad}}$ & 3.45 & 36.75 & 2.44 & $31.58^{d}$ & 2.44 \\
\hline
\end{tabular}

Significant p-value for multiple comparison of panel * view interaction

${ }^{a}$ Repose vs. smile for orthodontist.

${ }^{b}$ Repose vs. smile for laypeople

${ }^{\mathrm{C}}$ Orthodontist vs. laypeople for repose

${ }^{d}$ Orthodontist vs. laypeople for smile

Table 6 Adjusted multiple comparison of Least square (LS) means of ranking scores for patient with significant sex * view interaction

\begin{tabular}{|c|c|c|c|c|c|c|c|c|}
\hline \multirow[b]{3}{*}{ Patient } & \multicolumn{4}{|c|}{ Male } & \multicolumn{4}{|c|}{ Female } \\
\hline & \multicolumn{2}{|l|}{ REPOSE } & \multicolumn{2}{|l|}{ SMILE } & \multicolumn{2}{|l|}{ REPOSE } & \multicolumn{2}{|l|}{ SMILE } \\
\hline & $\begin{array}{l}\text { LS } \\
\text { MEAN }\end{array}$ & Std Err & $\begin{array}{l}\text { LS } \\
\text { MEAN }\end{array}$ & Std Err & $\begin{array}{l}\text { LS } \\
\text { MEAN }\end{array}$ & $\begin{array}{l}\text { Std } \\
\text { Err }\end{array}$ & $\begin{array}{l}\text { LS } \\
\text { MEAN }\end{array}$ & Std Err \\
\hline 5 & $49.56^{a}$ & 2.43 & $38.33^{a}$ & 2.43 & $53.11^{b}$ & 2.43 & $32.67^{b}$ & 2.43 \\
\hline 15 & $34.05^{\mathrm{ac}}$ & 2.57 & $44.86^{a}$ & 2.57 & $18.99^{b c}$ & 2.57 & $39.31^{b}$ & 2.57 \\
\hline 16 & 33.20 & 4.11 & 29.52 & 4.11 & $37.09^{b}$ & 4.11 & $21.85^{b}$ & 4.11 \\
\hline 23 & $37.91^{\mathrm{ac}}$ & 3.52 & $26.98^{a}$ & 3.52 & $16.47^{c}$ & 3.52 & 18.98 & 3.52 \\
\hline 29 & $43.38^{\mathrm{ac}}$ & 2.91 & $22.97^{a}$ & 2.91 & $31.71^{c}$ & 2.91 & 27.03 & 2.91 \\
\hline
\end{tabular}

Significant $p$-value for multiple comparison of sex* view interaction

${ }^{a}$ Repose vs. smile for orthodontist.

${ }^{\mathrm{b}}$ Repose vs. smile for laypeople

${ }^{\mathrm{C}}$ Orthodontist vs. laypeople for repos 
Table 7 Means of ranking scores for GV position by rater

\begin{tabular}{|c|c|c|c|c|c|c|c|}
\hline \multirow[b]{3}{*}{ Rater } & \multicolumn{6}{|c|}{ GV Position } & \multirow[b]{3}{*}{$p$-value* } \\
\hline & \multicolumn{2}{|l|}{ Black } & \multicolumn{2}{|l|}{ Green } & \multicolumn{2}{|l|}{ Red } & \\
\hline & Mean & SD & Mean & SD & Mean & SD & \\
\hline 1 & 27.00 & 17.00 & 36.00 & 6.71 & 23.25 & 19.53 & 0.41 \\
\hline 2 & $19.35^{a}$ & 14.00 & $42.00^{a}$ & 19.04 & 29.88 & 14.91 & 0.02 \\
\hline 3 & $20.59^{a}$ & 16.87 & $41.40^{\mathrm{a}}$ & 12.90 & 31.88 & 17.31 & 0.04 \\
\hline 4 & $25.29^{\mathrm{ac}}$ & 14.48 & $46.40^{\mathrm{a}}$ & 10.60 & $41.00^{C}$ & 12.96 & 0.005 \\
\hline 5 & 32.41 & 19.50 & 31.60 & 8.62 & 21.75 & 16.72 & 0.37 \\
\hline 6 & 26.00 & 16.02 & 35.40 & 19.71 & 33.13 & 18.90 & 0.46 \\
\hline 7 & 29.76 & 18.88 & 19.60 & 15.34 & 23.38 & 16.10 & 0.466 \\
\hline 8 & 29.47 & 18.57 & 25.00 & 12.17 & 30.00 & 10.39 & 0.84 \\
\hline 9 & $20.12^{a}$ & 12.27 & $47.60^{\mathrm{a}}$ & 7.30 & 31.50 & 18.08 & 0.001 \\
\hline 10 & 27.88 & 19.25 & 43.00 & 14.11 & 29.00 & 16.59 & 0.26 \\
\hline 11 & 24.47 & 18.11 & 35.00 & 14.42 & 30.50 & 23.63 & 0.51 \\
\hline 12 & $25.41^{a}$ & 19.46 & $50.40^{\mathrm{ab}}$ & 10.06 & $25.63^{\mathrm{b}}$ & 7.71 & 0.002 \\
\hline 13 & 25.18 & 16.97 & 33.60 & 25.94 & 32.13 & 15.27 & 0.54 \\
\hline 14 & 28.41 & 18.76 & 35.60 & 20.16 & 23.63 & 11.50 & 0.49 \\
\hline 15 & 30.82 & 19.04 & 45.20 & 8.58 & 23.25 & 14.64 & 0.09 \\
\hline 16 & 26.88 & 14.66 & 42.00 & 11.58 & 30.88 & 20.79 & 0.20 \\
\hline 17 & 22.59 & 18.20 & 37.40 & 16.24 & 36.75 & 13.65 & 0.08 \\
\hline 18 & 28.59 & 18.49 & 34.00 & 19.95 & 27.88 & 18.22 & 0.82 \\
\hline 19 & 28.41 & 16.63 & 30.80 & 13.54 & 25.88 & 16.49 & 0.86 \\
\hline 20 & 26.71 & 17.53 & 31.20 & 19.59 & 28.88 & 17.97 & 0.88 \\
\hline 21 & 29.65 & 15.94 & 23.40 & 17.99 & 25.88 & 18.00 & 0.73 \\
\hline 22 & 26.12 & 15.58 & 22.80 & 19.87 & 34.13 & 21.22 & 0.47 \\
\hline 23 & 29.88 & 19.24 & 35.20 & 14.24 & 18.00 & 11.26 & 0.16 \\
\hline 24 & 24.88 & 18.52 & 25.20 & 10.03 & 24.25 & 17.42 & 0.99 \\
\hline 25 & $26.24^{a}$ & 18.10 & $48.40^{\mathrm{a}}$ & 12.48 & 26.50 & 11.60 & 0.03 \\
\hline 26 & $21.24^{a}$ & 15.13 & $44.40^{\mathrm{a}}$ & 13.13 & 32.50 & 9.55 & 0.006 \\
\hline 27 & 29.29 & 18.42 & 37.80 & 16.04 & 33.50 & 18.43 & 0.63 \\
\hline 28 & 30.65 & 16.81 & 26.60 & 21.22 & 22.38 & 15.77 & 0.54 \\
\hline 29 & 28.59 & 19.23 & 42.40 & 13.74 & 25.63 & 16.64 & 0.24 \\
\hline 30 & 24.53 & 17.46 & 40.00 & 14.34 & 27.13 & 14.94 & 0.20 \\
\hline 31 & 26.24 & 16.94 & 34.80 & 13.72 & 28.50 & 15.76 & 0.59 \\
\hline 32 & 30.24 & 18.44 & 38.20 & 15.45 & 22.63 & 16.35 & 0.30 \\
\hline 33 & 25.59 & 17.01 & 37.60 & 21.04 & 29.38 & 16.82 & 0.42 \\
\hline 34 & 30.12 & 18.06 & 33.00 & 17.73 & 21.88 & 14.23 & 0.44 \\
\hline 35 & $21.12^{\mathrm{a}}$ & 14.87 & $49.40^{\mathrm{ab}}$ & 10.14 & $27.50^{\circ}$ & 18.10 & 0.004 \\
\hline 36 & 17.47 & 14.77 & 36.00 & 18.28 & 29.63 & 14.19 & 0.04 \\
\hline
\end{tabular}

*p-value from ANOVA test.

Significant $p$-value for multiple comparison of GV position: 
a Black vs. Green position.

${ }^{\mathrm{b}}$ Green vs. Red position

c Black vs. Red position

Table 8 Mixed model analysis of ranking scores for all patients. Test of main effects for rater (panel), panel, sex, view, panel* view, sex *view interaction

\begin{tabular}{|c|c|c|c|c|}
\hline source & NDF & DDF & F & Pr $>F$ \\
\hline Fixed Effect & & & & \\
\hline View & 1 & 2092 & 23.54 & $<0.0001^{* * *}$ \\
\hline Panel & 1 & 33 & 0.28 & 0.5937 \\
\hline Sex & 1 & 33 & 0.01 & 0.9395 \\
\hline Panel*View & 1 & 2092 & 1.68 & 0.1954 \\
\hline Sex*View & 1 & 2092 & 1.25 & 0.2640 \\
\hline & & & $Z$ & Pr $>Z$ \\
\hline Random & & & & \\
\hline Effect & & & -31.33 & $<0.0001$ \\
\hline Rater(Panel) & & & 3.71 & 0.0002 \\
\hline Patient & & & &
\end{tabular}

Table 9 Least Square means of ranking scores on view for all patients

\begin{tabular}{|c|c|c|c|}
\hline \multicolumn{2}{|l|}{ Repose } & \multicolumn{2}{l|}{ Smile } \\
\hline LS Mean & Std Err & LS Mean & Std Err \\
\hline 31.47 & 1.92 & 28.36 & 1.92 \\
\hline
\end{tabular}

Table 10 Mixed model analysis of ranking scores for all patients. Test of main effects for rater (panel), patient, panel, sex, GVP, panel* GVP, sex *GVP interaction

\begin{tabular}{|c|c|c|c|c|}
\hline source & NDF & DDF & $\mathrm{F}$ & $\mathrm{Pr}>\mathrm{F}$ \\
\hline \multicolumn{5}{|l|}{ Fixed Effect } \\
\hline GVP & 2 & 27.4 & 2.17 & 0.1333 \\
\hline Panel & 1 & 80.3 & 0.00 & 0.9746 \\
\hline Sex & 1 & 80.3 & 0.78 & 0.3788 \\
\hline Panel*GVP & 2 & 1011 & 3.47 & $0.0315^{*}$ \\
\hline \multirow[t]{2}{*}{ Sex*GVP } & 2 & 1011 & 1.18 & 0.3067 \\
\hline & & & $Z$ & $\operatorname{Pr}>\mathrm{Z}$ \\
\hline \multicolumn{5}{|l|}{ Random Effect } \\
\hline Rater(Panel) & & & -3.93 & $<0.0001$ \\
\hline Patient & & & 3.48 & 0.0005 \\
\hline
\end{tabular}

GVP=GV position 
Table 11 Multiple comparison for Panel*GV position interaction

\begin{tabular}{|c|c|c|c|c|c|c|c|c|c|c|c|}
\hline \multicolumn{6}{|c|}{ Orthodontist } & \multicolumn{6}{|c|}{ Lay-people } \\
\hline \multicolumn{2}{|l|}{ Black } & \multicolumn{2}{|l|}{ Green } & \multicolumn{2}{|l|}{ Red } & \multicolumn{2}{|l|}{ Black } & \multicolumn{2}{|l|}{ Green } & \multicolumn{2}{|l|}{ Red } \\
\hline LS & Std & LS & Std & LS & Std & LS & Std & LS & Std & LS & Std \\
\hline MEAN & Err & MEAN & Err & MEAN & Err & MEAN & Err & MEAN & Err & MEAN & Err \\
\hline $24.5^{\mathrm{ab}}$ & 2.5 & $36.4^{a}$ & 4.7 & 30.0 & 3.7 & $27.2^{b}$ & 2.4 & 36.7 & 4.5 & 27.1 & 3.6 \\
\hline
\end{tabular}

Significant $p$-value for multiple comparison of panel*GVP

${ }^{a}$ Black vs. Green GV position for orthodontist.

${ }^{\mathrm{b}}$ Orthodontist vs Lay-people for Black GV position

Table12 Means of rating scores for smile by patient

\begin{tabular}{|l|l|l|r|r|}
\hline Patient & GV & Position & MEAN & \multicolumn{1}{l|}{ SD } \\
\hline 1 & 0 & G & 47.69 & 21.78 \\
\hline 2 & 0 & G & 56.17 & 19.74 \\
\hline 3 & 0 & G & 42.92 & 16.93 \\
\hline 4 & 0 & G & 51.39 & 19.76 \\
\hline 5 & 0 & G & 45.08 & 16.46 \\
\hline 6 & 1 & R & 41.00 & 18.97 \\
\hline 7 & 2 & R & 45.50 & 17.76 \\
\hline 8 & 3 & R & 47.39 & 18.38 \\
\hline 9 & 4 & R & 54.56 & 23.32 \\
\hline 10 & 5 & R & 27.44 & 12.24 \\
\hline 11 & 5 & R & 44.61 & 15.96 \\
\hline 12 & 6 & R & 34.36 & 20.18 \\
\hline 13 & 10 & R & 28.69 & 13.64 \\
\hline 14 & -1 & B & 53.47 & 19.75 \\
\hline 15 & -2 & B & 52.44 & 13.67 \\
\hline 16 & -3 & B & 39.75 & 20.79 \\
\hline 17 & -3 & B & 40.19 & 17.93 \\
\hline 18 & -3 & B & 22.81 & 11.97 \\
\hline 19 & -3 & B & 32.39 & 16.17 \\
\hline 20 & -4 & B & 19.00 & 17.23 \\
\hline 21 & -5 & B & 45.89 & 16.63 \\
\hline 22 & -5 & B & 25.58 & 11.12 \\
\hline 23 & -6 & B & 34.25 & 16.45 \\
\hline 24 & -6 & B & 59.78 & 16.62 \\
\hline 25 & -7 & B & 32.61 & 14.46 \\
\hline 26 & -8 & B & 44.28 & 15.49 \\
\hline 27 & -9 & B & 29.42 & 12.88 \\
\hline 28 & -11 & B & 41.47 & 14.86 \\
\hline 29 & -13 & B & 39.58 & 15.20 \\
\hline
\end{tabular}




\begin{tabular}{|l|l|l|l|l|}
\hline 30 & -14 & B & 37.44 & 17.97 \\
\hline
\end{tabular}

Table 13 Means of rating scores (smile) of panel by patient

\begin{tabular}{|c|c|c|c|c|c|c|c|}
\hline \multirow[t]{2}{*}{ Patient } & \multirow[t]{2}{*}{ GV } & \multirow[t]{2}{*}{ position } & \multicolumn{2}{|c|}{ Orthodontist } & \multicolumn{2}{|c|}{ Lay-people } & \multirow[t]{2}{*}{ P-value* } \\
\hline & & & MEAN & SD & MEAN & SD & \\
\hline 1 & 0 & G & 62.00 & 18.85 & 40.54 & 19.79 & 0.04 \\
\hline 2 & 0 & G & 59.33 & 21.98 & 54.58 & 18.82 & 0.50 \\
\hline 3 & 0 & G & 44.00 & 18.39 & 42.38 & 16.53 & 0.79 \\
\hline 4 & 0 & $\mathrm{G}$ & 46.33 & 20.13 & 53.92 & 19.50 & 0.28 \\
\hline 5 & 0 & $\mathrm{G}$ & 55.67 & 20.72 & 39.79 & 10.91 & 0.03 \\
\hline 6 & 1 & $\mathrm{R}$ & 41.17 & 17.99 & 40.92 & 19.82 & 0.97 \\
\hline 7 & 2 & $\mathrm{R}$ & 49.67 & 22.80 & 43.42 & 14.76 & 0.33 \\
\hline 8 & 3 & $\mathrm{R}$ & 53.08 & 23.77 & 44.54 & 14.78 & 0.19 \\
\hline 9 & 4 & $\mathrm{R}$ & 68.50 & 19.15 & 47.58 & 22.36 & 0.01 \\
\hline 10 & 5 & $\mathrm{R}$ & 26.75 & 16.01 & 27.79 & 10.24 & 0.81 \\
\hline 11 & 5 & $\mathrm{R}$ & 50.25 & 17.01 & 41.79 & 14.98 & 0.14 \\
\hline 12 & 6 & $\mathrm{R}$ & 42.33 & 19.09 & 30.38 & 19.89 & 0.09 \\
\hline 13 & 10 & $\mathrm{R}$ & 31.08 & 14.67 & 27.50 & 13.25 & 0.47 \\
\hline 14 & -1 & $\mathrm{~B}$ & 60.00 & 21.35 & 50.21 & 18.50 & 0.16 \\
\hline 15 & -2 & B & 58.75 & 16.80 & 49.29 & 10.88 & 0.05 \\
\hline 16 & -3 & $\mathrm{~B}$ & 28.75 & 18.33 & 45.25 & 20.06 & 0.02 \\
\hline 17 & -3 & $B$ & 47.42 & 16.74 & 36.58 & 17.73 & 0.09 \\
\hline 18 & -3 & $B$ & 22.33 & 11.67 & 23.04 & 12.36 & 0.87 \\
\hline 19 & -3 & $B$ & 42.00 & 18.25 & 27.58 & 12.89 & 0.01 \\
\hline 20 & -4 & $\mathrm{~B}$ & 28.67 & 22.85 & 14.17 & 11.35 & 0.06 \\
\hline 21 & -5 & B & 49.83 & 19.28 & 43.92 & 15.20 & 0.32 \\
\hline 22 & -5 & $B$ & 32.17 & 10.33 & 22.29 & 10.16 & 0.01 \\
\hline 23 & -6 & B & 36.42 & 15.42 & 33.17 & 17.16 & 0.58 \\
\hline 24 & -6 & B & 58.08 & 18.67 & 60.63 & 15.85 & 0.67 \\
\hline 25 & -7 & B & 27.33 & 9.15 & 35.25 & 16.01 & 0.12 \\
\hline 26 & -8 & B & 42.00 & 14.46 & 45.42 & 16.16 & 0.54 \\
\hline 27 & -9 & B & 31.67 & 9.12 & 28.29 & 14.44 & 0.47 \\
\hline 28 & -11 & B & 38.92 & 14.93 & 42.75 & 14.97 & 0.47 \\
\hline 29 & -13 & B & 33.83 & 13.37 & 42.46 & 15.51 & 0.11 \\
\hline 30 & -14 & $B$ & 37.50 & 19.86 & 37.42 & 17.40 & 0.99 \\
\hline
\end{tabular}

\footnotetext{
*p-value from two sample t-test
} 
Table 14 Means of rating scores (smile) of sex by patient

\begin{tabular}{|c|c|c|c|c|c|c|c|}
\hline \multirow[t]{2}{*}{ Patient } & \multirow[t]{2}{*}{ GV } & \multirow[t]{2}{*}{ position } & \multicolumn{2}{|l|}{ Male } & \multicolumn{2}{|l|}{ Female } & \multirow[t]{2}{*}{ P-value* } \\
\hline & & & MEAN & SD & MEAN & SD & \\
\hline 1 & 0 & $G$ & 48.33 & 22.78 & 47.06 & 21.37 & 0.86 \\
\hline 2 & 0 & G & 50.17 & 19.83 & 62.17 & 18.25 & 0.07 \\
\hline 3 & 0 & G & 40.94 & 18.59 & 44.89 & 15.37 & 0.49 \\
\hline 4 & 0 & $\mathrm{G}$ & 46.56 & 21.93 & 56.22 & 16.54 & 0.14 \\
\hline 5 & 0 & $\mathrm{G}$ & 45.00 & 16.60 & 45.17 & 16.79 & 0.98 \\
\hline 6 & 1 & $\mathrm{R}$ & 32.11 & 12.32 & 49.89 & 20.54 & 0.004 \\
\hline 7 & 2 & $\mathrm{R}$ & 42.94 & 17.89 & 48.06 & 17.76 & 0.40 \\
\hline 8 & 3 & $\mathrm{R}$ & 42.61 & 18.18 & 52.17 & 17.79 & 0.12 \\
\hline 9 & 4 & $\mathrm{R}$ & 51.33 & 24.12 & 57.78 & 22.70 & 0.41 \\
\hline 10 & 5 & $\mathrm{R}$ & 24.39 & 12.18 & 30.50 & 11.84 & 0.14 \\
\hline 11 & 5 & $\mathrm{R}$ & 41.50 & 15.25 & 47.72 & 16.47 & 0.25 \\
\hline 12 & 6 & $\mathrm{R}$ & 31.83 & 16.38 & 36.89 & 23.59 & 0.46 \\
\hline 13 & 10 & $\mathrm{R}$ & 24.72 & 13.14 & 32.67 & 13.30 & 0.08 \\
\hline 14 & -1 & $\mathrm{~B}$ & 47.72 & 21.96 & 59.22 & 15.83 & 0.08 \\
\hline 15 & -2 & $B$ & 51.39 & 14.34 & 53.50 & 13.30 & 0.65 \\
\hline 16 & -3 & $\mathrm{~B}$ & 39.44 & 23.35 & 40.06 & 18.56 & 0.93 \\
\hline 17 & -3 & $\mathrm{~B}$ & 38.17 & 15.11 & 42.22 & 20.61 & 0.51 \\
\hline 18 & -3 & $B$ & 20.44 & 9.53 & 25.17 & 13.87 & 0.24 \\
\hline 19 & -3 & $B$ & 28.50 & 14.73 & 36.28 & 17.00 & 0.15 \\
\hline 20 & -4 & $B$ & 14.00 & 8.15 & 24.00 & 22.18 & 0.09 \\
\hline 21 & -5 & $B$ & 43.67 & 17.55 & 48.11 & 15.84 & 0.43 \\
\hline 22 & -5 & $B$ & 23.33 & 8.57 & 27.83 & 13.06 & 0.23 \\
\hline 23 & -6 & $B$ & 34.94 & 17.42 & 33.56 & 15.89 & 0.80 \\
\hline 24 & -6 & $B$ & 54.94 & 16.37 & 64.61 & 15.84 & 0.08 \\
\hline 25 & -7 & $B$ & 29.78 & 11.04 & 35.44 & 17.07 & 0.25 \\
\hline 26 & -8 & B & 42.67 & 14.08 & 45.89 & 17.04 & 0.54 \\
\hline 27 & -9 & $B$ & 26.00 & 12.21 & 32.83 & 12.94 & 0.11 \\
\hline 28 & -11 & $B$ & 37.22 & 13.16 & 45.72 & 15.59 & 0.09 \\
\hline 29 & -13 & $B$ & 33.89 & 11.37 & 45.28 & 16.68 & 0.02 \\
\hline 30 & -14 & $B$ & 36.83 & 21.75 & 38.06 & 13.82 & 0.84 \\
\hline
\end{tabular}

${ }^{*}$ p-value from two sample $t$-test 
Table 15 Contingency table of GV position by Opinion

\begin{tabular}{|l|l|l|l|l|}
\hline $\begin{array}{l}\text { GV } \\
\text { position }\end{array}$ & $\begin{array}{l}\text { Backward } \\
(\%)\end{array}$ & $\begin{array}{l}\text { Forward } \\
(\%)\end{array}$ & $\begin{array}{l}\text { Stay } \\
(\%)\end{array}$ & p-value* \\
\hline B & 2.3 & 60.8 & 36.9 & $<0.0001$ \\
\hline G & 6.7 & 13.9 & 79.4 & \\
\hline R & 22.6 & 15.3 & 32.7 & \\
\hline
\end{tabular}

*p-value from chi-square test

Table 15 Contingency table of GV position by Opinion by Panel

\begin{tabular}{|c|c|c|c|c|c|c|c|c|}
\hline \multirow{2}{*}{$\begin{array}{l}\text { GV } \\
\text { Position }\end{array}$} & \multicolumn{3}{|c|}{ Orthodontist } & \multirow[b]{2}{*}{$\begin{array}{l}\text { P- } \\
\text { value* }\end{array}$} & \multicolumn{3}{|c|}{ Lay-people } & \multirow[b]{2}{*}{$\begin{array}{l}\text { P- } \\
\text { value* }\end{array}$} \\
\hline & $\begin{array}{l}\text { Backward } \\
\text { (\%) }\end{array}$ & $\begin{array}{l}\text { Forward } \\
\text { (\%) }\end{array}$ & $\begin{array}{l}\text { Stay } \\
(\%)\end{array}$ & & Stay & Forward & Backward & \\
\hline B & 0 & 73.5 & 26.5 & $<0.0001$ & 3.4 & 54.4 & 42.2 & $<0.0001$ \\
\hline G & 3.3 & 10.0 & 86.7 & & 8.3 & 15.8 & 75.8 & \\
\hline $\mathrm{R}$ & 30.2 & 11.5 & 58.3 & & 18.8 & 17.2 & 64.1 & \\
\hline
\end{tabular}

${ }^{*}$ p-value from The Cochran-Mantel-Haenszel statistic

Table 16 Contingency table of GV position by Opinion by Panel

\begin{tabular}{|c|c|c|c|c|c|c|c|c|c|c|c|c|}
\hline & \multicolumn{3}{|c|}{ B } & \multirow[b]{2}{*}{$\begin{array}{l}\text { P- } \\
\text { value* }\end{array}$} & \multicolumn{3}{|c|}{ G } & \multirow[b]{2}{*}{$P$} & \multicolumn{3}{|c|}{$\mathrm{R}$} & \multirow[b]{2}{*}{$\begin{array}{l}\mathrm{P} \text { - } \\
\text { value } \\
*\end{array}$} \\
\hline Panel & $B$ & $\mathrm{~F}$ & $S$ & & $B$ & $\mathrm{~F}$ & $S$ & & $B$ & $\mathrm{~F}$ & $S$ & \\
\hline $\begin{array}{l}\text { Orthodonti } \\
\text { st }\end{array}$ & 0 & $\begin{array}{l}73 . \\
5\end{array}$ & $\begin{array}{l}26 . \\
5\end{array}$ & \multirow[t]{2}{*}{$\begin{array}{l}<0.000 \\
1\end{array}$} & $\begin{array}{l}3 . \\
3\end{array}$ & $\begin{array}{l}10 . \\
0\end{array}$ & $\begin{array}{l}86 . \\
7\end{array}$ & \multirow[t]{2}{*}{$\begin{array}{l}<0.2 \\
2\end{array}$} & $\begin{array}{l}30 . \\
2\end{array}$ & $\begin{array}{l}11 . \\
5\end{array}$ & $\begin{array}{l}58 . \\
3\end{array}$ & \multirow[t]{2}{*}{0.07} \\
\hline Lay-people & $\begin{array}{l}3 . \\
4\end{array}$ & $\begin{array}{l}54 . \\
4\end{array}$ & $\begin{array}{l}42 . \\
2\end{array}$ & & $\begin{array}{l}8 . \\
3\end{array}$ & $\begin{array}{l}15 . \\
8\end{array}$ & $\begin{array}{l}75 . \\
8\end{array}$ & & $\begin{array}{l}18 . \\
8\end{array}$ & $\begin{array}{l}17 . \\
2\end{array}$ & $\begin{array}{l}64 . \\
1\end{array}$ & \\
\hline
\end{tabular}

*p-value from The Cochran-Mantel-Haenszel statistic 


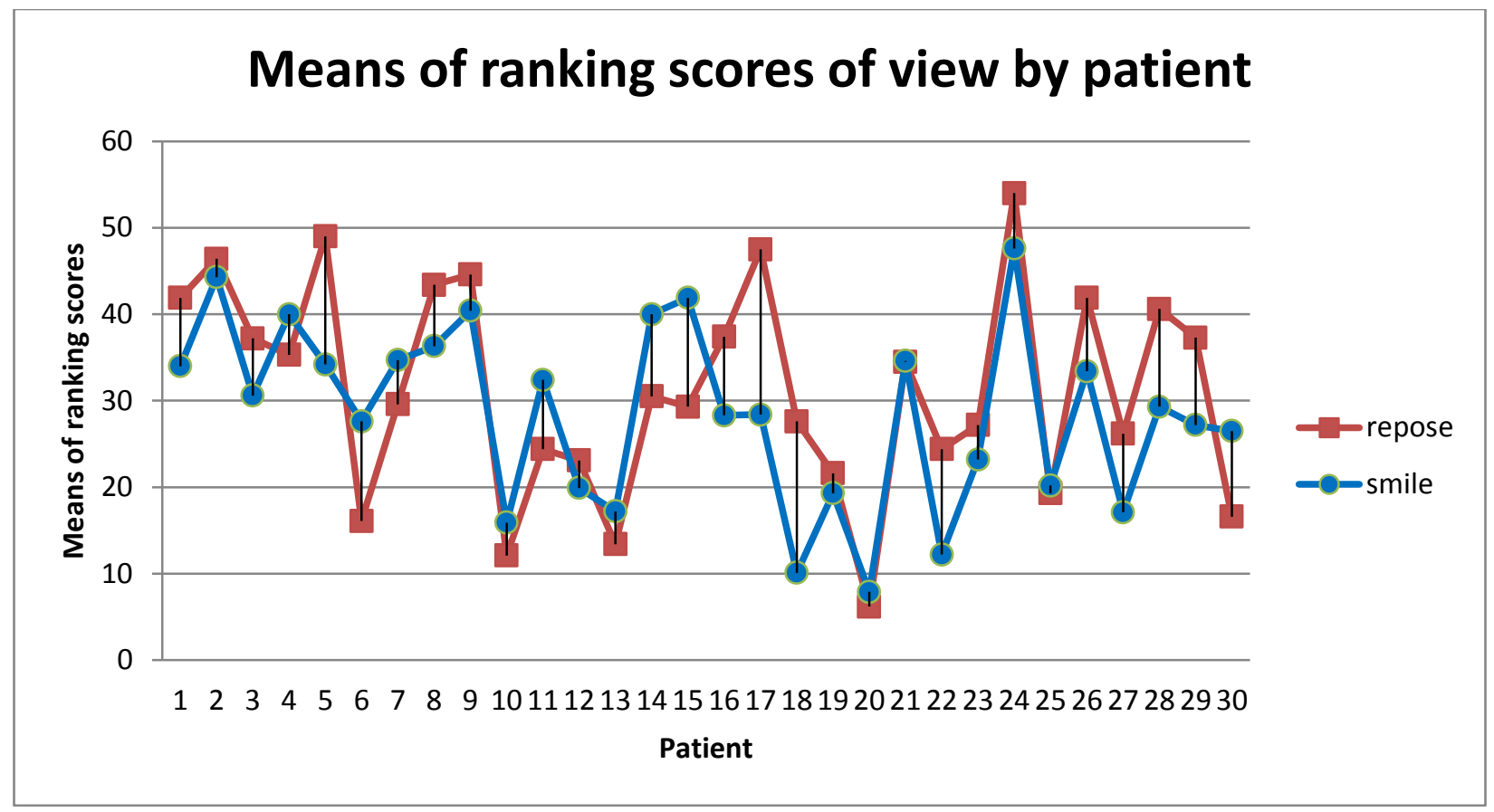

Figure 2

Mean ranking scores of GV position by rater

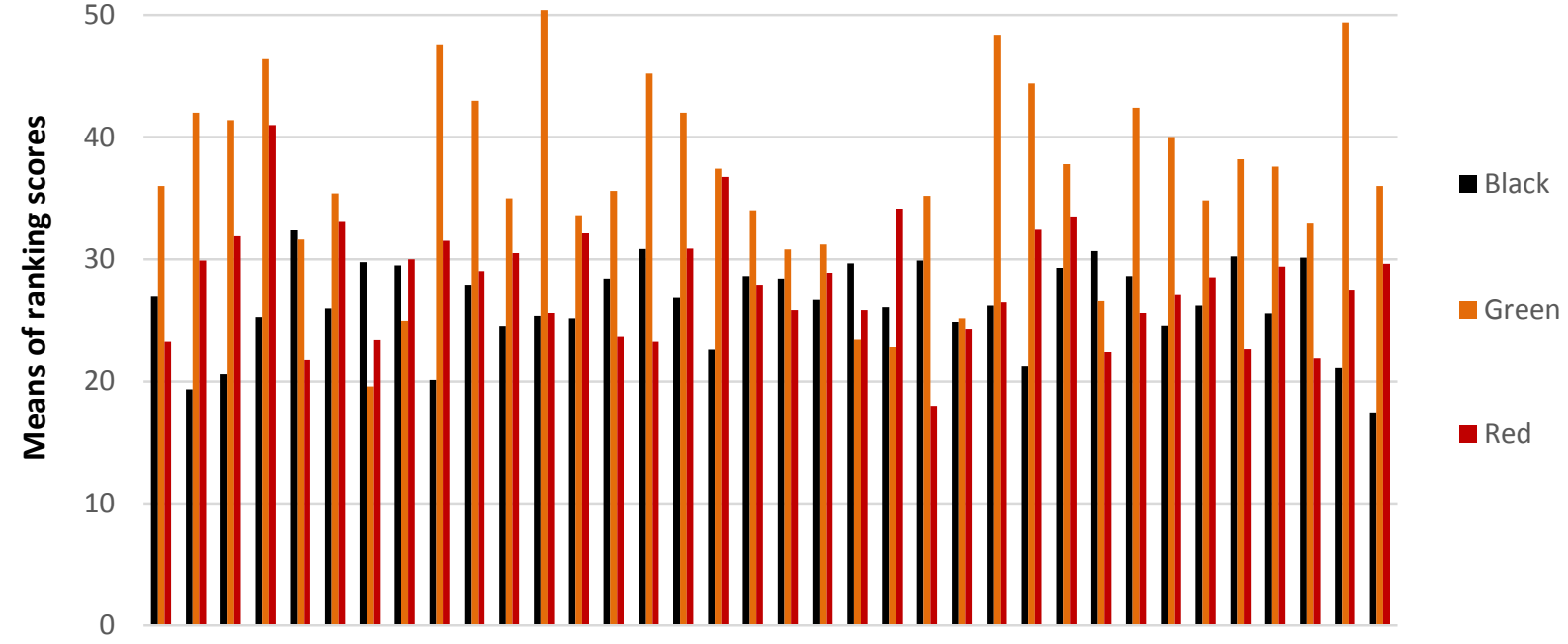

123456789101112131415161718192021222324252627282930313233343536

Rater 